\title{
An integrated strategy for managing Grapevine leafroll-associated virus 3 in red berry cultivars in New Zealand vineyards
}

By

Vaughn Antony Bell

\author{
A thesis \\ submitted to Victoria University of Wellington \\ in fulfilment of the requirements for the degree of \\ Doctor of Philosophy \\ in Ecology and Biodiversity
}

Victoria University of Wellington 

This thesis was conducted under the supervision and guidance of

\author{
Professor Philip J. Lester (Supervisor) \\ Victoria University of Wellington \\ Wellington, New Zealand
}
and
Professor Gerhard Pietersen (Co-supervisor)
University of Pretoria
Pretoria, South Africa

and

\title{
Dr. James T.S. Walker (Advisor)
}

The New Zealand Institute for Plant \& Food Research Limited Havelock North, New Zealand 



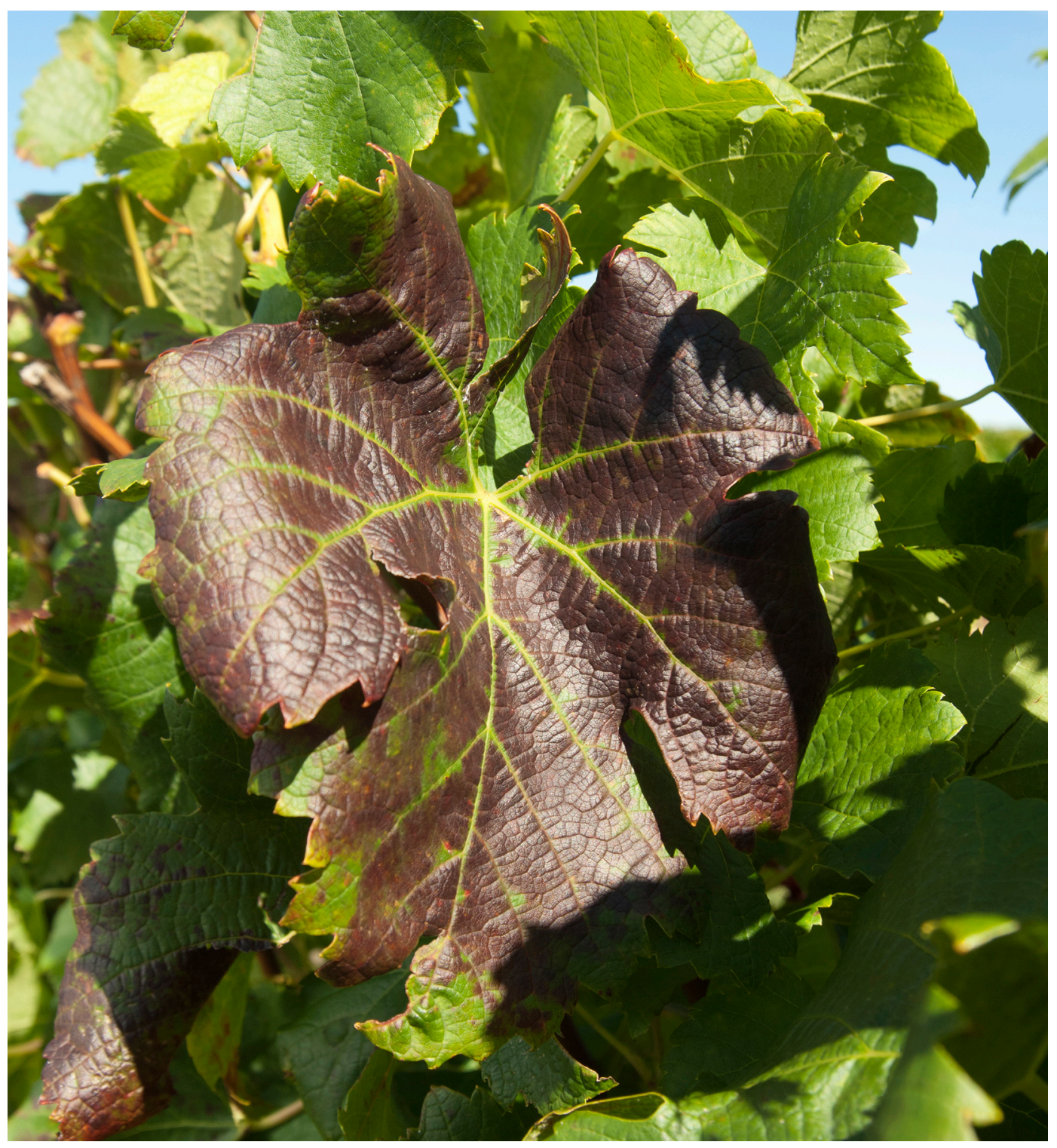

A Merlot vine with the classical foliar symptoms of Grapevine leafroll-associated virus 3: dark red inter-vein areas, green main veins, and downward rolling leaf margins, Hawke's Bay, April 2014. 



\section{Abstract}

To sustain growth and revenue projections, the New Zealand wine sector aims to produce premium quality wine to supply lucrative export markets. In grapevines, however, the presence of virus and virus-like diseases can negatively influence qualitative parameters of wine production. Where such risks are identified, sustainable remediation protocols should be developed. One risk factor is Grapevine leafroll-associated virus 3 (GLRaV-3), an economically important virus of Vitis. In this thesis, I develop components of an integrated management plan with the aim of reducing and sustaining GLRaV-3 incidence at $<1 \%$.

In Hawke's Bay vineyard study blocks, three aspects related to GLRaV-3 management were explored between 2008 and 2013: Firstly, herbicidetreated vines and/or land left fallow after removing infected vines may mitigate the effects of GLRaV-3. Historically though, vine root removal was not well implemented, meaning persistent roots may be long term reservoirs for GLRaV-3. I tested the virus reservoir hypothesis in vineyard blocks where virus incidence of $\geq 95 \%$ necessitated removing all vines. Enzyme-linked immunosorbent assay (ELISA) and/or real-time polymerase chain reaction (real-time PCR) detected GLRaV-3 in most remnant root samples tested, independent of the herbicide active ingredient applied (glyphosate, triclopyr, or metsulfuron) or the fallow duration ( 6 months to 4 years). On some viruspositive root samples, the GLRaV-3 mealybug vector, Pseudococcus calceolariae, was found, and after real-time PCR testing, virus was detected in some mealybugs. Thus, without effective vine removal, unmanaged sources of virus inoculum and viruliferous vectors could pose a risk to the health of replacement vines.

Secondly, in most red berry cultivars, GLRaV-3 is characterised by dark red downward curling leaves with green veins. With visual diagnostics predicted to be a reliable identifier of GLRaV-3-symptomatic red berry vines, early identification could support a cost-effective and sustainable virus management plan. In blocks planted in Merlot, Cabernet Sauvignon, Syrah, 
and Malbec vines, the reliability of visual symptom identification was compared with ELISA. In terms of sensitivity (binomial generalised linear model, 0.966) and specificity (0.998), late-season visual diagnostics reliably predicted virus infection. Moreover, accuracy appeared unaffected by the genetically divergent GLRaV-3 populations detected in Hawke's Bay.

Thirdly, by acting to visually identify and remove (rogue) symptomatic vines when GLRaV-3 incidence is low ( $<20 \%)$, an epidemic may be averted. In this ongoing study, an integrated approach to virus management was adopted in 13 well established Hawke's Bay vineyard study blocks. All were planted in vines from one of five red berry cultivars. When monitoring commenced in 2009 , all symptomatic vines visually identified $(n=2,544$ or $12 \%)$ were rogued. Thereafter, integrating visual diagnostics with roguing reduced virus incidence so that by 2013, just 434 (2.0\%) vines were identified with virus symptoms. Annual monitoring revealed within-row vines immediately either side of an infected vine were most at risk of vector mediated virus transmission, although by 2013 , just $4 \%$ of these vines had virus symptoms. Hence, roguing symptomatic vines only was recommended. In individual study blocks in 2013, virus management was tracking positively in four blocks; while in another four, results were inconclusive. In the remaining five blocks, contrasting but definitive results were evident. In three of those blocks, mean virus incidence of $10 \%$ in 2009 was sustained at $\leq 0.3 \%$ within 2-3 years of roguing commencing; in the other two blocks, mean incidence was $12 \%$ but cumulative vine losses of $37 \%$ (2011) and $46 \%$ (2013) culminated in roguing being replaced with whole block removal. In all five blocks, roguing protocols were standardised but in those with effective virus control, mealybug numbers were significantly lower in all years (mean: <0.2 per vine leaf; $p \leq 0.036$ ) relative to those where all vines were removed (mean: 0.4-2.3 per vine leaf).

Overall, the results of this research suggest that rather than adopting a single management tactic in isolation, effective GLRaV-3 control instead requires an integrated plan to be implemented annually. 


\section{Acknowledgements}

The privilege of being able to undertake this $\mathrm{PhD}$ owes much to the support and guidance of many people. Firstly, I wish to acknowledge my supervisors - Professors Phil Lester and Gerhard Pietersen. As leaders in their respective disciplines, I am grateful to have had the benefit of their insightful suggestions, wisdom and unconditional support throughout my studies. To both of you - thank you so much.

I am grateful to my Plant \& Food Research colleague and PhD advisor, Dr Jim Walker. His support of me and enthusiasm for my studies showed no boundaries. I also wish to thank my General Manager, Philippa Stevens. With Jim's support, it was Philippa I turned to in 2009 to help fund this part-time PhD. I will not forget the faith shown in me by Jim and Philippa.

Along the way, I encountered some truly remarkable people. One such person was Dr Rod Bonfiglioli. Rod was a plant virologist with a passion for grapevine viruses and during the course of our research, we interacted a great deal. Not long after talking with Professor Pietersen at a conference in South Africa in 2006, Rod discussed with me the issue of remnant vine roots. It was this sequence of events that inspired the research reported in chapter 2. Having urged me to undertake an applied PhD focused on GLRaV-3 management, Rod's passing in May 2009 sadly preceded the commencement of my studies by just a few months. It is my hope that Rod would have enjoyed following my studies and the new knowledge that has emerged from them. I dedicate this dissertation to Rod's memory.

My research also owes a great deal to the financial support of the New Zealand Grape and Wine Programme, which is a joint initiative of Plant \& Food Research and New Zealand Winegrowers. I am especially indebted to several people who either work for New Zealand Winegrowers or who are closely associated with it; namely, Dr Simon Hooker, Nick Hoskins, Ruby Andrew, and Caine Thompson. I enjoyed working with them and wish to 
thank them for their encouragement and support. My sincere hope is that our collaboration continues.

I received practical and logistical support from numerous colleagues at Plant \& Food Research. Lyn Cole, Tara Taylor, Terrence Makea, and Rachael Horner assisted me in the collection of mealybug data. The results reported in chapter 4 are the richer for their involvement. I acknowledge the support of Auckland colleagues - Dr Dan Cohen, Dr Robin MacDiarmid, Arnaud Blouin (a worthy PhD candidate), and Dr Karmun Chooi. Along with Dr Bonfiglioli, they instilled in me a much deeper appreciation of plant virology. Dr Kieren Arthur (chapter 3) and Dr Anne Gunson (chapters 2 and 3) reviewed parts of this thesis, and Carol Dolman assisted with its formatting. Ian Brooking helped develop my Endnote library, and Duncan Hedderley provided statistical guidance. Tony Corbett assisted me to produce the high resolution images in this thesis. The input of all these people was appreciated.

In respect of the research outlined in chapter 2, I am grateful to the financial support provided by The Bragato Trust and the awarding to me of their Research Fellowship. In particular, I am grateful to have benefited from the input of Kevan Moore (QSM) and Ross Goodin (ONZM).

For an applied scientist, it is important to supplement the development of recommendations with critical feedback from intended recipients. In this regard, I am grateful to Xan Harding and Dave Werrey for their comments and analysis.

My research was heavily reliant upon the goodwill and generosity of many vineyard owners in Hawke's Bay. They, along with a large number of their managers and viticulture staff, allowed me to access their vines and/or their institutional memories. This support was of incalculable value to me. In honouring the wishes of a few owners who wanted their involvement in this study to remain anonymous, I have decided not to name any winery or vineyard staff member. They know who they are and upon reading this acknowledgement, I hope they will have a strong sense of how appreciative I 
am of their assistance and cooperation. It was my privilege to have worked closely with so many good people dedicated to improving the future of their beloved wine industry.

Last but by no means least I want to thank my family. While they were genuinely disinterested in the detail of my research $(;)$, they were, and have always been, incredibly supportive of me and the things I have done. For that, I will always be grateful. To my partner (soon to be wife), Alison, I simply say this - I could not have fulfilled my academic or professional goals without your unconditional support, loyalty, and love. I will always treasure our relationship.

I have one final comment. During the many hours spent reading papers and writing this thesis, Kerri - my loyal Jack Russell companion - lay resting by my feet. Sadly, she left us on 25 November 2013. It was the worst day of my PhD experience. During the final months of thesis writing, I missed my wee friend by my feet.

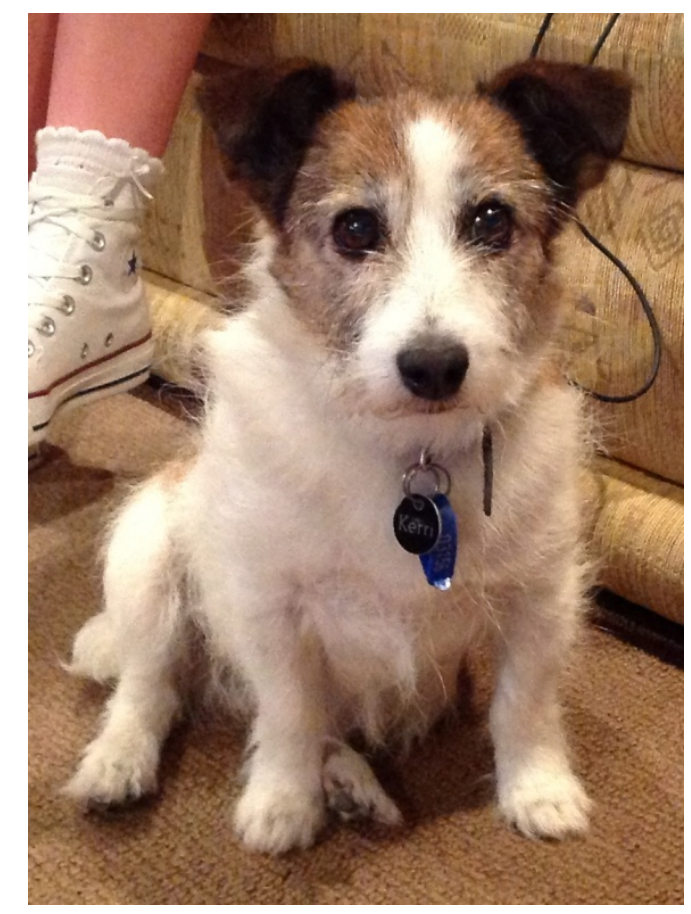

Kerri, January 2013. 


\section{Table of Contents}

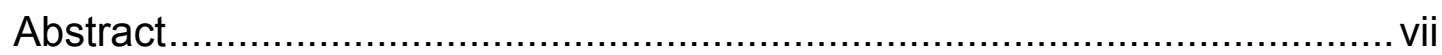

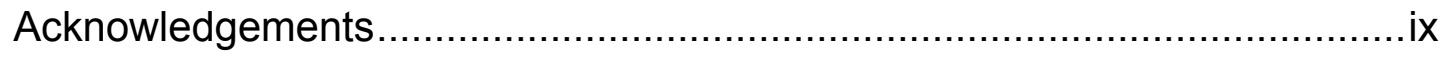

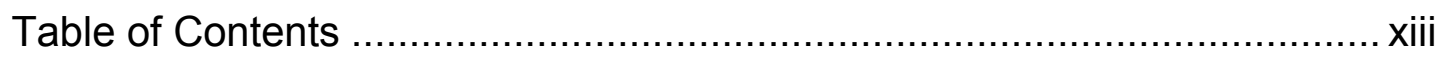

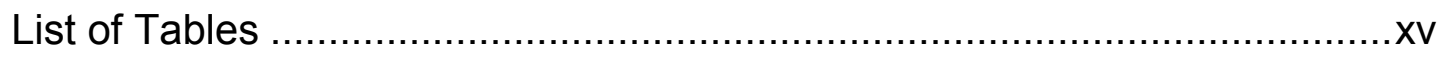

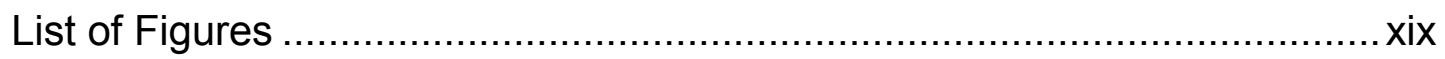

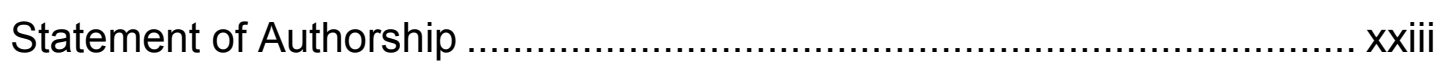

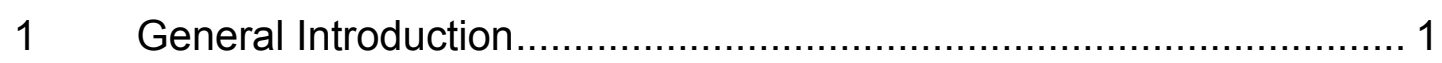

1.1 An overview of wine production in New Zealand ................... 1

1.2 Grapevine leafroll disease ............................................. 2

1.3 GLRaV-3 detection .................................................... 4

1.4 Visual symptom identification ...................................... 5

1.5 Managing GLRaV-3 ................................................... 7

1.6 Insect vectors facilitating secondary spread of GLRaV-3........ 9

1.7 Mealybug biology, ecology, and monitoring ....................... 10

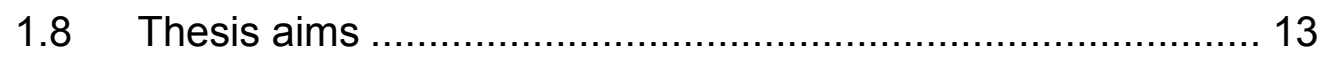

2 Grapevine leafroll-associated virus 3 persistence in Vitis vinifera remnant roots ..................................................................... 15

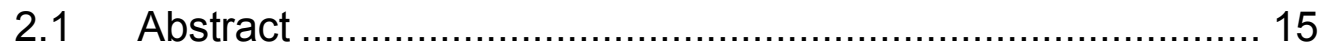

2.2 Introduction ......................................................... 16

2.3 Methods and materials ......................................... 19

2.4 Results................................................................. 23

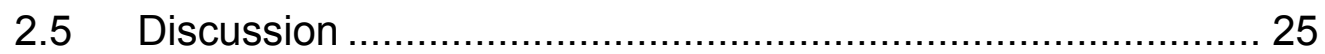

3 Visual symptom identification supports integrated control of Grapevine leafroll-associated virus 3 in red berry cultivars ........................... 29

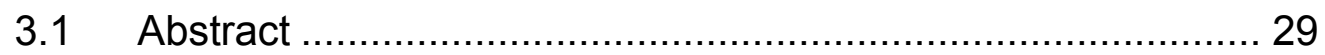

3.2 Introduction................................................................ 30

3.3 Methods and materials ........................................ 32 


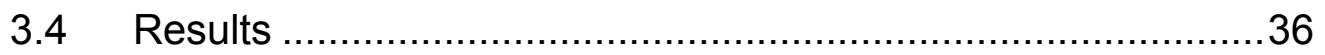

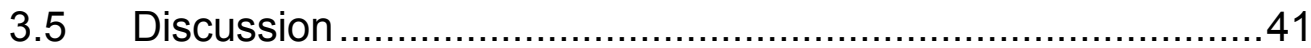

$4 \quad$ Management of Grapevine leafroll-associated virus 3 in red berry

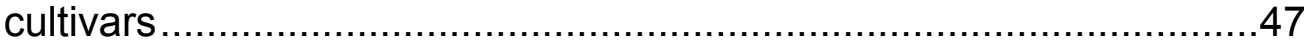

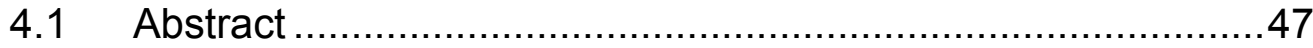

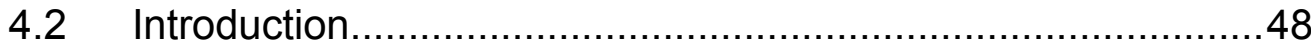

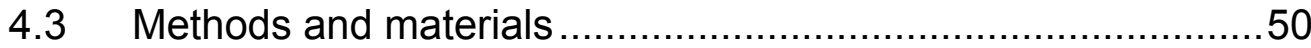

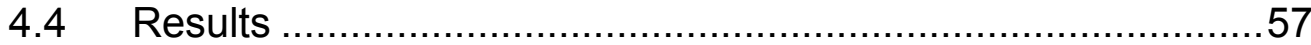

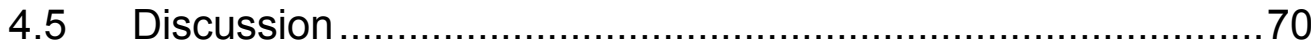

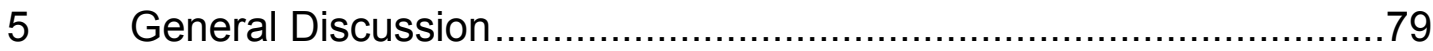

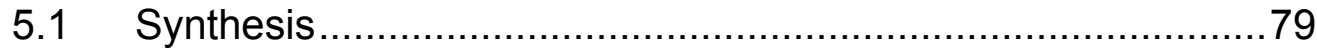

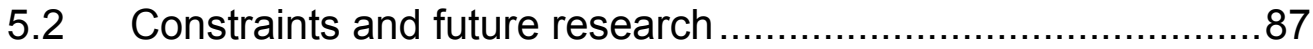

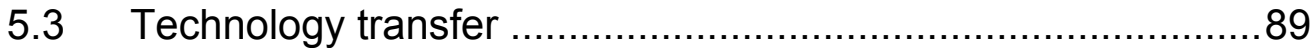

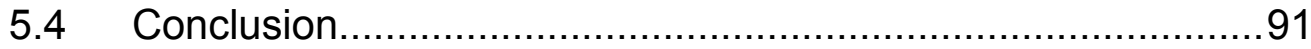

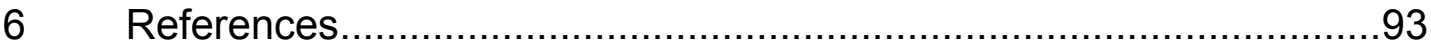

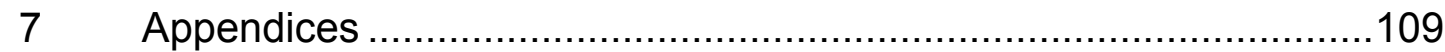

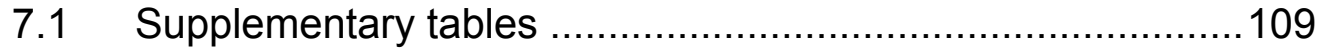

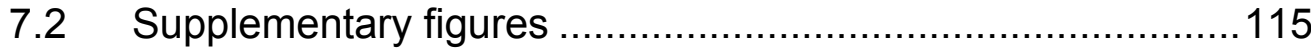




\section{List of Tables}

Table 1.2.1. Classification of Grapevine leafroll-associated viruses (GLRaV's)

Table 1.6.1. Mealybug and soft scale species identified around the world as vectors of Grapevine leafroll-associated virus 3 (GLRaV-3)

Table 2.4.1.1. Grapevine leafroll-associated virus 3 (GLRaV-3) infection status among remnant vine roots collected from the three stump-applied herbicide treatments in the research vineyard for the 12-months to May 2008 ( $n=4$ root samples/treatment/sampling date). All root samples were tested by enzyme-linked immunosorbent assay (ELISA) 23 Table 2.4.2.1. Grapevine leafroll-associated virus 3 (GLRaV-3) infections detected in remnant vine roots collected from a commercial vineyard in the fallow study 1, 26 weeks (February 2008) and 49 weeks (July 2008) after aerial parts of the vines were removed. Prior to removal, no herbicide was applied to the vines. Vine roots were initially enzymelinked immunosorbent assay (ELISA) tested ( $n=30$ root samples/date). In February 2008, a randomly selected sub-sample of three ELISAnegative root samples were re-analysed by real-time polymerase chain reaction (real-time $\mathrm{PCR})^{\ddagger}$.

Table 3.3.1.1. Block-specific details related to grape variety, vine planting date, the number of vines per block and the Grapevine leafrollassociated virus 3 (GLRaV-3) incidence before roguing commenced in the Hawke's Bay vineyard study blocks in 2009. 32

Table 3.4.1.1. Summary of the results to validate Grapevine leafrollassociated virus 3 (GLRaV-3) visual assessments by enzyme-linked immunosorbent assay (ELISA) testing vine leaves or budwood collected from five Hawke's Bay vineyard study blocks, 2011 to 2013. In addition to ELISA-testing material from vines expressing foliar symptoms of GLRaV-3, material was also collected from non-symptomatic vines in each block to assess the prevalence of asymptomatic infections (no symptoms, ELISA-positive). In all cases, ELISA testing was completed within 5 days of vine material being collected. 
Table 4.3.1.1. Summary of grapevine variety, clone, planting date, the number of vines and Grapevine leafroll-associated virus 3 (GLRaV-3) incidence recorded in each of the 13 Hawke's Bay vineyard study blocks in 2009.

Table 4.4.3.1. Percentage of vine leaves found with $P$. calceolariae in five Hawke's Bay vineyard study blocks, 2010 to 2013 ( $n=400$ leaves/block/year; 300 in 2010). The blocks were a subset of the 13 study blocks, which were divided into two groups based on interim results for GLRaV-3 control: in group 1 (including blocks $A, C$, and $E$ ) the evidence suggested effective virus control; in group 2 blocks, GLRaV-3 control was inconclusive, or in the case of blocks I and $\mathrm{K}$, roguing was ineffective and was replaced with whole block removal. .68

Table 4.4.3.2. Numbers of consecutive 'first' and 'second' Grapevine leafroll-associated virus 3 (GLRaV-3)-symptomatic vines recorded in five study blocks within a single season between 2010 and 2013. The blocks were a subset of the 13 Hawke's Bay vineyard study blocks, which were divided into two groups based on interim results for GLRaV-3 control: in group 1 (including blocks $A, C$, and $E$ ) the evidence suggested effective virus control; in group 2 blocks, GLRaV-3 control was inconclusive, or in the case of blocks I and $\mathrm{K}$, roguing was ineffective and was replaced with whole block removal. .69

Table 4.4.4.1. The timing and numbers of vines planted to replace the rogued vines in eight of the Hawke's Bay vineyard study blocks between 2009 and 2012. All vines were sourced from nurseries producing highhealth planting material in accordance with the New Zealand grafted grapevine standard

Table 5.3.1. A summary of the technology transfer undertaken as part of the commitment of this PhD research to New Zealand Winegrowers, August 2009 to February 2014 .90

Supplementary table 3.4.1.1. The detection and differentiation of Grapevine leafroll-associated virus 3 (GLRaV-3) genetic variants using multiplex reverse transcription-polymerase chain reaction (mRT-PCR) from Malbec vine cane scrapings. In a Hawke's Bay vineyard study block (E), 50 vines tested were initially identified with GLRaV-3 based on foliar 
symptoms only. Eighty non-symptomatic 'first' vines were also tested, of which two asymptomatic vines (no symptoms, enzyme-linked immunosorbent assay positive) were detected (table continued overleaf).

Supplementary table 4.3.1.2. Mealybug insecticide spray diary records for the 13 Hawke's Bay vineyard study blocks, 2009 to 2012 (table continued overleaf).

Supplementary table 4.4.2.1. Percent Grapevine leafroll-associated virus 3 (GLRaV-3) incidence among the 'nearest neighbour' and 'random' categories in the Hawke's Bay vineyard study blocks, 2010 to 2013. Results of fitting binomial generalised linear models in 2010 (this page, top table), 2011 (this page, lower table), 2012 (over page, top table) and 2013 (over page, lower table) (level of significance, $\alpha=0.05$ ). 


\section{List of Figures}

Figure 3.4.3.1. Cumulative percent changes to vines showing symptoms of Grapevine leafroll-associated virus 3 (GLRaV-3) in Hawke's Bay vineyard study blocks planted in Merlot $(F)$ and Cabernet Sauvignon $(G)$ vines during visits in 2012 (graphs A, C) and 2013 (graphs B, D). The timing of symptom expression in the Cabernet Sauvignon vines identified in 2012 but not rogued (C) was plotted separately from newly identified symptomatic vines in the same block that were first observed with symptoms in 2013 (D). 39

Figure 3.4.3.2. Cumulative percent changes to Pinot noir vines showing symptoms of Grapevine leafroll-associated virus 3 (GLRaV-3) in a Hawke's Bay vineyard study block $(\mathrm{H})$ during visits in 2012 (graph A) and 2013 (graph B). In 2012, symptom identification included vines that will have acquired GLRaV-3 during the interval between the initial planting (2004) and the first monitoring visit. 40

Figure 4.3.4.1. A diagrammatic view of three vine rows showing the position of the 10 'nearest neighbour' vines relative to a Grapevine leafroll-associated virus 3 (GLRaV-3)-symptomatic vine (V). 'Nearest neighbour' vines comprised four categories: Within-row 'first' $(F)$ and 'second' $(S)$ vines $(n=4)$; across-row 'opposite' $(O)$ and 'diagonal' $(D)$ vines $(n=6)$. The vines within rows were planted $1.8 \mathrm{~m}$ apart; row width ranged from 2.0-3.0 $\mathrm{m}$, depending on the study block.

Figure 4.4.1.1. Mean ( \pm SEM) Grapevine leafroll-associated virus 3 (GLRaV-3) incidence recorded in the Hawke's Bay vineyard study blocks, 2009 to 2013 ( $\mathrm{n}=9$ blocks in 2009, 10 in 2010, 12 in each of 2011, 2012 and 2013). Where relevant, data were corrected to include the planting of replacement vines. Note: the 2009 incidence data will have included vines that acquired GLRaV-3 in the interval between initial planting and the start of this research. 58

Figure 4.4.1.2. Percent annual Grapevine leafroll-associated virus 3 (GLRaV-3) incidence (graphs A, B) and cumulative GLRaV-3 incidence (graphs C, D) in the 13 Hawke's Bay vineyard study blocks, 2009 to 
2013. On the basis of preliminary results, the study blocks were divided into two groups: in group 1 (blocks $A, C, E, J, M, N$, and O) good progress was being made towards effective virus control; in group 2 ( $B$, $\mathrm{D}, \mathrm{F}, \mathrm{I}, \mathrm{K}$, and L) virus control was either ineffective or inconclusive. Where relevant, data were corrected to include the planting of replacement vines. Data from the first year of assessment in each block will have included vines that acquired GLRaV-3 in earlier years. In block $\mathrm{I}$, the residual vines were removed in July 2011 ; blocks $L, M, N$, and $O$ were recent additions to the study. In 2011, all residual vines in blocks $\mathrm{G}$ and $\mathrm{H}$ were removed for commercial reasons unrelated to GLRaV-3...60 Figure 4.4.2.1. (A) Percentage of Grapevine leafroll-associated virus 3 (GLRaV-3)-symptomatic vines recorded as either 'nearest neighbour' (combining 'first', 'second', 'opposite', 'diagonal') or 'random' infections; and (B) the GLRaV-3-symptomatic vines identified by 'nearest neighbour' category (excluding the 'random' category) in the Hawke's Bay vineyard study blocks, 2010 to 2013. F='first'; S='second'; O='opposite'; $D=$ 'diagonal' ( $\mathrm{n}=9$ study blocks in 2010, 10 in 2011, 11 in 2012, and 12 in 2013).

Figure 4.4.2.2. Mean (+SEM) Grapevine leafroll-associated virus 3 (GLRaV-3) incidence observed among 'nearest neighbour' and 'random' categories in the Hawke's Bay vineyard study blocks, 2010 to 2013 ( $n=9$ study blocks in 2010, 10 in 2011, 11 in 2012, and 12 in 2013).

Statistically significant differences between years within a category are denoted by different letters $(\alpha=0.05)$.

Figure 4.4.3.1. The mean number of mealybugs per vine leaf recorded in the 13 Hawke's Bay vineyard study blocks, 2010 to 2013 ( $n=400$ vine leaves inspected/block/year; 300 in 2010). In block I, the residual vines were removed in July 2011; blocks L, M, N, and O were recent additions to the study. Between 2009 and 2013, the vines in blocks C and E received no mealybug-specific insecticides.

Supplementary figure 1.4.1. A Grapevine leafroll-associated virus 3symptomatic Cabernet Sauvignon vine in Hawke's Bay, March 2012. 115 
Supplementary figure 1.4.2. Comparison of foliar symptoms for Grapevine leafroll-associated virus 3 (left) and magnesium deficiency (right) in Pinot noir vines in Hawke's Bay, April 2014.

Supplementary figure 1.7.1. The mealybug Pseudococcus longispinus on the underside of a grapevine leaf in Hawke's Bay, March 2011. Red arrow points to a crawler or $1^{\text {st }}$ instar.

Supplementary figure 5.3.1. New Zealand Winegrowers factsheet: Vine removal and leafroll 3 (NZVE108, February 2014) - page 119.

Supplementary figure 5.3.2. New Zealand Winegrowers factsheet:

Leafroll symptoms on red varieties (NZVE101, February 2014) - page 121

Supplementary figure 5.3.3. New Zealand Winegrowers factsheet:

Mealybugs - knowing the pest (NZVE105, October 2009) - page 123.

Supplementary figure 5.3.4. New Zealand Winegrowers factsheet: How

to look for mealybugs (NZVE106, October 2009) - page 125.

Supplementary figure 5.3.5. New Zealand Winegrowers factsheet: Preharvest mealybug monitoring (NZVE111, August 2013) - page 127. . 117 


\section{Statement of Authorship}

This thesis comprises five chapters. Data chapters 2 and 3 were written in the form of manuscripts intended for submission to journals. Data from chapter 4 are also intended for publication when the study concludes in 2015. Hence, with a goal to publish, some repetition exists between chapters. As each of the data chapters included several collaborators, they were written in the first person plural tense. In all cases I wrote the manuscripts. My supervisors provided guidance throughout my studies, and reviewed the draft manuscripts. Consequently, they are co-authors of all chapters except chapter 2. The contributions of the other co-authors in each chapter are outlined below, and are indicated by author initials ${ }^{1}$.

Chapter 2 was accepted for publication in 2009, and was published in the Journal of Plant Pathology (91: 527-533). Author contributions: VB and RG formulated the research objective. JW and PL assisted VB to plan the experimental design. In the non-commercial research block, VB applied the herbicide treatments. In all the study blocks, VB collected remnant vine roots and subterranean mealybugs, analysed the data, and interpreted the results. JM and SM undertook the serological and molecular tests.

Author contributions, chapter 3: VB formulated the research questions, and designed the various experiments. DC and GP guided the experimental design to test for the presence of GLRaV-3-latent infections. VB undertook visual symptom identification in all study blocks in all years, collected and interpreted the data, and collected the vine material to enable serological

\footnotetext{
${ }^{1}$ Author initials and names: AG Arnaud Blouin, DC Dan Cohen, DH Duncan Hedderley, GP Gerhard Pietersen, JM John Mackay, JW Jim Walker, KC Karmun Chooi, PL Peter Lo, PJL Phil J. Lester, RB Rod Bonfiglioli, SM Sue McGregor, VB Vaughn Bell.
} 
$(\mathrm{AB}, \mathrm{DC})$ and molecular $(\mathrm{KC})$ tests. VB travelled to Plant \& Food Research, Auckland, to assist with the serological testing.

Author contributions, chapter 4: GP, PJL and JW assisted VB with the experimental design. VB formulated the research questions, undertook visual symptom identification in all study blocks in all years, collected data, and constructed and maintained block-specific Excel maps identifying annual GLRaV-3 incidence and spread. DH analysed the data, and along with VB, interpreted the results. 


\section{General Introduction}

In a cropping monoculture, a vector-mediated plant pathogen can rapidly diminish the profitability of affected areas. Remediating disease incidence and vector-mediated disease transmission can be problematic. Hence, multiyear studies may be required to fully understand complex interactions between the crop, the pathogen, and the vector. Factors such as climatic conditions, disease epidemiology, and vector ecology will influence the spatial and temporal variability of the pathogen. While these factors not only determine the pace of control, they are likely to influence the outcomes of control. Such considerations apply to Grapevine leafroll-associated virus 3 (GLRaV-3), an economically important, insect-vectored virus of Vitis vinifera. By focusing on the dynamic interactions between the vine, the virus, and the vector, my research aims to develop components of a sustainable and integrated plan to assist the wine sector manage GLRaV-3 effectively.

\subsection{An overview of wine production in New Zealand}

Wine has been produced in New Zealand for over a century (Bragato 1902). During its relatively short history in this country, the sector has experienced numerous fluctuations, with the most recent significant decline attributed to the vine-pull of the 1980's when central government sought to correct market distortions (Beverland and Lockshin 2001). Since 1990, however, wine has become an important export commodity, with the sector having undergone rapid vineyard planting (Wilson and Goddard 2004). In the 23 years since 1990 , the total area under grapevines increased seven-fold to 35,700 ha (Anonymous 2013). Commensurate with more vines and a diversity of red and white berry cultivars, the sector has developed a lucrative export business, the value of which increased 66-fold from 1990 to surpass NZ\$1.2 billion in 2013 (Anonymous 2013).

As a consequence of this rapid growth, the New Zealand economy was boosted by the sector, which in 2008, was estimated to have created 16,500 full-time equivalent jobs and generated gross output of NZ\$3.5 billion (NZIER 
2009). Supporting this result were wine exports to 80 countries, with the largest being Australia (NZ\$373 million or $31 \%$ of total export revenue), USA (NZ\$284 m, 24\%), United Kingdom (NZ\$278 m, 23\%), and Canada (NZ\$78 $\mathrm{m}, 6.5 \%$ ) (Anonymous 2013). In continuing to develop traditional markets, the sector has also built new relationships. For example, as recently as 2006 , wine exports to China represented just NZ\$1.2 million (0.2\%); by 2013, revenue of NZ\$27 million (2\%) made that country the sector's fifth largest market by value (Anonymous 2013). Thus, having targeted wine production and marketing towards high-value niche markets, it is imperative that the sector sustains the goal of producing premium quality wine (Beverland and Bretherton 1998, Wilson and Goddard 2004). Doing so, however, necessitates the maintenance of good vine health across the wine estate. Where virus and virus-like diseases for example, begin to put at risk the qualitative parameters of grape and wine production, the sector must be able to respond with appropriate remediation protocols. The presence of Grapevine leafroll-associated virus 3 (GLRaV-3) poses precisely the kind of risk requiring intervention and remediation (Bonfiglioli et al. 2002).

\subsection{Grapevine leafroll disease}

Grapevine leafroll disease (GLD) is distributed throughout the world, and is one of the most important viral diseases of Vitis vinifera (L.) (Martelli 1986, 2014). Up until 2011, there were 11 different viruses associated with GLD and these were referred to as grapevine leafroll-associated viruses (GLRaV's), all belonging to the family Closteroviridae (Martelli 2014). However, advances such as the sequencing of whole genomes of all GLRaV's has recently enabled critical revisions to the classification of these viruses (Martelli 2014, summarised in Table 1.2.1). 
Table 1.2.1. Classification of Grapevine leafroll-associated viruses (GLRaV's)

\begin{tabular}{lll}
\hline Virus $^{\S}$ & Genus & Vectors \\
\hline GLRaV-1 & Ampelovirus & Mealybugs, soft scale insects \\
GLRaV-2 & Closterovirus & Unknown \\
GLRaV-3 & Ampelovirus & Mealybugs, soft scale insects \\
GLRaV-4 & Ampelovirus & Mealybugs \\
GLRaV-7 & Velarivirus & Unknown \\
\hline
\end{tabular}

$\S$ As reviewed by Martelli (2014)

Around the world, GLRaV-3 is regarded as the primary agent associated with GLD (Martelli et al. 2002, reviewed by Maree et al. 2013). Limited to $V$. vinifera, V. labruscana, V. californica, and V. californica $x$ V. vinifera hybrids (Klaassen et al. 2011, Bahder et al. 2013), GLRaV-3 infects white and red berry cultivars. While the virus is graft transmissible (Sheu 1936), it cannot be transmitted by sap inoculation during activities such as pruning or mechanical leaf plucking (Martelli et al. 2002). Among infected vines, GLRaV-3 adversely alters yield, soluble solids, $\mathrm{CO}_{2}$ assimilation, titratable acidity, and anthocyanins, which when combined, delays fruit ripening and lowers wine quality (reviewed by Charles et al. 2006, Endeshaw et al. 2014, Martelli 2014). Thus, temporal increases to the number of persistent virus-infected vines risks degrading quantitative and qualitative parameters of the crop.

In New Zealand, V. vinifera is a host for at least 17 virus and virus-like diseases (Pearson et al. 2006). Of these, GLRaV-3 was recognised as the most widespread and the most destructive (Bonfiglioli et al. 2002, Bonfiglioli and Hoskins 2006, Hoskins et al. 2011). However, following early research undertaken by McKissock (1964), Chamberlain (1967), Over de Linden and Chamberlain (1970a), and Thomas (1976), it was a further 40 years before remedial action was taken to minimise the risks associated with GLRaV-3.

One of the first remedial actions was the introduction of the New Zealand grafted grapevine standard (Anonymous 2006). With the aim of producing and distributing high-health, virus-free propagating material, this vine certification scheme was modelled on those developed for wine sectors 
elsewhere in the world (Rowhani et al. 2005, Almeida et al. 2013, Maree et al. 2013, Pietersen et al. 2013). For vines produced in accordance with robust certification schemes, there has been an improvement in the quality and health status of the planting material supplied to vineyard owners, thereby reducing the risk of primary introductions of virus and virus-like diseases such as GLRaV-3 (Walter and Martelli 1997). However, prior to certification, GLRaV-3-infected propagating material was widely distributed to grape growing regions around the world (Almeida et al. 2013).

\subsection{GLRaV-3 detection}

Laboratory-based techniques have been developed to aid the identification of plant pathogens like Citrus tristeza virus (Permar et al. 1990), mealybug wilt of pineapple (Hu et al. 1996), cauliflower stunt (Rappussi et al. 2012), Plum pox virus strain M (Dallot et al. 2004), and grapevine leafroll disease (Forsline et al. 1996). One such method is the serological diagnostic technique, enzyme-linked immunosorbent assay (ELISA), which is routinely used in the grafted grapevine standard to detect GLRaV-3 (Bonfiglioli et al. 2002, Cohen et al. 2004, Anonymous 2006). More recently, nucleic acidbased methods such as reverse-transcriptase polymerase chain reaction (RT-PCR) have been developed (reviewed by Maree et al. 2013). Using this technology, phylogenetic analyses of various regions of the GLRaV-3 genome suggest there is sufficient genetic variability to warrant up to seven separate variant groups, each represented as group I, II, III ... to VII (Jooste et al. 2010, Sharma et al. 2011, Bester et al. 2012, Chooi et al. 2013a, b, Maree et al. 2013).

In view of these genetically divergent GLRaV-3 populations, the weak detection of some variant groups present in New Zealand vineyards (e.g. NZ1 and NZ2) saw established ELISA protocols modified so as to improve detection capabilities. Specifically, grapevine extracts (leaves, phloem scrapings from canes or roots) were tested using two ELISA tests: the first was a double-antibody sandwich-ELISA that was commercially available (Bioreba) and based on detection of the virus by monoclonal antibodies 
raised against GLRaV-3 group I. The second was a modified triple antibody sandwich-ELISA protocol using a polyclonal anti-GLRaV-3 antiserum (G5/1 from Darius Goszczynski, ARC, South Africa). The first ELISA using monoclonal antibodies reacted strongly to the GLRaV-3 from the group I, but weakly to the NZ-1 and NZ2 strains. The second ELISA using polyclonal antibodies reacts equally to all known variants of GLRaV-3 (Cohen et al. 2012). Similarly, the molecular detection and differentiation of genetic variant groups was improved through the use of multiplex PCR, as developed by Chooi et al. (2013a). Refining serological and molecular techniques demonstrates the high genetic variability in New Zealand's GLRaV-3 population (Chooi et al. 2012), and implementation will enhance prospects to exclude known genetic variants from propagating material produced for vineyard plantings.

In reality though, the logistics and financial cost of these techniques cannot be sustained on the scale and frequency required to support the ongoing removal of infected vines (Hoskins et al. 2011). To achieve this outcome, owners instead require a practical, cost-effective way to reliably identify vines infected with GLRaV-3. One such method recognised as being potentially advantageous is visual symptom identification (Pietersen 2004, 2006, Pietersen et al. 2013).

\subsection{Visual symptom identification}

The principle behind visual symptom identification is that a particular plant pathogen will induce specific and visible changes to the morphology of its host. Thus, an appropriately trained assessor may be able to interpret these changes within a particular crop to reliably differentiate infected plants from those that are healthy. For example, the morphology of plants infected with cauliflower stunt is broadly distinguished from healthy plants by their reduced size, malformed inflorescence, and/or leaf reddening (Rappussi et al. 2012). In respect of GLRaV-3, symptomatic red berry vines are characterised by dark red downward curling leaves with green veins (Golino et al. 2002, Golino et al. 2008, Martelli 2014, Supplementary figure 1.4.1). In theory, 
systematic inspections of vines by trained assessors should enable the reliable identification of vines specifically infected with GLRaV-3. While there are currently no published empirical data supporting visual diagnostics of GLRaV-3, this method is likely to be more cost-effective than ELISA where a single test currently costs between NZ\$10-15 (Hoskins et al. 2011).

Applying visual symptom identification to a pathogen that induces a definitive morphological response in an infected plant could be perceived as a relatively straightforward process. In reality, visually diagnosing plant pathogens is neither a simple task nor is it trivial (Grogan 1981). Applying this detection method to Pierce's disease (Krell et al. 2006), cauliflower stunt (Rappussi et al. 2012), cocoa swollen shoot disease (Thresh and Owusu 1986), Plum pox virus strain M (Dallot et al. 2004), and Potato virus $Y^{\circ}$ (Sturz et al. 1997) was unreliable, with assessors unable to accurately and consistently differentiate diseased plants from those that were healthy.

Applying visual diagnostics to GLRaV-3 could also be problematic. For example, environmental factors such as variable temperature may lead to differential symptom development, as evidenced during grapevine woody indexing studies in Australia (Constable et al. 2013). There is also natural variability in GLRaV-3 symptoms, with some rootstocks and many white $V$. vinifera cultivars being symptomless, thus making visual diagnostics impractical (Maree et al. 2013, Martelli 2014). Hence, the lack of practical, cost-effective means of identifying infected white berry vines suggest these persistent virus reservoirs pose an ongoing risk to healthy vines within and between blocks (Maree et al. 2013). Consequently, only in red berry cultivars does visual symptom identification remain a possible detection option, although even among these, care is required. For instance, the similarities in foliar symptoms induced by magnesium deficiency and GLRaV-3 may create confusion among assessors with limited training (Jordan 1993, Supplementary figure 1.4.2). Likewise, within a single variety block, some red berry vines develop foliar symptoms soon after veraison; in others, symptoms are delayed until post-harvest, and if the symptomology is subtle or limited to a few leaves, infected vines are at risk of being overlooked (Golino et al. 
2008). Observations from Hawke's Bay vineyards suggest a lag phase of at least 12 months from the time a red berry vine is infected to the appearance of foliar symptoms (Bell, unpublished data, 2011). Therefore, quite apart from the possibility of latent infections (ELISA positive, asymptomatic vines), infection duration may explain the temporal variation in symptom appearance between vines. Others have suggested the presence of genetically divergent GLRaV-3 populations, either as single or mixed infections, contributes to differential symptom development (Jooste et al. 2011, Bester et al. 2012, Chooi et al. 2013b). In essence, if owners are to contemplate deploying resources to manage this virus, they must first be confident there is a low risk of visual symptom identification over-estimating virus incidence (false positives) or under-estimating it (false negatives) (Fox 1997). Thus, an important goal of this thesis is to ascertain if visual symptom identification in red berry cultivars can reliably support an integrated plan to manage GLRaV3.

\subsection{Managing GLRaV-3}

From the perspective of an owner whose vineyard is affected by GLRaV-3, there are essentially three management options available to them. Firstly, they could choose to do nothing but with good reason, this option is not endorsed by New Zealand Winegrowers, the national industry body. Instead, they recommend individual owners minimise the risk of further virus spread by managing both the virus and vectors (Hoskins et al. 2011). Indeed, simulation modelling indicated a 'no control' option was inferior to that of active disease control where pathogen spread slowed and the loss of plants was reduced (Sisterson and Stenger 2013). With regional compliance critical to this outcome, it was notable that in addition to the research described in this thesis, New Zealand Winegrowers simultaneously supported research aimed at area-wide virus control in Hawke's Bay and Martinborough (Hoskins et al. 2011). The results from those studies will be reported separately.

Secondly, where vines across entire blocks are infected with GLRaV-3, owners may decide to remove all vines simultaneously (Pietersen et al. 
2013). However, for this process to be effective, there must be an emphasis on significantly reducing persistent sources of virus inoculum above the ground (i.e. trunks, cordons, and canes) as well as the roots below ground (Pietersen 2004, 2006). When this strategy formed part of an integrated plan in South Africa, GLRaV-3 incidence was sustained below $0.1 \%$ in blocks of newly planted high-health red berry vines (Pietersen et al. 2013). Therefore, by intervening early in a disease cycle an epidemic may be averted, which gives rise to the third option: to apply visual diagnostics to target the virus when incidence is low by removing individual infected vines in a process known as roguing (Pietersen et al. 2013).

The concept of roguing in horticulture is not new. It has been the subject of much theoretical and applied study across a range of crops against a range of pathogens: cocoa swollen shoot disease (Thresh and Owusu 1986), Citrus tristeza virus (Spharim and Shalhevet 1988), Plum pox virus strain M (Dallot et al. 2004), and GLRaV-3 (Pietersen et al. 2013, Sokolsky et al. 2013). Although widely practiced, roguing outcomes are variable and appear to be dependent upon the conditions under which it is applied. For instance, simulation modelling of Citrus tristeza virus indicated roguing was effective in young groves where virus incidence was low; in older groves with a high incidence, whole block removal replaced roguing as the optimal strategy (Spharim and Shalhevet 1988). Similarly, peach orchards with a Plum pox virus incidence of $10-20 \%$ were removed in their entirety because under conditions of high virus incidence, roguing was considered to be incompatible with a virus control objective (Dallot et al. 2004).

In South Africa, roguing was applied against GLRaV-3 (Pietersen et al. 2013). Like whole block removal, an integrated plan incorporating roguing was effective at controlling the virus in all target blocks planted in young red berry vines where virus incidence was less than 2.5\% (Pietersen et al. 2013). What remains to be determined, however, is the extent to which this outcome can be replicated in blocks where infection incidence is higher but within proposed roguing thresholds. In New Zealand, the virus incidence threshold beyond which roguing was considered uneconomic was estimated to be $20 \%$ 
(Hoskins et al. 2011), while in the USA, a 25\% threshold was proposed (Atallah et al. 2012). Hence, in this thesis, the focus is on vineyard study blocks where upon discovery, GLRaV-3 incidence ranges from 4-24\%.

The evidence from modelling suggests that attempting to manage the virus by way of roguing is ultimately a more cost-effective option than that of 'nocontrol'. By roguing, the economic effect of GLRaV-3 was estimated to be between US $\$ 3,000$ and $\$ 23,000$ per hectare, depending on virus prevalence up to a maximum of $25 \%$ (Atallah et al. 2012). By comparison, a scenario where yield loss and fruit quality penalties accompanied a 'no control' option, the economic effect of GLRaV-3 was estimated to be US $\$ 41,000$ per hectare (Atallah et al. 2012).

\subsection{Insect vectors facilitating secondary spread of GLRaV-3}

Vine to vine transmission of GLRaV-3 by insect vectors, hereafter referred to as secondary spread (Pietersen 2004), can quickly undermine vine certification. This risk was demonstrated first by Engelbrecht and Kasdorf (1990), who found the mealybug Planococcus ficus (Hemiptera) could transmit GLRaV-3 to healthy recipient vines. Over ensuing years, further studies confirmed GLRaV-3 transmission by other mealybug and soft scale species (Table 1.6.1).

Of the 14 known vectors of GLRaV-3, only the mealybugs $P$. calceolariae, $P$. longispinus, and $P$. viburni were commonly found in New Zealand vineyards (Cox 1977, Charles 1993, Charles et al. 2010). Since 1993, however, vineyard inspections in winegrowing regions in the North and South Islands have rarely detected $P$. viburni, suggesting it may now be an insignificant component of the mealybug fauna (Charles et al. 2010). Despite the apparent absence of $P$. viburni in grapevines, the presence of $P$. calceolariae and $P$. longispinus in vineyards in the North Island and upper South Island (Marlborough, Nelson) culminated in these species being regarded as the most important insect pests in New Zealand vineyards (Charles et al. 2006). 
Table 1.6.1. Mealybug and soft scale species identified around the world as vectors of Grapevine leafroll-associated virus 3 (GLRaV-3).

\begin{tabular}{|c|c|}
\hline Mealybug (Pseudococcidae) & Citation \\
\hline Heliococcus bohemicus (Sulc) & (Sforza et al. 2003) \\
\hline Phenococcus aceris (Signoret) & (Sforza et al. 2003) \\
\hline Planococcus citri (Risso) & (Cabaleiro and Segura 1997b) \\
\hline Pl. ficus (Signoret) & (Engelbrecht and Kasdorf 1990) \\
\hline Pseudococcus calceolariae (Maskell) & (Petersen and Charles 1997) \\
\hline P. longispinus (Targioni-Tozzetti) & (Petersen and Charles 1997) \\
\hline P. maritimus (Ehrhorn) & (Golino et al. 2002) \\
\hline P. viburni (Signoret) & (Golino et al. 2002) \\
\hline \multicolumn{2}{|l|}{ Soft scale (Coccidae) } \\
\hline Ceroplastes rusci (L.) & (Mahfoudhi et al. 2009) \\
\hline Coccus longulus (Douglas) & (Kruger and Douglas-Smit 2013) \\
\hline Parasaissetia nigra (Nietner) & (Kruger and Douglas-Smit 2013) \\
\hline Parthenolecanium corni (Bouché) & (Bahder et al. 2013) \\
\hline Pulvinaria vitis (L.) & (Belli et al. 1994) \\
\hline Saissetia sp. Deplanche & (Kruger and Douglas-Smit 2013) \\
\hline
\end{tabular}

In respect of scale insects, little is known about the distribution and relative abundance of this group in New Zealand vineyards. While P. corni has been found on vines in Hawke's Bay, interceptions have been relatively uncommon, suggesting it was unlikely to have had a significant role in the secondary spread of GLRaV-3 (Bell, unpublished data, 2012).

\subsection{Mealybug biology, ecology, and monitoring}

Mealybugs are soft bodied, plant feeding insects covered in a water repellent, waxy secretion (Supplementary figure 1.7.1). Temperature-dependent development limits $P$. longispinus to three generations per year in vineyards in northern New Zealand (Charles 1981). Pseudococcus calceolariae develops through two and possibly three generations in Hawke's Bay (Bell, unpublished data, 2012). For most species, female mealybugs have three larval instars; males have four (Gullan 2000, Daane et al. 2012). Of the mealybugs commonly found in vineyards around the world, fecundity varies widely (50-800 offspring) and is influenced by the species, the environment and food supply (Daane et al. 2012). 
The mealybug first instar, or crawler, is the most mobile life stage, moving within whole fruit trees by walking (Furness 1976) and between them by windborne dispersal (Barrass et al. 1994, Grasswitz and James 2008). Relative to older instars, crawlers acquire and transmit GLRaV-3 more efficiently (Petersen and Charles 1997, Tsai et al. 2008, Mahfoudhi et al. 2009), with a single PI. ficus and P. longispinus crawler capable of transmitting the virus to healthy recipient vines (Douglas and Kruger 2008). For these reasons, crawlers play an important role in the epidemiology of GLRaV-3. In comparison to juveniles (c. $2 \mathrm{~mm}$ long) and adult females (c. 5 $\mathrm{mm}$ ), crawlers are small (c. $0.5 \mathrm{~mm}$ ). Thus, with a strong likelihood of crawlers being overlooked during in situ vine inspections, data linked to vector presence, abundance, and spatial and temporal distribution, could be substantially underestimated. Consequently, all mealybug monitoring reported in this thesis relied on the use of microscopes in the laboratory.

Apart from adult males, which do not feed, mealybugs can only acquire GLRaV-3 by feeding on infected Vitis; the virus is not vertically transmitted from a viruliferous (infected) female to its offspring (Tsai et al. 2008). Indeed, in Pl. ficus, GLRaV-3 was described as semi-persistent, with individuals no longer viruliferous 4 days after ceasing to feed on an infected vine (Tsai et al. 2008). A long thin stylet allows mealybugs to access phloem cells to feed on the sap, and in so doing, to acquire phloem-limited GLRaV-3 infection (Sandanayaka et al. 2013). With a continuous gut, mealybugs eject copious quantities of honeydew containing a high percentage of sugars (Gray 1952, Charles 1982). Accumulating on plant tissues, honeydew forms a substrate suitable for the growth of black sooty mould fungi, which along with mealybug contamination in bunches, can adversely influence wine quality (Charles 1982, Bordeu et al. 2012). The presence of honeydew on leaves can be a useful aid to mealybug monitoring (Daane et al. 2012), perhaps helping to inform owners about future control decisions with insecticides.

That honeydew was suggested as a means of assessing mealybug presence and distribution demonstrates the difficulties of monitoring this pest group effectively. Following the discovery of the female-produced sex pheromone 
for each of Pl. ficus (Hinkens et al. 2001), P. viburni (Millar et al. 2005), $P$. longispinus (Zou and Millar 2009), P. maritimus (Figadere et al. 2007) and $P$. calceolariae (Unelius et al. 2011), monitoring efficiency for these species has improved (Millar et al. 2002, Daane et al. 2006, Daane et al. 2008). While management options continue to be tested for several of these compounds (Daane et al. 2012), counts of male Pl. ficus attracted to pheromone-baited traps was used to predict future economic damage in South African vineyards (Walton et al. 2004). In a wider sense though, reliably interpreting pheromone trap-catch data can be fraught. Mealybugs are polyphagus, colonising vines and many groundcover plants commonly found in vineyard inter-rows in New Zealand (Clarke and Honore 1973, Charles 1981). Under these circumstances, the active space of a single pheromone-baited trap yield data that make it difficult to interpret if source mealybug populations originated from the vines, the groundcover plants or both habitats. The only way of reliably determining mealybug presence in the vines, and hence the risk of GLRaV-3 acquisition and transmission, is to undertake physical inspections. However, rather than being a trivial task, monitoring can instead be confounded by the cryptic lifestyle of mealybugs and by a high degree of within-vine spatio-temporal variability (Charles 1981, Geiger and Daane 2001, Geiger et al. 2001).

During winter, $P$. longispinus reside under flaking bark on old wood, and in cracks and crevices in the woody trunks and cordons of spur-pruned vines (Charles 1981). Also, with populations of $P$. calceolariae and PI. ficus colonising vine roots (Walton and Pringle 2004, Bell et al. 2009), physical inspections are further confounded by inaccessibility. Overwintering sites are vacated in spring as mealybugs move to occupy developing shoots where they are commonly found on the underside of leaves beside the main veins (Charles 1981, 1982). During this time, sampling and monitoring protocols should control for low numbers of mealybug and highly aggregated populations (Geiger and Daane 2001). Not until the second generation of $P$. longispinus (and $P$. calceolariae) in January (Southern Hemisphere summer) do populations increase to a point where they can be easier to find in the 
grape bunches and on vine leaves through until leaf-fall (Charles 1981, Geiger and Daane 2001, Daane et al. 2012).

\subsection{Thesis aims}

The studies described in this thesis were undertaken in Hawke's Bay vineyard study blocks. My primary objective is to determine whether an integrated approach to GLRaV-3 management can reduce and maintain incidence to $<1 \%$ under Hawke's Bay conditions. Each data chapter is linked to this primary objective and addresses a specific aspect of an integrated management plan.

Chapter 2 investigates vineyard study blocks where different protocols were adopted to facilitate the death and/or removal of vines infected with GLRaV3 , and whether such actions adequately controlled for the possibility of remnant vine roots being reservoirs of the virus.

In chapter 3, I investigate if GLRaV-3 visual symptom identification undertaken in red berry cultivars can reliably guide a roguing strategy, and whether the existence of genetically divergent virus populations and/or asymptomatic vines could pose problems for the efficacy of GLRaV-3 management. In this chapter, the use of study block identifiers $(A, B, C \ldots I)$ was independent of those referred to in chapter 4.

In chapter 4, I investigate patterns of GLRaV-3 spread in 13 Hawke's Bay vineyard study blocks. Visual symptom identification is the method used to identify virus-infected vines. I assess the influence of roguing these vines on overall GLRaV-3 management. I compare and contrast the outcomes of virus management in a subset of study blocks, and propose a link between virus control outcomes and vector abundance in the vine canopy.

In chapter 5, I summarise and synthesise the main findings of my studies. Constraints based on unanswered questions or incomplete research is discussed. I also suggest future research opportunities that if pursued, could provide new and important insights into GLRaV-3 management. As an 
applied study that was sector-aligned, I discuss the dissemination of new knowledge to end-users, which was an important aspect of this PhD. 


\section{Grapevine leafroll-associated virus 3 persistence in Vitis vinifera remnant roots}

\subsection{Abstract}

Grapevine leafroll-associated virus 3 (GLRaV-3) adversely alters qualitative parameters of wine production. New Zealand vineyard owners respond to this economic threat by removing virus-infected vines and replacing them with certified virus-tested vines. When vines are removed, most roots remain in situ, potentially acting as long-term reservoirs of GLRaV-3. In New Zealand, this virus is vectored by three species of mealybugs: Pseudococcus longispinus, $P$. calceolariae and $P$. viburni. The two latter species are frequently found on roots of host plants, including grapevines. Viruliferous mealybugs moving from GLRaV-3-infected remnant vine roots to healthy vines are a probable pathway explaining the re-appearance of the virus. In vineyards where virus incidence was $\geq 95 \%$, vines were herbicide-treated and/or the ground left fallow after vine removal. The virus status of recovered remnant roots was assessed at variable intervals thereafter. In a noncommercial vineyard, one of three herbicide active ingredients (glyphosate, triclopyr, or metsulfuron) was applied to freshly cut vine stumps. One year after treatment, enzyme-linked immunosorbent assay (ELISA) detected GLRaV-3 in sampled roots. Using real-time polymerase chain reaction (realtime PCR), some $P$. calceolariae found on sampled roots also tested positive for the virus. In the first of three commercial vineyards, no herbicide was applied to cut vines, which were removed and the ground left fallow for 12 months. Twenty-six weeks after vine removal, mealybugs found on remnant roots tested positive for GLRaV-3 and after 12 months, virus was detected in $97 \%$ of roots. The absence of any real decline in the proportion of roots with GLRaV-3 prompted testing in the second commercial vineyard, where 4 years earlier vines were cut and the stumps swabbed with glyphosate. ELISA did not detect GLRaV-3 in tested samples but subsequent real-time PCR detected virus in a sub-set of samples. Before vine removal in the third commercial vineyard, glyphosate was applied to the foliage. Six months later, 
ELISA detected GLRaV-3 in $87 \%$ of root samples. Evidence from this study suggests wine sectors around the world may need to review protocols for vine removal and vector management, both above and below ground.

\subsection{Introduction}

Grapevine leafroll-associated virus 3 (GLRaV-3) imposes severe economic costs in all major grape-growing regions of the world (Walker et al. 2004, Charles et al. 2006, Golino et al. 2008). Included in the genus Ampelovirus (Closteroviridae) (Martelli et al. 2002), GLRaV-3 is phloem-limited and is one of a number of recognised serologically distinct viruses associated with grapevine leafroll disease (Martelli and Boudon-Padieu 2006, Golino and Almeida 2008). Physiological symptoms in advanced infections include declines in yield, delayed crop maturity and lower soluble solids, reduced berry anthocyanin, and elevated berry titratable acidity, which result in reduced wine quality (reviewed by Charles et al. 2006). GLRaV-3 occurs only in Vitis and affects both white and red grape cultivars. It is visually most apparent in the latter where it is characterised by dark-red, downward rolling leaves with green veins (Golino et al. 2008).

In New Zealand, a 'leafroll disease' was recognised in the 1960s, with visual symptoms observed in many vineyards (McKissock 1964). Subsequent studies quantified the effects of the virus on vine performance and wine quality (Chamberlain 1967, Chamberlain et al. 1970, Over de Linden and Chamberlain 1970a, b, Thomas 1976), and although not formally classified, the symptoms described were probably those of GLRaV-3. The momentum generated by these studies was not maintained, resulting in a lack of cohesive strategies to manage the virus and its rate of spread. Indeed, a nationwide survey of owners in 2005 revealed that few were conducting optimal controls to minimise the threat of leafroll virus spread (Bonfiglioli and Stewart 2005). GLRaV-3 is now regarded as the most common and the most destructive virus affecting New Zealand grapevines (Bonfiglioli et al. 2002, Bonfiglioli and Hoskins 2006). 
Two factors exacerbate the spread of GLRaV-3: the use of infected propagating material (Golino et al. 2008) and insect vectors (Charles et al. 2006). To manage the quality of new plantings for New Zealand's rapidly growing wine industry, the sector implemented the grafted grapevine standard (Anonymous 2006). One objective was to deliver high-health rootstock and scion wood that had been rigorously tested for the presence of GLRaV-3. This initiative, coupled with recent publicity, raised awareness of GLRaV-3 to a point where New Zealand vineyard owners would be unlikely to risk using non-certified planting stock.

Pivotal to the success of the grafted grapevine standard is reducing the level of pressure exerted by insect species capable of transmitting GLRaV-3. Especially problematic are phloem-feeding mealybugs (Hemiptera: Pseudococcidae). Worldwide, a number of mealybug species have been identified as vectors of GLRaV-3. In New Zealand, three species have been recorded in vineyards: Pseudococcus longispinus, $P$. calceolariae, and $P$. viburni (Charles 1993). All three species are vectors of GLRaV-3 (Petersen and Charles 1997, Golino et al. 2002).

Today, mealybugs are regarded as the most important pest group in New Zealand vineyards. While some aspects of their biology are known (Charles 1981, Wakgari and Giliomee 2003) other aspects remain poorly understood. For example, $P$. calceolariae is frequently found on grapevine roots but whether individuals are feeding on the roots is unclear. Subterranean settlement and behaviour confounds efforts to monitor populations on grapevines, and may also mitigate biological control and the effects of contact insecticides (e.g. buprofezin) (Godfrey and Pickel 1998, Walton and Pringle 2004).

Following the removal of vines infected with GLRaV-3, vineyard personnel in New Zealand often report visual symptoms of the virus appearing within 1218 months of a block being re-planted. New sources of infection typically appear as random occurrences but because of the grafted grapevine standard and adherence to sourcing vines from accredited nurseries only, we 
believe it is increasingly unlikely the virus was introduced via the nursery. In South Africa, a similar distribution of young virus-infected vines was found to be spatially correlated with an earlier vineyard that contained a high incidence of GLRaV-3 (Pietersen 2004). The same author (Pietersen 2004) argued that this mode of virus spread might be attributed to the survival of viruliferous mealybugs on residual vine roots during the interval between the removal of the old vineyard and the re-establishment of the new one. In other words, remnant roots may act as long-term reservoirs of GLRaV-3.

Until very recently, roots were not considered to be an important part of vine removal. Vines were either cut (leaving all roots behind) or pulled from the ground (removing perhaps only $20 \%$ of the roots). For cut vines, it was widely believed that an immediate application of herbicide to the surface of a freshly cut stump would kill the roots. Historically, the herbicide of choice was glyphosate, and, although its use was specifically aimed at preventing shoot re-growth from rootstocks, in recent years it was thought it might also offer prospects to mitigate the effects of GLRaV-3. However, there is no efficacy information supporting the use of glyphosate to kill grapevine stumps and roots (O'Connor 2006) and we could find nothing in the literature linking its use to a reduced effect of GLRaV-3. Given the New Zealand wine sector's reliance on glyphosate, it was important to establish the efficacy of this product when developing protocols for managing this virus.

In this paper, we report on four field studies undertaken during 2007 and 2008 following the removal of whole blocks of vines infected with GLRaV-3. In each vineyard, differing protocols were used to facilitate vine death and/or vine removal. The objective of each study was to determine the GLRaV-3 status of sampled remnant vine roots at variable intervals following the respective treatments adopted at each site. 


\subsection{Methods and materials}

\subsubsection{Study sites and trial designs}

The vineyards were located around Hastings, Hawke's Bay, on the east coast of New Zealand's North Island (3965'S $\left.176^{\circ} 83^{\prime} E\right)$. One vineyard was a small ( $0.27 \mathrm{ha})$ non-commercial research property with Chardonnay vines on rootstock 3309, which were planted in 1993. The other three vineyards were commercial properties where treatment strategies or vine removal protocols were decided by vineyard owners. The studies reported here were therefore designed around the unique circumstances of each vineyard operation.

\subsubsection{Comparison of stump-applied herbicides}

At the non-commercial vineyard, budwood from each of the 48 vines used in the study was GLRaV-3 tested (as described below) in early May 2007. All samples tested positive for the virus. Two weeks later, the trunk of each vine was cut c. $15 \mathrm{~cm}$ above ground and a vertical 1-cm diameter hole was drilled $2 \mathrm{~cm}$ into the cut surface to create a reservoir. One of three herbicides, (Roundup $®$ Renew (200 ml/200 ml water; active ingredient glyphosate), Answer® (15 g/L; ai metsulfuron) or Grazon ${ }^{\circledR}(50 \mathrm{ml} / \mathrm{L}$; ai triclopyr)) was applied with a small paint brush at $5 \mathrm{ml}$ per stump per treatment. Herbicide was applied to a stump within 30 seconds of the trunk being cut. An organosilicone spreader-penetrant (Boost $\circledast$ Penetrant, $1 \mathrm{ml} / \mathrm{L}$ ) was added to each herbicide. The study included an untreated control with each treatment replicated four times. Pending root extraction, the stumps remained undisturbed for the duration of the study. To measure virus persistence over time, root sampling was undertaken six days after treatment and again at weeks 9,20 and 51.

\subsubsection{Fallow study 1}

In August 2007, a 1.0-ha commercial block of 25-year-old own-rooted Gewürztraminer vines was tagged for removal due to widespread GLRaV-3 infection. Before removing the vines, we ELISA tested budwood for GLRaV-3 
from 10 vines within each of three randomly selected plots $\left(108 \mathrm{~m}^{2}\right)$ separated from each other by $50 \mathrm{~m}$. With all 30 samples testing positive for GLRaV-3, it was inferred that $100 \%$ of the vines in the block were viruspositive. Herbicide was not applied to the vines prior to removal. The block remained unplanted (fallow) for a further 12 months.

The vines were removed using a large ' $L$ '-shaped steel blade mounted onto the bucket of a front-end loader. The blade cut the roots to a depth of c. 30 $\mathrm{cm}$ and c. $15 \mathrm{~cm}$ out from the vine trunk on both sides of the row. Applying this technique allowed for the removal of all aerial parts of the vine but only a relatively small proportion of the roots, particularly from these relatively old vines.

On 11 February 2008 (6 months after vine removal), remnant vine roots were extracted from the three plots using a 3-tonne mechanical digger $(n=10$ samples per plot). Each sample consisted of two root fragments with a minimum length of $15-20 \mathrm{~cm}$ and a minimum diameter of c. $1 \mathrm{~cm}$. In all the studies reported here, root samples collected were first checked for the presence of mealybugs. Those found were transferred to individually labelled vials for species identification and real-time PCR testing for GLRaV-3.

The block remained fallow until a second root extraction was undertaken on 23 July 2008 (49 weeks after vine removal). However, by this time, the infrastructure in the block (posts, wires, and irrigation) had been reestablished with a view to planting replacement grapevines. Consequently, the mechanical digger had difficulty manoeuvring within the three plots described above. Instead, remnant roots were recovered at c. $10 \mathrm{~m}$ intervals along one of the four vine rows. All root samples collected were tested for the presence of GLRaV-3, as described below.

\subsubsection{Fallow study 2}

This large commercial vineyard contained multiple blocks affected by GLRaV-3. No definitive measure of GLRaV-3 incidence was undertaken prior to vine removal in 2004 , but the owners indicated that the occurrence of 
visual symptoms across affected red cultivar blocks suggested $>95 \%$ of vines were infected. Hence in our study block (1.0-ha of own-rooted Merlot vines planted in 1981), it was assumed that any remnant vine roots recovered would have originated from infected vines. The vine roots were sampled from $10 \times 4 \mathrm{~m}^{2}$ plots, each of which was separated from the nearest plot by c. 20 $\mathrm{m}$. The virus-infected vines were removed in August 2004 and by the time we extracted remnant roots in 2008 , replacement vines had not been planted.

In 2004, the vine trunks were cut c. $15 \mathrm{~cm}$ above ground, with c. $5 \mathrm{ml}$ of glyphosate $(200 \mathrm{ml} / 200 \mathrm{ml}$ water) swabbed directly onto the cut surface of each stump. During the 4-year interval between herbicide treating and root extraction the block was periodically cultivated, although a specific programme to remove vine roots was not undertaken. In late July 2008, we used a 3-tonne mechanical digger to extract remnant roots. The samples from each plot consisted of at least two root fragments $15-20 \mathrm{~cm}$ in length with a minimum diameter of c. $1 \mathrm{~cm}$. Each sample was tested for the presence of GLRaV-3 as described below.

\subsubsection{Foliar-applied herbicide}

The third commercial vineyard was planted in 15-year old Pinot noir vines on SO4 rootstock. In mid March 2008, the vine foliage was sprayed with glyphosate (boom spray, 1 L/100 L water). In mid July, budwood samples were collected from 30 randomly selected vines across the block. ELISA confirmed all samples were positive for GLRaV-3. The vines remained in situ until mid August at which time the roots were cut (using the ' $L$ '-shaped blade described above) and the vines removed. There was no targeted programme for vine root removal. Six months after herbicide was applied, a 3-tonne mechanical digger was used to extract remnant roots from 15 randomly selected plots $\left(4 \mathrm{~m}^{2}\right)$. The root samples, which were a minimum length of 15$20 \mathrm{~cm}$ and a minimum diameter c. $1 \mathrm{~cm}$, were tested for the presence of GLRaV-3. 


\subsubsection{GLRaV-3 testing}

ELISA and real-time PCR methods were used to test for GLRaV-3. A sample of $100 \mathrm{mg}$ of cortical root phloem material was taken from three locations per root sample. These were combined and homogenised in $3 \mathrm{ml}$ of extraction buffer as described by Bioreba

(http://www.bioreba.ch/files/tecinfo/TI_Buffer_formulation.pdf). 2ml of each sample was then centrifuged for $1 \mathrm{~min}$ at $16,000 \mathrm{~g}$ and $200 \mu \mathrm{l}$ was processed in a DAS-ELISA as per manufacturers' instructions (Bioreba, Switzerland and Sediag, France). Samples with a normalised absorbance reading of 3-fold higher than background levels were considered positive.

Detection of viral RNA was performed using two independent real-time PCR methods. RNA from $150 \mathrm{mg}$ of cortical root material was extracted using published procedures (MacKenzie et al. 1997) and cDNA synthesised using Transcriptor reverse transciptase (Roche Applied Science); primed with a mix of random primers and oligodT following the manufacturer's instructions.

Extraction controls were employed to guard against sample carry-over during the RNA extraction process and no template PCR reactions were used. Realtime PCR analyses were performed with SYBR Green-based methods on a LightCycler 480 instrument (Roche Applied Science). Primers for one assay (GLRaV3-56 F, GLRaV3-285 R) was described by Osman and Rowhani (2006), while primers for the other assay (LR3-247F, LR3-385R) was designed at Linnaeus laboratory, Gisborne, New Zealand (Mackay et al. 2009). The two assays were simultaneously employed due to the high sequence variation observed in GLRaV-3. Reactions were performed in 96well format with $10 \mu \mathrm{l}$ reactions, $2.5 \mu \mathrm{l}$ of cDNA, $0.3 \mu \mathrm{M}$ each primer and $1 \mathrm{X}$ LightCycler 480 SYBR Green Master (Roche Applied Science). Reactions were cycled using the Linnaeus virus template of $95^{\circ} \mathrm{C} 5$ minutes initial denaturation followed by 45 cycles consisting $95^{\circ} \mathrm{C}$ for 5 seconds, $60^{\circ} \mathrm{C}$ for 5 seconds and $72^{\circ} \mathrm{C}$ for 11 seconds. Melting curve analysis was subsequently performed to verify resulting amplicon identity. Amplification by either (or both) primer sets was considered a positive result. For real-time PCR testing of mealybugs, individual mealybugs were homogenised with a pipette tip in 
$500 \mu l$ extraction buffer (MacKenzie et al. 1997) and processed and amplified as for root samples.

\subsection{Results}

\subsubsection{Comparison of stump-applied herbicides}

Vine roots recovered from the block over the 12-month period remained suitable for GLRaV-3 testing. Up to 9 weeks following the application of herbicide active ingredients to the cut stumps, the virus was detected in 75$100 \%$ of all root samples tested (Table 2.4 .1 .1 ). Twenty weeks posttreatment, GLRaV-3 was not detected in the Answer® samples, although the virus was detected in the remaining treatments. However, the Answer® result was not replicated beyond this date; after 51 weeks, GLRaV-3 was detected in most remnant root samples tested, independent of the herbicide active ingredient.

Table 2.4.1.1. Grapevine leafroll-associated virus 3 (GLRaV-3) infection status among remnant vine roots collected from the three stump-applied herbicide treatments in the research vineyard for the 12-months to May 2008 ( $n=4$ root samples/treatment/sampling date). All root samples were tested by enzyme-linked immunosorbent assay (ELISA).

\begin{tabular}{|c|c|c|c|c|}
\hline Date tested & ${\text { Grazon }{ }^{\dagger}}^{\dagger}$ & $\begin{array}{l}\text { Roundup }{ }^{\text {Renew }} \\
\text { Ren }\end{array}$ & Answer® & $\begin{array}{l}\text { Untreated } \\
\text { control }\end{array}$ \\
\hline May $2007(1)^{\ddagger}$ & $3 / 4^{\S}$ & $4 / 4$ & $4 / 4$ & $3 / 4$ \\
\hline July 2007 (9) & $4 / 4$ & $4 / 4$ & $4 / 4$ & $4 / 4$ \\
\hline October 2007 (20) & $4 / 4$ & $4 / 4$ & $0 / 4$ & $3 / 4$ \\
\hline May 2008 (51) & $4 / 4$ & $4 / 4$ & $4 / 4$ & $3 / 4$ \\
\hline
\end{tabular}

\footnotetext{
${ }^{\ddagger}$ Figures in brackets denote the number of weeks since herbicide was applied

${ }^{\dagger}$ Herbicide active ingredients: Grazon $®=$ triclopyr; Roundup $®$ Renew = glyphosate;

Answer ${ }^{\circledR}=$ metsulfuron

$\S$ Results are given as the number of replicate remnant vine roots in which GLRaV-3 was detected/number of samples ELISA tested
}

Eight live $P$. calceolariae (six crawlers and two adults) were found on one root sample (Answer®) at a depth of $10 \mathrm{~cm}$ during one sampling date (week 51). The root from which the mealybugs were recovered tested positive for 
GLRaV-3. The virus status of two crawlers was 'weakly positive' (the interpretation for real-time PCR amplifications with Cp's (crossing points) between cycles 35 and 40 with specific GLRaV-3 melting curves). GLRaV-3 was not detected in the remaining mealybugs.

\subsubsection{Fallow study 1}

On both sampling dates, vine roots were readily recovered from depths ranging from $20-50 \mathrm{~cm}$. The roots were in good condition and suitable for GLRaV-3 testing. The initial ELISA results in February 2008 revealed 12 of the 30 root samples (40\%) were positive for GLRaV-3 (Table 2.4.2.1). Of the remaining 18 samples, three randomly selected samples were re-analysed using real-time PCR: GLRaV-3 was detected in two of the three samples tested.

A total of $20 P$. calceolariae encompassing juveniles and adults were found on roots recovered from two plots in February. The roots from both plots tested positive for GLRaV-3. Using real time-PCR, five mealybugs tested positive for GLRaV-3 from one plot; in the second plot, GLRaV-3 was not detected in any of the six mealybugs tested.

On the second sampling date, ELISA detected GLRaV-3 in 29 of 30 samples tested $(97 \%)$. No mealybugs were recovered. 
Table 2.4.2.1. Grapevine leafroll-associated virus 3 (GLRaV-3) infections detected in remnant vine roots collected from a commercial vineyard in the fallow study 1, 26 weeks (February 2008) and 49 weeks (July 2008) after aerial parts of the vines were removed. Prior to removal, no herbicide was applied to the vines. Vine roots were initially enzyme-linked immunosorbent assay (ELISA) tested ( $\mathrm{n}=30$ root samples/date). In February 2008, a randomly selected sub-sample of three ELISA-negative root samples were re-analysed by real-time polymerase chain reaction (real-time $\mathrm{PCR})^{\ddagger}$.

\begin{tabular}{lll}
\hline Date tested & & ELISA (real-time PCR) ${ }^{\ddagger}$ positive for GLRaV-3 \\
${$\cline { 1 - 1 }$}{ }^{\dagger} }$ & & $12 / 30^{\S}(2 / 3)^{\ddagger}$ \\
July 2008 (49) & $29 / 30$ \\
\hline
\end{tabular}

\footnotetext{
${ }^{\dagger}$ Figures in brackets denote weeks since vines were removed from the block

$\S$ Results are given as the number of replicate remnant vine roots in which GLRaV-3 was detected/number of samples ELISA (or real-time PCR) tested
}

\subsubsection{Fallow study 2}

Despite a 4-year interval between herbicide application and vine root extraction, remnant roots were readily recovered from each plot. Roots were suitable for virus testing. Root samples from each of the 10 plots were initially ELISA tested; no GLRaV-3 was detected. Samples from three plots randomly selected were re-analysed using real-time PCR; roots from two of the plots tested positive for GLRaV-3. No mealybugs were recovered.

\subsubsection{Foliar-applied herbicide}

Remnant vine roots were readily recovered from each plot. All material was suitable for GLRaV-3 testing. Six months after the foliar application of glyphosate, 13 of 15 (87\%) root samples tested by ELISA were positive for GLRaV-3. No mealybugs were recovered.

\subsection{Discussion}

The vine removal protocols adopted in each vineyard enabled an assessment of the persistence of GLRaV-3 in remnant roots. For many owners the use of herbicide was viewed as a credible strategy for killing grapevines and this action, coupled with the adoption of a suitable fallow 
period, was thought to effectively prevent GLRaV-3 infection in newly planted vines. However, in this study, GLRaV-3 continued to be detected in remnant root samples from all vineyards, independent of the herbicide used, its use pattern (stump or foliar) or the fallow duration. These data call into question the potential value of herbicides when replanting vineyards, especially the current industry practice based around glyphosate.

Unlike stump swabbing, the application of glyphosate to actively growing plant foliage was the more accepted use pattern for this herbicide, a practice which was adopted by some Hawke's Bay winegrowers. The detection of GLRaV-3 in almost $90 \%$ of remnant roots 6 months after treating either stumps or vine foliage suggest that glyphosate use as described here was probably of limited value in killing remnant roots from virus-infected vines and therefore did not reduce the potential for GLRaV-3 re-infection. It is possible that a fallow period exceeding this timeframe may result in a different outcome and this aspect remains to be tested. However, the financial sustainability of an extended fallow period must also be considered, with calls for prolonged delays to re-planting likely to be financially unattractive to most vineyard owners.

Notwithstanding the financial implications or the use of herbicides, it would appear that the fallow option per se may be of limited usefulness. After 4 years of fallow, real-time PCR tests detected GLRaV-3 in some remnant vine roots. This result suggests glyphosate applied to vine stumps does not eliminate GLRaV-3, either by killing the roots or more specifically, by destroying phloem structure. It seems that a strategy to effectively manage GLRaV-3 may be compromised where there is little or no attempt to actively remove remnant vine roots (G. Pietersen, personal communication, 2008).

The excavation of remnant roots in 'Fallow study 1' where herbicide was not applied, highlighted the disparity between test results undertaken at different times of the year from samples collected in the same block. In February 2008 (Southern Hemisphere summer) less than half the ELISA-tested remnant roots were positive for GLRaV-3. However, ELISA testing conducted five 
months later (July; mid-winter) found almost all samples tested were viruspositive. It is not immediately apparent why the results were so different but they did highlight that like budwood, the timing of root collection and its testing appear to be important parameters when attempting to detect GLRaV3 (Teliz et al. 1987, Matthews 2006).

The discovery of some viruliferous $P$. calceolariae on remnant vine roots up to 12 month after herbicide treatment, added a further dimension to this study. The results suggest that this mealybug species was sustained by feeding on remnant vine roots and hence was viruliferous due to this association. While the remnant roots were in remarkably good condition and appeared to be alive, it was unclear if the mealybugs found on them were feeding or if the GLRaV-3 that was detected was degraded and therefore no longer infectious. These aspects are expected to be the subject of further research (see section 5.2). If future studies confirm the presence of infectious virus particles in remnant roots, vine certification could be compromised if newly planted vines are exposed to dispersing viruliferous vectors.

These results suggest mealybugs colonising vine roots may be of far greater importance than previously thought. We recently observed $P$. calceolariae colonies on the roots of young vines lifted just 12 days after planting. Washed and bare-rooted before planting, it was unlikely mealybugs were introduced with the young vines. Instead, observations during planting suggest that the source of the infestation was the remnant roots of vines removed four years earlier. In South Africa, the vine mealybug (Planococcus ficus) was seen on remnant roots of vines removed two years earlier (Walton and Pringle 2004). In New Zealand, P. calceolariae is widely distributed throughout most of the country, so it is probable that many vineyards host significant populations in the soil and on the roots of many groundcover plant species. The movement patterns of mealybugs through the soil both between healthy and infected vines and between vines and other host plants should be examined further. However, these observations support the idea first proposed by Pietersen (2004), that the resumption of feeding by viruliferous mealybugs moving from 
virus-infected remnant roots to newly planted virus-free vines may be an important component of GLRaV-3 transmission and spread.

For the New Zealand wine sector, these issues are important in defining the role that remnant vine roots and subterranean mealybug populations have in perpetuating the cycle of GLRaV-3. There is certainly mounting evidence that the association between mealybugs and remnant vine roots may have some influence on the fate of newly planted vines. Should the evidence from further research support this view, we envisage that economic necessity will compel wine sectors around the world to review protocols for vine removal and vector management, both above and below ground. 


\section{Visual symptom identification supports integrated control of Grapevine leafroll- associated virus 3 in red berry cultivars}

\subsection{Abstract}

Grapevine leafroll-associated virus 3 (GLRaV-3) is the most serious virus in New Zealand vineyards. Its potential to adversely influence qualitative parameters of wine production means control is a priority. In red berry varieties, changes to leaf colour could usefully aid the visual identification of symptomatic vines. We tested the efficacy of visual symptom identification by comparing results of this potentially cost-effective option with those of enzyme-linked immunosorbent assay (ELISA). Visual diagnostics identified symptomatic Merlot ( $n=5$ vines), Cabernet Sauvignon (193), Syrah (15) and Malbec (50) vines, $98 \%$ of which tested positive by ELISA. In symptomatic Syrah and Malbec vines, GLRaV-3 group I and NZ2 variants were commonly detected by ELISA and identified by multiplex reverse transcriptionpolymerase chain reaction, indicating that for these variants, visual diagnosis was reliable. To test for the presence of symptomless infections, we ELISA tested non-symptomatic Merlot (763), Cabernet Sauvignon $(1,122)$, Syrah (990) and Malbec (80) vines: few latent infections (no symptoms, ELISApositive) were detected (mean: $0.3 \%$ ). Analyses of sensitivity (0.966; binomial generalised linear model) and specificity (0.998) supported the reliability of visual assessments relative to ELISA. Temporal changes to the number of symptomatic vines were recorded from véraison, at which point $<19 \%$ of the final seasonal total were visually identified, independent of cultivar. Over the next 35-40 days, $80 \%$ of the seasonal total of new infections was found. With trained personnel, the results suggest visual diagnostics is a reliable method for detecting GLRaV-3 in red berry cultivars, with late-season inspections identifying most sources of virus inoculum. 


\subsection{Introduction}

Grapevine leafroll-associated virus 3 (GLRaV-3) is one of the most important viral diseases of Vitis vinifera L. (Vitaceae). GLRaV-3 occurs in all major winegrowing regions of the world (Maree et al. 2013), and has potential to adversely influence the quantitative and qualitative parameters of grape and wine production (Cabaleiro et al. 1999). GLRaV-3 is graft-transmissible (Sheu 1936) and is also transmitted vine to vine by dispersing mealybug (Hemiptera: Pseudococcidae) and soft scale species (Hemiptera: Coccidae) (Daane et al. 2012, Almeida et al. 2013). In New Zealand, two cosmopolitan mealybugs, Pseudococcus calceolariae (Maskell) and $P$. longispinus (Targioni-Tozzetti), are commonly found on grapevines (Charles et al. 2010). Both species are vectors of GLRaV-3 (Petersen and Charles 1997).

In New Zealand, GLRaV-3 is the most widespread and destructive virus of Vitis, meaning control is a priority (Charles et al. 2006). Therefore, like South Africa, increased numbers of vineyard owners in New Zealand are roguing (removing) symptomatic vines as a means of controlling GLRaV-3 (Pietersen et al. 2013, Bell, unpublished data, 2013). However, the efficacy of a roguing strategy is partially constrained by the natural variability in symptom expression displayed by different varieties (Maree et al. 2013). For example, in many white berry varieties, a lack of foliar symptoms makes visual diagnosis of infected vines unreliable. In Sauvignon blanc, New Zealand's most commonly grown white berry variety, estimates of virus incidence are achieved by enzyme-linked immunosorbent assay (ELISA) testing (Cohen et al. 2012). However, the cost of ELISA prevents most owners from testing on a scale and frequency required to support roguing. Hence, with no costeffective way to identify specific infected vines, sustained GLRaV-3 control in white berry varieties remains, for now, problematic, and where ELISA is used, it is relatively expensive (Pietersen et al. 2013).

Red wine production in New Zealand is currently dominated by varieties like Pinot noir, Merlot, Syrah, Cabernet Sauvignon and Malbec. In these varieties post-véraison, GLRaV-3 symptomatic vines are broadly characterised by 
dark red downward curling leaves with green veins (Golino et al. 2002); the implication being that with the aid of visual diagnostics, roguing virus-infected vines could be a potentially cost-effective control measure. While these persistent changes to leaf colour and morphology allow us to observe infected vines independently of ELISA confirmation, we frequently observe variable symptom expression, both within and between varieties. Among a number of possible explanations for this variability is the existence of multiple GLRaV-3 genetic variants (Jooste et al. 2010, Sharma et al. 2011, Bester et al. 2012, Chooi et al. 2013b). Whether symptom severity and expression are altered by the different variants, either as single or mixed infections requires clarification (Bester et al. 2012, Chooi et al. 2013b). Questions therefore remain as to the reliability of visual assessments and the likelihood of efficacy being confounded by interactions between the virus, its variants and grapevine variety.

The value of visual assessments to GLRaV-3 control was recently demonstrated in South Africa, where annual roguing of symptomatic red berry vines culminated in year-on-year reductions to virus incidence (Pietersen et al. 2013). Although clearly inferred from the positive outcomes, no empirical data were presented to support the relative accuracy of visual diagnostics. For roguing to be accepted by New Zealand vineyard owners, it must be demonstrated that the underpinning visual assessments are comparable with ELISA (Sturz et al. 1997) and unlikely to generate significant numbers of 'false negatives' and 'false positives' (Fox 1997).

In red berry varieties, reliable visual assessments are a prerequisite for costeffective GLRaV-3 control by roguing. Hence, the objective of this research was to assess the accuracy of visual symptom identification and to determine if this method was a sufficiently reliable platform for GLRaV-3 control in New Zealand. To achieve this objective, we sought answers to four questions: (1) Are the results of field-based visual assessments comparable with those derived from ELISA testing? (2) Do different GLRaV-3 variants adversely alter the ability of assessors to identify symptomatic vines visually? (3) To what extent is visual assessments under-estimating GLRaV-3 incidence 
because of the occurrence of latent infections? (4) Is there an optimal time to undertake visual symptom identification?

\subsection{Methods and materials}

\subsubsection{Site selection}

All the vineyard study blocks were located in Hawke's Bay (39³9'S $\left.176^{\circ} 52^{\prime} \mathrm{E}\right)$, a horticultural region on the east coast of New Zealand's North Island. The studies were undertaken across nine spatially distinct vineyard blocks (hereinafter identified as A, B, C ... I). Each study block was planted in a single red berry variety (Table 3.3.1.1). The vines in study blocks $A, B, C$, $E, F$, and $G$ were visually inspected for symptoms of GLRaV-3 annually from 2009. Virus management commenced later in blocks D, I (2011) and H (2012). In all the blocks, the symptomatic vines visually identified were rogued later in the same year. The vines were grown using a vertical shoot positioned trellis.

Table 3.3.1.1. Block-specific details related to grape variety, vine planting date, the number of vines per block and the Grapevine leafroll-associated virus 3 (GLRaV-3) incidence before roguing commenced in the Hawke's Bay vineyard study blocks in 2009.

\begin{tabular}{|c|c|c|c|c|}
\hline Block & Grape variety & Planted & $\begin{array}{l}\text { Vines per } \\
\text { block }\end{array}$ & $\begin{array}{l}\text { GLRaV-3 incidence } \\
(\%)^{\S}\end{array}$ \\
\hline A & $\begin{array}{l}\text { Cabernet } \\
\text { Sauvignon }\end{array}$ & $2006 / 7$ & 4,204 & 9.3 \\
\hline$B$ & Merlot & 1997 & 1,536 & 4.0 \\
\hline C & $\begin{array}{l}\text { Cabernet } \\
\text { Sauvignon }\end{array}$ & 1999 & 2,251 & 16.0 \\
\hline$D^{\ddagger}$ & Syrah & 2002 & 1,625 & 27.0 \\
\hline$E$ & Malbec & 2002 & 3,072 & 8.6 \\
\hline $\mathrm{F}$ & Merlot & 2000 & 2,410 & 8.7 \\
\hline G & $\begin{array}{l}\text { Cabernet } \\
\text { Sauvignon }\end{array}$ & 2000 & 1,243 & 9.9 \\
\hline $\mathrm{H}^{\dagger}$ & Pinot noir & 2004 & 2,221 & 9.5 \\
\hline $1^{\ddagger}$ & Syrah & 2001 & 3,118 & 7.8 \\
\hline
\end{tabular}

GLRaV-3 control initiatives commenced in $2011\left(^{\ddagger}\right)$ and $2012\left(^{\dagger}\right)$

$\S$ As determined by visual symptom identification from the 'vines per block' column 


\subsubsection{GLRaV-3 visual identification}

In red berry cultivars, changes to leaf colour and morphology were used to visually identify GLRaV-3-symptomatic vines each year. This task was undertaken by the same experienced assessor (V. A. Bell). Using a blockspecific spreadsheet of row numbers and vine number per row, the precise position and number of symptomatic vines identified per visit was recorded as the assessor walked the length of the inter-row separating two adjacent vine rows. The process was repeated in all rows in each study block.

\subsubsection{Comparing the results of visual diagnostics with ELISA}

Between 2011 and 2013, we compared the accuracy of visual diagnostics with ELISA by undertaking late-season (March to May) collections of vine leaves or budwood as specified by Cohen et al. (2012). Collections were from study blocks planted in Cabernet Sauvignon (A, C), Merlot (B), Syrah (D), and Malbec (E) vines. Within 24 hours of collection, samples were sent by overnight courier to the Plant Virus Testing Laboratory (PVTL), an ISO 17025 ELISA-accredited laboratory at The New Zealand Institute for Plant \& Food Research Limited in Auckland. ELISA testing was limited to GLRaV-3 detection only, with the testing protocols using both monoclonal and polyclonal antibodies as described by Cohen et al. (2012). In the Malbec block $(E)$, vine material was also tested for GLRaV-3 variants using multiplex reverse transcription-polymerase chain reaction (mRT-PCR) protocols developed by Chooi et al. (2013a). Pending the tests, vine samples were stored at $4^{\circ} \mathrm{C}$.

In May 2011, three weeks post-harvest, budwood was cut from 190 Cabernet Sauvignon (A) vines visually diagnosed with GLRaV-3 earlier in the season. An additional 10 non-symptomatic vines served as negative controls.

Budwood was cut from the basal section of a single cane on each of the two cordons per vine and cut to a length of c. $250 \mathrm{~mm}$. The sampled material from each vine was added to an individually labelled bag according to its precise location (row and vine number). 
In late March 2012, a single leaf was collected from each of 768 Merlot and 1,125 Cabernet Sauvignon vines in study blocks B and C, respectively. Vines visually identified with GLRaV-3 in blocks $B(n=5)$ and $C(3)$, were individually ELISA tested. In addition, we sought to assess the presence of GLRaV-3 asymptomatic vines (or 'false negatives' based on visual diagnostics) by ELISA testing leaves from non-symptomatic vines. Leaves were collected from close to the cordon of every vine in consecutive rows across $50 \%$ of each block. In early April 2013, this protocol was repeated in a block planted in Syrah (D) vines, with leaves taken from 1,005 vines (62\% of all vines). Using a waterproof marker pen, every leaf was individually numbered according to vine position along a row. During the collection, symptomatic leaf samples were identified by a circled number. After collecting and bundling 20 leaves in numerical order, they were placed in labelled bags (e.g. block $B$, row 1 , and vines 1-20).

In May 2013, budwood from 50 symptomatic Malbec (E) vines was collected in the same manner as described for block $A$. Previous research indicated that GLRaV-3 spread was generally clustered around earlier infections, with adjacent within-row vines most at risk (Habili and Nutter 1997, Pietersen et al. 2013). Therefore, to assess the prevalence of asymptomatic infections within a row, budwood was cut from a further 80 vines immediately adjacent to those vines rogued either in 2012 or from those yet to be rogued in 2013. At sampling, none of the 80 vines had visible symptoms of GLRaV-3.

In blocks B, C, and D, the leaves from every GLRaV-3 symptomatic vine and the non-symptomatic within-row vines either side of it, were individually tested by ELISA. The remaining non-symptomatic leaves from each bag of twenty leaves were then tested as a composite sample using protocols modified by Cohen et al. (2012) (see section 1.3). Composite samples that tested positive were re-tested as composites of five leaves and finally, single vine extracts were prepared to identify the individual infected vine(s). Budwood samples from symptomatic and non-symptomatic Cabernet Sauvignon $(A)$ and Malbec $(E)$ vines were individually ELISA and/or mRTPCR tested for GLRaV-3. The mRT-PCR assay included generic primers to 
detect GLRaV-3 variant groups I to $\mathrm{V}$, as well as specific primers to detect only group I, group II, NZ-1, and NZ2 isolates, as stated by Chooi et al. (2013a).

\subsubsection{The timing of GLRaV-3 visual identification}

During 2012 and 2013, visual symptom identification was undertaken in blocks planted with Merlot (F), Cabernet Sauvignon (G), Pinot noir $(H)$, and Syrah (I) vines. To measure temporal changes to the observed number of symptomatic vines, each study block was visited on at least six separate occasions over a period of between 66 and 75 days. In general, the first visit to each block coincided with the onset of berry ripening (véraison), which in Hawke's Bay in both years was early February (Southern Hemisphere summer). At each visit, symptomatic vines were tagged and the numbers identified were recorded. Visits continued until leaf condition deteriorated to a point where visual assessments were no longer feasible (early- to mid-April). In graphs, we refer to time on the x-axis as 'days post véraison', as determined by the viticulturalist supervising each block.

\subsubsection{Statistics}

The sensitivity (probability of a positive test outcome when GLRaV-3 is present) and specificity (probability of a negative outcome when GLRaV-3 is absent) of visual assessment to detect GLRaV-3 were calculated by comparing the results with ELISA, the method specified in the grafted grapevine standard (Anonymous 2006). Proportions were calculated separately for each block. Using a binomial generalised linear model, both sensitivity and specificity were found to be over-dispersed (i.e. the sensitivity and specificity estimates varied more between blocks than would be expected by binomial random variability), so the confidence intervals were calculated using an over-dispersion factor estimated from the residual deviance. Calculations were performed in GenStat (version 16, VSN International Ltd, Hemel Hempstead, UK). 


\subsubsection{Weather monitoring}

Temperature and rainfall data were collected from Roy's Hill weather station $\left(39.60^{\circ} \mathrm{N} 176.75^{\circ} \mathrm{E}\right)$, a permanent facility situated in the midst of the reported study blocks. Recorded at hourly intervals, temperature and rainfall data were automatically uploaded to a website administered by MetWatch Online (www.hortplus.metwatch.co.nz/index.php).

\subsection{Results}

\subsubsection{Comparing the results of visual diagnostics with ELISA}

Between April 2011 and May 2013, leaves and/or budwood were collected from vines in four red berry varieties across five study blocks (Table 3.4.1.1). In all blocks except Cabernet Sauvignon (A), GLRaV-3 visual symptom identification was confirmed by ELISA in $100 \%$ of vines tested. In Cabernet Sauvignon (A), ELISA did not detect the virus in budwood from six of the 190 vines (3.2\%) visually identified with GLRaV-3 (absorbance readings: monoclonal 0.02-0.04 mOD/min; polyclonal 0.05-0.07 mOD/min). However, upon re-visiting the block 12 months later, the characteristic visual symptoms of GLRaV-3 were clearly evident on the foliage of five of the six vines. Early roguing of these vines prevented further ELISA testing, but based on experience, the symptoms were clearly that of GLRaV-3. Thus, of the 190 Cabernet Sauvignon vines visually identified in 2012, GLRaV-3 infection was incorrectly attributed to a single vine $(0.5 \%)$ using this method.

To assess the prevalence of asymptomatic infections in the same five study blocks, we ELISA tested leaves or budwood collected from the vines (Table 3.4.1.1). Of the 10 non-symptomatic Cabernet Sauvignon (A) and 763 Merlot (B) vines ELISA tested, no asymptomatic infections were detected. In blocks planted in Cabernet Sauvignon (C) and Syrah (D) vines, asymptomatic infections were detected but incidence was low (range: 0.2-0.5\%). In the Malbec $(E)$ block, ELISA detected GLRaV-3 in two (2.5\%) of the 80 nonsymptomatic within-row neighbouring vines. 
In order for the visual symptom identification method to be supported, its sensitivity and specificity relative to ELISA must be demonstrated. Allowing for block-to-block variation across the five sites, the results for sensitivity (96.6\%; 95\% confidence interval 66.2-99.8\%; binomial generalised linear model) and specificity (99.8\%; 95\% confidence interval 83.5-99.9\%) supported the use of visual diagnostics to identify GLRaV-3-symptomatic grapevines reliably.

Table 3.4.1.1. Summary of the results to validate Grapevine leafroll-associated virus 3 (GLRaV-3) visual assessments by enzyme-linked immunosorbent assay (ELISA) testing vine leaves or budwood collected from five Hawke's Bay vineyard study blocks, 2011 to 2013. In addition to ELISA-testing material from vines expressing foliar symptoms of GLRaV-3, material was also collected from non-symptomatic vines in each block to assess the prevalence of asymptomatic infections (no symptoms, ELISA-positive). In all cases, ELISA testing was completed within 5 days of vine material being collected.

\begin{tabular}{|c|c|c|c|c|c|}
\hline $\begin{array}{l}\text { Grape Variety } \\
\text { (block identifier) }\end{array}$ & $\begin{array}{l}\text { Cabernet } \\
\text { Sauvignon } \\
\text { (A) }\end{array}$ & Merlot (B) & $\begin{array}{l}\text { Cabernet } \\
\text { Sauvignon } \\
\text { (C) }\end{array}$ & $\begin{array}{l}\text { Syrah } \\
\text { (D) }\end{array}$ & $\begin{array}{l}\text { Malbec } \\
(\mathrm{E})\end{array}$ \\
\hline $\begin{array}{l}\text { Vine material ELISA } \\
\text { tested }\end{array}$ & Budwood & Leaves & Leaves & Leaves & Budwood \\
\hline $\begin{array}{l}\text { Dates vine material } \\
\text { collected }\end{array}$ & 2 May 2011 & $\begin{array}{l}31 \text { March } \\
2012\end{array}$ & $\begin{array}{l}31 \text { March } \\
2012\end{array}$ & $\begin{array}{l}5 \text { April } \\
2013\end{array}$ & $\begin{array}{l}1 \text { May } \\
2013\end{array}$ \\
\hline $\begin{array}{l}\text { No. of visually } \\
\text { symptomatic vines }\end{array}$ & 190 & 5 & 3 & 15 & 50 \\
\hline $\begin{array}{l}\text { Symptomatic ELISA- } \\
\text { positive vines (\%) }\end{array}$ & $184(96.8)$ & $5(100)$ & $3(100)$ & $15(100)$ & $50(100)$ \\
\hline $\begin{array}{l}\text { No. of non-symptomatic } \\
\text { vines tested }\end{array}$ & 10 & 763 & 1,122 & 990 & $80^{\S}$ \\
\hline $\begin{array}{l}\text { Asymptomatic ELISA- } \\
\text { positive vines (\%) }\end{array}$ & $0^{\dagger}$ & 0 & $2(0.2)$ & $5(0.5)$ & $2(2.5)$ \\
\hline
\end{tabular}

${ }^{\ddagger}$ As determined during the final late-season vine assessments in each block

${ }^{\dagger}$ GLRaV-3 was later detected in three asymptomatic Cabernet Sauvignon vines using multiplex RT-PCR as stated by Chooi et al. (2013a)

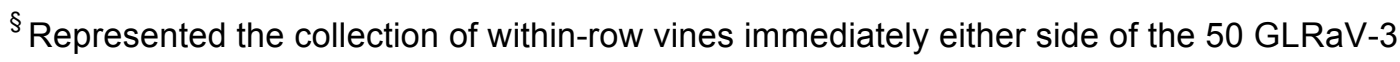
symptomatic vines

\subsubsection{GLRaV-3 variants}

Evidence from this study suggests the presence of several GLRaV-3 genetic variants did not adversely affect the reliability of the initial visual 
assessments. In the blocks planted in Malbec (E) and Syrah (I) vines, the diversity of GLRaV-3 genetic variants was assessed. Of the 52 infected Malbec vines, group I was the most commonly detected variant (43 vines or $82.7 \%$ ) followed by the NZ2 variant, either as a single infection (two vines or $3.8 \%$ ) or dual infection with a group I to $\mathrm{V}$ variant (five vines or $9.6 \%$;

Supplementary table 3.4.2.1). Single infections of a group I to $V$ variant were also detected (two vines or 3.8\%). Of the 20 Syrah vines found with GLRaV3 , a single infection of NZ2 were the most commonly detected variant (14 vines or $70 \%$ ), along with a single infection of a group I variant (six vines or $30 \%$ ). Among the few asymptomatic vines detected, no single GLRaV-3 variant was more or less prevalent.

\subsubsection{The timing of visual symptom identification}

At the start of véraison in 2012 and 2013, the proportion of symptomatic Merlot $(F)$ and Cabernet Sauvignon $(G)$ vines was relatively low, ranging from 9 to $19 \%$ of the total positive vines visually detected (Figures 3.4.3.1A-D). Thereafter, numbers of symptomatic vines increased exponentially until 4045 days post véraison, during which time $80 \%$ of total seasonal infections were visually identified. Although the frequency of newly identified symptomatic vines in both varieties slowed beyond day 50 in both years, sporadic new infections continued to be observed into April when monitoring ceased. Among these varieties and the others referred to here, all vines visually identified with GLRaV-3 remained symptomatic for the duration of monitoring.

In the Cabernet Sauvignon block (G), GLRaV-3 resulted in the cumulative loss of $41 \%$ of vines between 2009 and 2012. In 2012, the 99 symptomatic vines identified were not rogued. Instead, it was deferred 12 months in lieu of whole block removal. In Hawke's Bay, this scenario offered a rare opportunity to compare and contrast the timing of symptom expression in un-rogued vines known to have been infected for up to 2 years with vines infected more recently. Between-year comparisons of the 99 vines showed that in 2012, 93 (94\%) had symptoms by 53 days post véraison (Figure 3.4.3.1C); in 2013, 94 
(95\%) of the same infected vines expected to express visual symptoms did so just 20 days post véraison, at which point monitoring of the already tagged vines ceased (Figure 3.4.3.1D, filled circles). Also assessed were within-year comparisons between 'old' and 'new' infections (Figure 3.4.3.1D). In 2013, the block was visited 11 days before the onset of véraison and while no new symptomatic vines were identified, 27 of the 99 un-rogued vines from 2012 had already developed virus symptoms. Six days post véraison, 89 (90\%) of the un-rogued vines from 2012 were symptomatic while at the same time, we found just nine of the 54 (17\%) newly identified infections from the 2013 seasonal total.
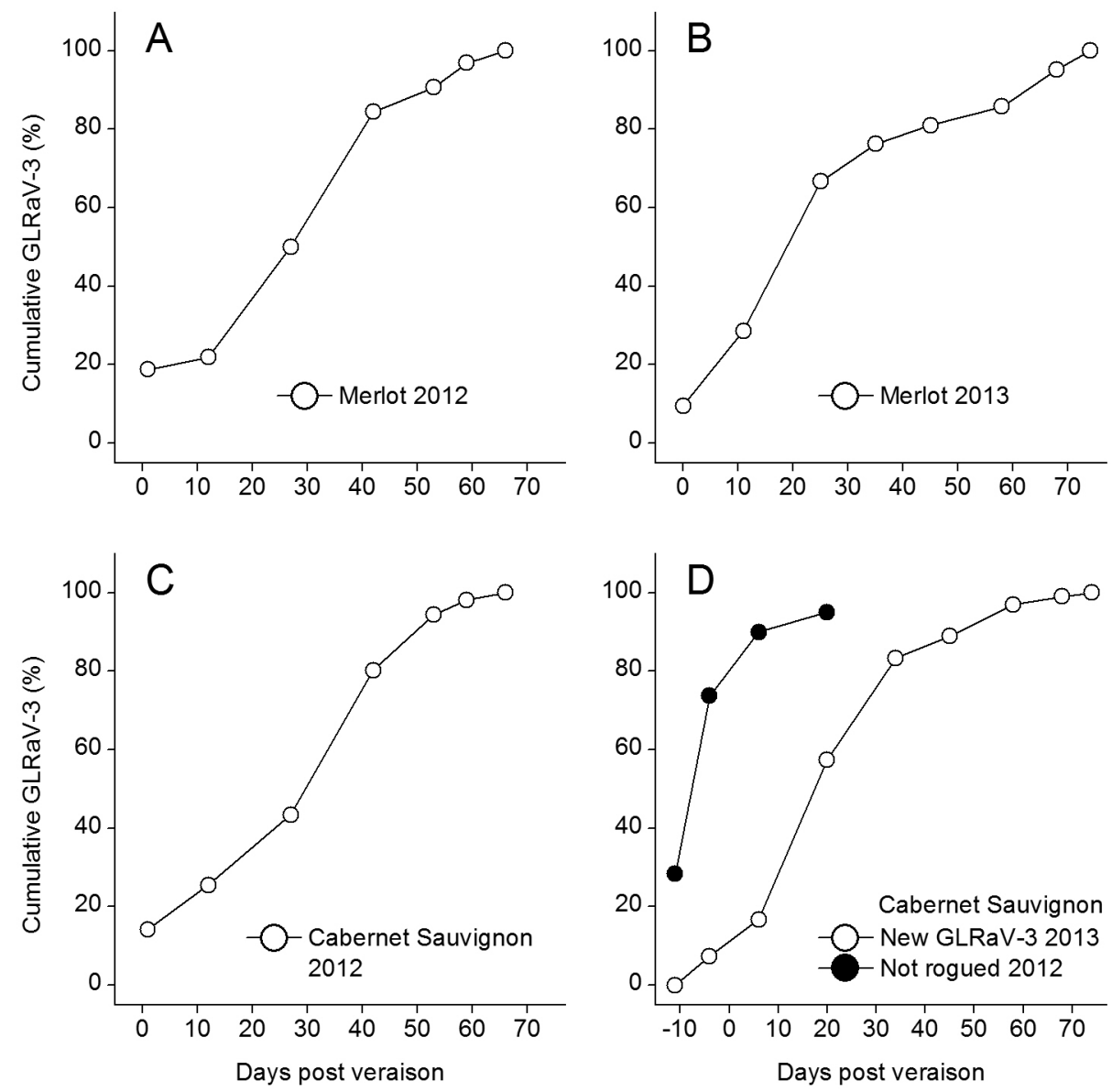

Figure 3.4.3.1. Cumulative percent changes to vines showing symptoms of Grapevine leafroll-associated virus 3 (GLRaV-3) in Hawke's Bay vineyard study blocks planted in Merlot $(F)$ and Cabernet Sauvignon (G) vines during visits in 2012 (graphs A, C) and 2013 (graphs B, D). The timing of symptom expression in the Cabernet Sauvignon vines identified in 2012 but not rogued $(\mathrm{C})$ was plotted separately from newly identified symptomatic vines in the same block that were first observed with symptoms in 2013 (D). 
Until 2012, no GLRaV-3 control measures were adopted in the Pinot noir study block $(H)$. Consequently, many of the symptomatic vines observed that year could have been infected for multiple years, some potentially dating back to planting in 2004. Thus, during the first visit in early February 2012, GLRaV-3 symptoms were observed on $53 \%$ of vines from the seasonal total (Figure 3.4.3.2A). All the symptomatic vines observed in 2012 were removed later that year. In 2013, the first visit to the block was 5 January, 25 days earlier than our first visit in 2012; new symptomatic vines were not observed for another three weeks (Figure 3.4.3.2B). Six days post verraison, the cumulative number of symptomatic vines ( $\mathrm{n}=10$ or $46 \%$ of the seasonal total) was similar to that recorded at the start of verraison in 2012 (126 vines or $53 \%$ of the seasonal total). In both years, symptomatic vines not previously observed continued to be found until monitoring concluded in early-April.
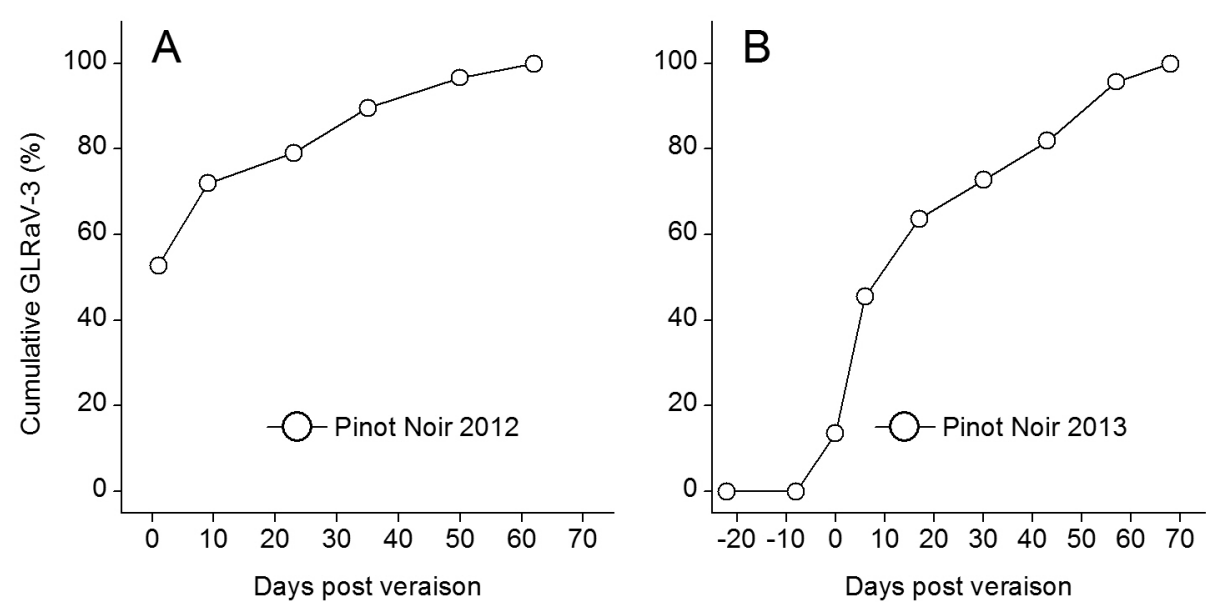

Figure 3.4.3.2. Cumulative percent changes to Pinot noir vines showing symptoms of Grapevine leafroll-associated virus 3 (GLRaV-3) in a Hawke's Bay vineyard study block $(\mathrm{H})$ during visits in 2012 (graph A) and 2013 (graph B). In 2012, symptom identification included vines that will have acquired GLRaV-3 during the interval between the initial planting (2004) and the first monitoring visit.

In a block planted in Syrah (I) vines, new symptomatic vines were also observed during the initial four visits between véraison and mid March 2013. However, during the fifth visit on 31 March, monitoring was abandoned because early onset leaf senescence compromised the reliability of further visual assessments of vines across the entire block. 
Between November 2011 and April 2012, the temperature was, on average, $1.0^{\circ} \mathrm{C}$ cooler and rainfall was almost twice the seven-year average recorded in the study area. The following growing season, average monthly temperatures over the same six-month period were marginally warmer than the seven-year average (average: $+0.2^{\circ} \mathrm{C}$ ), while average rainfall was just $48 \%$ of that recorded over the previous eight years. Despite inter-seasonal variation for temperature and rainfall, no discernible changes to the extent or timing of symptom expression were evident in Merlot or Cabernet Sauvignon vines. With limited monitoring of vines in the Syrah block, and the absence of any roguing in the Pinot noir block until 2012, it remains unclear what influence, if any, climatic factors may have had on the severity or timing of symptom development in these varieties.

\subsection{Discussion}

The results of this study demonstrated that for red berry cultivars affected by GLRaV-3, visual symptom identification was an accurate method for identifying infected vines, both in terms of its sensitivity (0.966) and specificity (0.998). Hence, under the conditions tested in Hawke's Bay, vineyard owners need not feel compelled to validate field assessments of GLRaV-3 with supporting ELISA tests. Instead, they can be confident that visual diagnostics supports integrated control when undertaken by trained personnel.

In blocks planted in Merlot (B), Cabernet Sauvignon (C), Syrah (D), and Malbec $(F)$ vines, visual assessments of the virus were fully supported by ELISA results. Only in Cabernet Sauvignon (A) were discrepancies recorded, with ELISA not detecting GLRaV-3 in budwood from six (3.2\%) of the 190 vines visually diagnosed as infected. In returning to this block 12 months later, visual symptoms of GLRaV-3 were observed in the canopy on five of the six ELISA-negative vines, suggesting that overall, visual assessments a year earlier were actually $99.5 \%$ accurate. In other words, rather than limitations with visual assessments, the ELISA false negatives were probably due to uneven distribution of GLRaV-3 in newly infected vines (Rowhani et al. 1997). As observed in this study, $95 \%$ of Cabernet Sauvignon (G) vines 
infected for a period of at least two years developed foliar symptoms some 33 days earlier than the same vines identified with GLRaV-3 for the first time 12 months earlier. Therefore, if the five ELISA-negative vines were new infections in 2012, symptom development may have been restricted to a few canes on the vine and these canes may not have been sampled for ELISA.

Recent studies have confirmed significant genetic variability in GLRaV-3 populations around the world (Jooste et al. 2010, Sharma et al. 2011, Bester et al. 2012, Chooi et al. 2013b). While the biological implications of this variability are not yet fully understood, evidence from this study suggests the presence of several variants did not adversely influence our ability to visually identify symptomatic vines reliably. Specifically, in blocks planted in Syrah (D) and Malbec (E) vines, the ELISA and/or mRT-PCR testing detected at least three variants, with group I and NZ2 the most commonly detected. Furthermore, a sub-set of 149 of the 190 symptomatic Cabernet Sauvignon (A) vines, along with 10 non-symptomatic vines, which were previously ELISA negative, were later tested by mRT-PCR to assess the GLRaV-3 variants present (Chooi et al. 2013a). All 149 symptomatic vines together with three non-symptomatic vines, tested positive for GLRaV-3, with $98 \%$ of these infected with a single variant of either NZ2, group I or NZ-1 (Chooi et al. 2013a). Hence, the evidence from Hawke's Bay suggests the existence of at least three GLRaV-3 genetic variants did not adversely influence visual symptom identification, the method initially used to detect infected vines.

The objective of visual symptom identification is to identify GLRaV-3-infected vines reliably so that sources of virus inoculum can be quickly removed from targeted areas. By doing so, vineyard owners greatly reduce the incidence of virus foci, thereby lowering the risk of vector-mediated virus transmission to healthy vines (Pietersen et al. 2013). However, factors such as poorly defined or delayed symptom development as well as latent and asymptomatic infections may restrict the ability of assessors to identify infected vines reliably and adequately. 
In this study, visual diagnosis of GLRaV-3 yielded only a slight underestimation of virus incidence, with low numbers of latently infected vines (ELISA-positive, asymptomatic vines) observed. It remains unclear if these vines completely lacked foliar symptoms at the time of monitoring or if symptom development was so rudimentary that infected vines were simply overlooked. Regardless of the cause, the long term effect of a small number of undetected asymptomatic vines is likely to be negligible in circumstances where virus control is supported by effective vector management and sustained roguing (Pietersen et al. 2013). With no latently infected Merlot (B) vines detected, and only a low incidence of latently infected Cabernet Sauvignon (C) and Syrah (D) vines, it seems that for the GLRaV-3 genetic variants reported in this study, the risk of not detecting GLRaV-3 infection due to delayed and/or obscured symptom development was quite low.

While the incidence of latently infected vines was generally very low $(\leq 0.5 \%)$, the relatively high incidence recorded in Malbec $(E)$ vines $(2.5 \%)$ was unlikely to be representative of the whole block. Unlike the other study blocks, Malbec vine material was collected only from those within-row vines adjacent to symptomatic vines visually identified in 2012 and 2013. Previously, it was shown that GLRaV-3-infected vines are often clustered, with virus spread typically along rows as viruliferous vectors dispersed to adjacent vines (Habili and Nutter 1997, Pietersen 2006, Pietersen et al. 2013). In the Malbec vines, populations of the mealybug $P$. calceolariae in the vine canopy were relatively high, with an average of 1.0 mealybug per leaf since 2011 (chapter 4). Consequently, as the risk of secondary virus spread to adjacent withinrow vines increases, the likelihood of latent infections in vines adjacent to an infected vine is also expected to increase.

The timing of visual assessments was important in determining the extent of GLRaV-3. To minimise the risk of not detecting infected vines, visual monitoring should be undertaken when the greatest likelihood of symptom development exists, which in New Zealand is in March and April. Regrettably, with this timing coinciding with harvest activity, many vineyard owners face a dilemma: to cease visual assessments too early in a season increases the 
risk of unseen symptomatic vines remaining in situ; delay too long, and visual assessments may be confounded by defoliating frosts. In red berry cultivars, the optimal strategy in New Zealand is to undertake multiple visits timed from mid-March to mid-April (Southern Hemisphere autumn). However, from a practical perspective, detecting the highest number of symptomatic vines with the least number of visits may mean delaying monitoring for as long as possible whilst having regard for defoliating frosts. Therefore, we propose two inspections per red variety block. Based on the Hawke's Bay study results, it could be expected that the first inspection in mid- to late-March would identify most vines infected for 2 years or more, and about $80 \%$ of the final seasonal total of vines infected more recently (say, within the last 12-18 months). Assuming no frost events, a second visit in mid- to late-April should identify the remaining $20 \%$ of previously unseen symptomatic vines. If a frost event occurred before the second visit, the risk of secondary spread from any remaining symptomatic vines would be dependent upon the effectiveness of early-season vector management (Pietersen et al. 2013).

While the results of this study generally support an emphasis on late-season monitoring, a factor such as early onset leaf senescence may limit the effectiveness of visual assessments. In the Syrah study block (I) in particular, site-specific factors such as soil, clone, vine age and/or the Hawke's Bay environmental conditions in 2012 and 2013 could explain the observed early onset leaf senescence. Indeed, in Australia, the reliability of grapevine woody indexing to detect GLRaV-1, GLRaV-2, GLRaV-3 and GLRaV-9 in Cabernet Franc indicator plants resulted in differential symptom expression, a result explained by the influence of temperature designated as either 'hot' (annual average minimum/maximum temperature: $\left.9.0-23.8^{\circ} \mathrm{C}\right)$ or 'cool' $\left(7.3-20.2^{\circ} \mathrm{C}\right)$ (Constable et al. 2013). Hence, in the Syrah block, it is possible that climatic variables in Hawke's Bay in 2012 and 2013 affected canopy condition and therefore our ability to undertake visual symptom identification in April. In such circumstances, owners should practice ongoing vigilance and if necessary, be willing to alter work plans to accommodate visual assessments based on their knowledge of different varieties and different blocks. 
In conclusion, when considering the results of the present study alongside those from South Africa (Pietersen et al. 2013), there is now evidence supporting the use of visual symptom diagnosis as a reliable indicator of GLRaV-3 in red cultivar grapevines. Visual assessments by trained personnel timed for late in the growing season can greatly improve prospects to identify and then remove most sources of virus inoculum. Importantly, this outcome is achievable without also incurring ELISA or other laboratory testrelated costs and delays. Under the conditions tested in Hawke's Bay, the finding of a low incidence of asymptomatic vines indicated that unseen infections pose a low risk to overall virus identification, particularly when supported by effective vector management (Pietersen et al. 2013). Although our data support the efficacy of visual diagnostics, we cannot yet claim that the method is completely validated. Outcomes may be influenced by grapevine variety, GLRaV-3 variants, or variety/variant combinations not part of the present study. Consequently, such factors should to be the subject of further research to determine the extent to which visual diagnostics might be influenced by environmental conditions in winegrowing regions other than Hawke's Bay. 


\section{$4 \quad$ Management of Grapevine leafroll-associated virus 3 in red berry cultivars}

\subsection{Abstract}

Grapevine leafroll-associated virus 3 (GLRaV-3) can adversely influence qualitative parameters of wine production. By adopting sustainable remedial actions, an epidemic may be avoided. In this study, we assessed if visually identifying the virus and targeted vine removal (roguing), supported by low numbers of insect vectors, could reduce and maintain annual virus incidence at $<1 \%$. In 13 Hawke's Bay vineyard study blocks, each planted in one of five red berry cultivars ( $n=29,920$ vines), virus incidence ranged from $4-24 \%$ at discovery. Virus incidence and vector populations were monitored annually. When monitoring commenced in 2009 , 2,544 symptomatic vines (12\%) were identified and rogued; by 2013 , just 434 symptomatic vines $(2.0 \%)$ were identified. Within-row vines immediately either side of an infected vine were most at risk of vector mediated virus transmission, although by 2013 , just $4 \%$ of these vines had symptoms. Hence, roguing symptomatic vines only was recommended. In individual study blocks in 2013, virus management was tracking positively in four blocks $(\mathrm{J}, \mathrm{M}, \mathrm{N}$, and $\mathrm{O})$ or results were inconclusive in a further four $(B, D, F$, and $L)$. In the remaining five blocks $(A, C, E, I$, and $K)$, definitive but contrasting results were evident. In blocks $A, C$, and $E$, average virus incidence of $10 \%$ in 2009 was sustained at $\leq 0.3 \%$ within $2-3$ years of roguing commencing. By comparison, incidence in blocks I and $\mathrm{K}$ was only marginally higher in 2009 (mean: 12\%) but cumulative vine losses of $37 \%$ (2011) and 46\% (2013), respectively, culminated in roguing being replaced with whole block removal. Pre-harvest monitoring of the mealybug Pseudococcus calceolariae, the dominant GLRaV-3 vector found, revealed significantly lower numbers in blocks A, C, and $E$ in all years (mean: <0.2 per vine leaf) relative to blocks I and $\mathrm{K}$ (mean: 0.4-2.3 per vine leaf; Poisson generalised linear model: $2010 p=0.022 ; 2011 p=0.007 ; 2012 p=0.013 ; 2013$ $p=0.036$ ). Although effective vector management is important for GLRaV-3 control, adopting a single management tactic in isolation is unlikely to be as effective as an integrated management plan implemented annually. 


\subsection{Introduction}

For over a century, one of the most important and best studied viral diseases of Vitis vinifera L. (Vitaceae) has been grapevine leafroll disease (Hoefort and Gifford 1967), with which Grapevine leafroll-associated virus 3 (GLRaV3 ) is primarily associated. A type member of the genus Ampelovirus (Closteroviridae) (Martelli et al. 2002), GLRaV-3 occurs in all major winegrowing regions of the world. Of the viruses affecting Vitis in New Zealand, GLRaV-3 is the most widespread and the most destructive (Charles et al. 2006), with potential to adversely affect quantitative and qualitative parameters of grape and wine production (Vega et al. 2011, Mannini et al. 2012).

GLRaV-3 is a phloem-limited virus previously believed to be transmitted solely through the use of infected propagating material (Sheu 1936). Critical to mitigating this risk, was the development of vine certification schemes in wine-producing nations like France, USA, South Africa, and New Zealand (Almeida et al. 2013, Pietersen et al. 2013). Certification has greatly improved the quality and health status of the planting material supplied to owners, thus significantly reducing the risk of primary spread of virus and virus-like diseases such as GLRaV-3 (Walter and Martelli 1997). However, the advances achieved by certification can be quickly negated by vine to vine transmission of GLRaV-3 by insect vectors, as demonstrated first by Engelbrecht and Kasdorf (1990) with the mealybug Planococcus ficus (Hemiptera: Pseudococcidae). Another seven mealybug species and seven species of soft scale (Coccidae) have since been identified as vectors of GLRaV-3 (Daane et al. 2012, Almeida et al. 2013). In New Zealand, two mealybug species, Pseudococcus calceolariae (Maskell) and P. longispinus (Targioni-Tozzetti) are commonly found in vineyards (Charles et al. 2010). Both species are vectors of GLRaV-3 (Petersen and Charles 1997).

With no known cure, removing (roguing) GLRaV-3-infected vines has become an important consideration in different wine-producing regions of the world (Almeida et al. 2013, Pietersen et al. 2013, Sokolsky et al. 2013). In red 
berry cultivars, symptomatic vines undergo distinctive foliar changes characterised by dark red downward curling leaves with green veins (Golino et al. 2002). These persistent changes to leaf colour and morphology offer scope to visually identify symptomatic vines for later roguing (Pietersen et al. 2013). However, a potentially crucial constraint of virus control is the natural variability in symptoms induced by different vine cultivars. In white vine cultivars for example, the foliar symptoms of GLRaV-3 are often very subtle or even non-existent, thus preventing reliable visual diagnostics (Maree et al. 2013). Therefore, despite the risk to healthy vines posed by unseen infected white vines, the virus management described in this study was restricted to red berry cultivars only.

The New Zealand wine sector has long recognised grapevine leafroll disease as a serious threat to production (McKissock 1964). However, only recently has international research begun to quantify the economic costs associated with various mitigation options. Data from New Zealand vineyards affected by GLRaV-3 together with simulation studies from USA, concluded that when virus incidence was low, roguing symptomatic vines early ultimately improved vineyard income and profitability relative to the other management scenarios tested (Nimmo-Bell 2006, Atallah et al. 2012). However, roguing in blocks where virus incidence was $>20 \%$ was, in general, considered uneconomic in New Zealand (Hoskins et al. 2011); in USA, whole block removal rather than roguing, was the optimal response where incidence was $>25 \%$ (Atallah et al. 2012).

While simulation studies provide useful insights into various management options, it was the development of practical measures in South Africa that provided the first real demonstration of vineyard-wide control of GLRaV-3 (Pietersen et al. 2013). Across 37 ha, phase one of the South African study concentrated on relatively young ( $<5$ years) plantings of certified virus-free vines where virus incidence was low $(<2.5 \%)$. In another 41 ha, phase two focused on whole blocks cleared of mature vines, all which were virusinfected. During a 12-month fallow period that followed, attempts were made to remove remnant vine roots and volunteer (re-grown) vines, after which 
blocks were progressively planted with certified red berry cultivars (Pietersen et al. 2013). In the years following planting, new symptomatic vines were immediately rogued, with contact and systemic insecticides applied to control the dominant GLRaV-3 vector, the vine mealybug Planococcus ficus. By 2012, this integrated approach to virus control culminated in vineyard-wide virus incidence of $<0.03 \%$ (Pietersen et al. 2013).

In the present study, we sought to build upon the virus management recommendations developed by Pietersen et al. (2013). However, unlike the very low $(<2.5 \%)$ and very high virus incidence (100\%) reported by these authors, the Hawke's Bay study blocks were characterised by virus incidence at discovery ranging from low to moderate (range: 4-24\%). Based on this critical distinction between the South African and New Zealand studies, we sought to determine if integrated virus management was compatible with Hawke's Bay winegrowing conditions and vineyard practices. Specifically, the objective was to assess if roguing symptomatic vines, supported by low numbers of insect vectors, could reduce and sustain virus incidence at $<1 \%$. Varying management approaches adopted by different vineyard owners provided critical information on how vector numbers influenced the outcomes of virus control. Hence, in view of this important variable, we sought to answer two questions: (1) is roguing a viable method to reduce and maintain GLRaV-3 incidence at <1\%?; and (2) should roguing focus only on symptomatic vines or should the process also include removing one or more neighbouring vines, even if they have no symptoms of GLRaV-3?

\subsection{Methods and materials}

\subsubsection{Study sites}

Study block selection was confined to 13 vineyards located in Hawke's Bay $\left(39^{\circ} 39^{\prime} S 176^{\circ} 52^{\prime} \mathrm{E}\right)$, a horticultural region on the east coast of New Zealand's North Island. Each study block (hereinafter identified as A, B ... O) was planted in one of five red berry cultivars (Table 4.3.1.1). The vines were grown on a vertical shoot positioned trellis, typically on two cordons. In screening for GLRaV-3, the grafted grapevine standard, which was 
introduced in 2006, aimed to minimise the risk of infected propagating material being released to the sector (Anonymous 2006). However, other than block D, the vines in all study blocks in 2009 were planted well before the implementation of certification, meaning that in most blocks, GLRaV-3 may have been introduced during the initial planting. In planning this research in 2009, the project management team decided that virus incidence of c. $20 \%$ was the threshold beyond which roguing was unlikely to effectively control GLRaV-3 (Hoskins et al. 2011).

Table 4.3.1.1. Summary of grapevine variety, clone, planting date, the number of vines and Grapevine leafroll-associated virus 3 (GLRaV-3) incidence recorded in each of the 13 Hawke's Bay vineyard study blocks in 2009.

\begin{tabular}{|c|c|c|c|c|c|}
\hline Block & Variety & Clone (rootstock) & $\begin{array}{l}\text { Year } \\
\text { planted }\end{array}$ & $\begin{array}{l}\text { No. of } \\
\text { vines }\end{array}$ & $\begin{array}{l}\text { GLRaV-3 } \\
\text { incidence }(\%)^{\S}\end{array}$ \\
\hline A & Merlot & 6 (SO4) & 1997 & 1,536 & 4.0 \\
\hline B & $\begin{array}{l}\text { Cabernet } \\
\text { Sauvignon }\end{array}$ & LC10 \& 15 (3309) & 2003 & 3,262 & 24.1 \\
\hline C & Merlot & $481(3309)$ & 2000 & 1,040 & 10.6 \\
\hline D & $\begin{array}{l}\text { Cabernet } \\
\text { Sauvignon }\end{array}$ & LC10 (3309) & $2006 / 7$ & 4,204 & 9.3 \\
\hline$E$ & $\begin{array}{l}\text { Cabernet } \\
\text { Sauvignon }\end{array}$ & $\begin{array}{l}\text { Erindale \& } 7 \text { (101-14; } \\
3306)\end{array}$ & 1999 & 2,251 & 16.0 \\
\hline $\mathrm{F}$ & Malbec & $\begin{array}{l}1056 \text { \& } 595 \text { (101-14; } \\
R G)\end{array}$ & 2002 & 3,072 & 8.6 \\
\hline I & $\begin{array}{l}\text { Cabernet } \\
\text { Sauvignon }\end{array}$ & $420 \mathrm{~A}(101-14)$ & $1993 / 4$ & 1,584 & 15.1 \\
\hline J & Merlot & 481 (3309) & 2000 & 2,410 & 8.7 \\
\hline K & $\begin{array}{l}\text { Cabernet } \\
\text { Sauvignon }\end{array}$ & $420 \mathrm{~A}(\mathrm{RG})$ & 2000 & 1,243 & 9.9 \\
\hline $\mathrm{L}^{\dagger}$ & Syrah & MS4012 (RG) & 1999 & 2,354 & 7.1 \\
\hline$M^{\dagger}$ & Syrah & MS (101-14) & 2001 & 3,118 & 7.9 \\
\hline $\mathrm{N}^{\dagger}$ & Syrah & $383(101-14)$ & 2002 & 1,625 & 22.2 \\
\hline $\mathrm{O}^{\dagger}$ & Pinot noir & 667 (3309) & 2004 & 2,221 & 9.5 \\
\hline
\end{tabular}

${ }^{\dagger}$ Blocks added to the study in January 2012.

${ }^{\S}$ As determined by visual symptom identification from the number of vines present in 2009.

Residual vines in blocks G \& H were removed in mid 2011 for commercial reasons unrelated to GLRaV-3.

Commencing in 2009 , this research is expected to conclude in mid 2015. For this thesis, however, data collection was limited to consecutive years 
between 2009 and 2013. Accordingly, interpretation of the results in several study blocks is preliminary and may change as a consequence of data collection and analysis undertaken in 2014 and 2015.

All but two study blocks were conventionally managed, with the use of mealybug-specific insecticides sanctioned by New Zealand Winegrowers. Details of the insecticide active ingredients, the timing and number of applications, and water rates, are recorded in Supplementary table 4.3.1.2. In contrast, blocks $\mathrm{C}$ and $\mathrm{E}$ were certified organic, with no mealybug insecticides applied to the vines during this study.

In mid 2011, formal notification was received from the owner of blocks $G$ and $\mathrm{H}$ that the remaining vines would be removed for commercial reasons unrelated to GLRaV-3. When the residual vines were removed, virus control outcomes were inconclusive hence, with no ability to collect additional data it was decided those data we did have would be excluded from the analyses. In the same year, confirmation was received that the residual vines in study block I were also being removed. This decision was linked to the negative effects of GLRaV-3. Accordingly, virus incidence (2009 to 2011) and mealybug abundance data (2010 and 2011) form an integral part of the analyses.

To compensate for the loss of three blocks, four additional blocks were added to the study in late 2011. Three of the blocks were planted with Syrah vines. In one block (hereafter identified as $L$ ), roguing commenced in winter 2010, while in another two blocks (M, N), roguing started 12 months later. In visiting block $L$ for the first time in early 2012 , it was possible to distinguish the position of the vines rogued in 2010 because replacement Syrah vines were planted in 2011 while gaps within the vine rows in 2012 denoted the position of those vines rogued in 2011. In the fourth block planted in Pinot noir vines (O), there had been no GLRaV-3 management prior to 2012. 


\subsubsection{GLRaV-3 identification}

Of those blocks included from the outset of this study, GLRaV-3 identification commenced in 2009. Being red berry cultivars, the method used to detect GLRaV-3 was visual diagnostics based on persistent changes to leaf colour and morphology. Relative to enzyme-linked immunosorbent assay (ELISA), the sensitivity (0.966) and specificity (0.998) of visual diagnostics (chapter 3 ) supported the use of this detection method throughout this study.

Recording vine losses attributed to GLRaV-3 was first undertaken in 2010. It involved a two-stage process. Following visual symptom identification undertaken by vineyard personnel in March and April 2009, our first visit to each block was in January 2010. On a block-specific spreadsheet, we recorded the precise position of each symptomatic vine previously rogued, detailing row numbers and the number of vines per row. Although symptomatic vines were removed during winter 2009, re-creating vine position was possible due to (a) the planting of replacement vines (block D); (b) the residual 30-45 cm long vine stumps (I, J, and K), or (c) gaps in the vine rows (all other blocks). This information allowed us to quantify GLRaV-3 incidence as at 2009.

Stage two commenced on 5 April 2010 and focused on identifying new symptomatic vines for that season. In plotting the position of symptomatic vines in each study block, the length of every vine inter-row was walked. Thus, by mid April 2010, the spreadsheet for each block included the precise location of (a) every symptomatic vine rogued in 2009 and (b) those symptomatic vines visually identified for the first time in 2010 . Thereafter, the process was repeated annually by the same experienced assessor (V. A. Bell). Identifying symptomatic vines concluded by mid April each year.

Coloured flagging tape was tied around the trunk of those vines visually identified with GLRaV-3. Tape used in this manner was the agreed method by which vineyard personnel in each study block would later identify the leafless infected vines for removal during winter. 
With the vines in all study blocks planted in 2007 or earlier, the GLRaV-3 incidence recorded in $\mathbf{2 0 0 9}$ was likely to have represented an accumulation of infected vines during the interval between initial planting and the start of this research.

\subsubsection{Vine removal protocols}

In all but one study block, only symptomatic vines were rogued throughout the duration of this study. The exception was block F. In 2009, the owner rogued symptomatic vines and one or more within-row and across-row neighbouring vines. In 2010, and annually thereafter, the roguing strategy in block $\mathrm{F}$ was consistent with that of all other study blocks.

In 2010, a systemic mealybug insecticide (imidacloprid) was registered for use on non-cropping grapevines (Lo and Walker 2011). In all but the organic study blocks (C, E), this active ingredient was applied as a soil drench to the base of the trunk of each symptomatic vine 6-8 weeks prior to roguing. In each study block, roguing was expected to target aerial parts of a vine and as much of its root system as was practicable.

\subsubsection{GLRaV-3 mapping}

The vines immediately surrounding a symptomatic vine were referred to as 'nearest neighbours'. The 'first' and 'second' vines were within-row categories; 'opposite' and 'diagonal' vines were across-row categories (Figure 4.3.4.1). A maximum of 10 'nearest neighbour' vines surrounded a GLRaV-3 symptomatic vine. A fifth category, the 'random' infection, represented a symptomatic vine spatially distinct from 'nearest neighbour' vines.

In recording the precise position of actual infections, we also recorded the position of and counted the vines in each 'nearest neighbour' category with potential to be infected but which had no GLRaV-3 symptoms at the time of monitoring. A block count of actual infections among each 'nearest neighbour' category divided by the total number of vines in the same 
category with potential to be infected provided a percentage of GLRaV-3 incidence. 'Random' infections were assessed as a percentage of all other non-'nearest neighbour' and non-symptomatic vines.

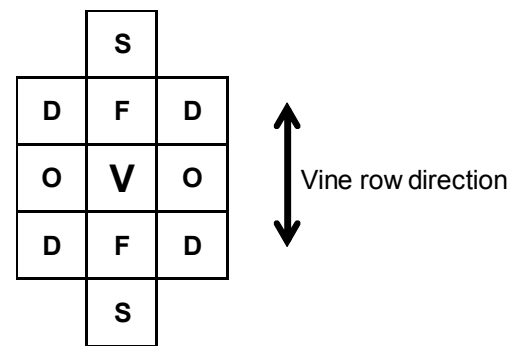

Figure 4.3.4.1. A diagrammatic view of three vine rows showing the position of the 10 'nearest neighbour' vines relative to a Grapevine leafroll-associated virus 3 (GLRaV-3)symptomatic vine $(\mathrm{V})$. 'Nearest neighbour' vines comprised four categories: Within-row 'first' $(F)$ and 'second' $(S)$ vines $(n=4)$; across-row 'opposite' $(O)$ and 'diagonal' $(D)$ vines $(n=6)$. The vines within rows were planted $1.8 \mathrm{~m}$ apart; row width ranged from 2.0-3.0 m, depending on the study block.

\subsection{5 'Nearest neighbour' model and the assumptions}

The probability of GLRaV-3 transmission infecting adjacent within-row vines ('first' and 'second') was high compared with the risk of infection to vines in adjacent rows ('opposite' and 'diagonal'), a prediction based on the results of earlier studies (Habili and Nutter 1997, Pietersen 2006, Pietersen et al. 2013). Hence, three assumptions underpinned the 'nearest neighbour' model: (1) where a new symptomatic vine was a 'nearest neighbour' of vines rogued over multiple years, the probable GLRaV-3 infection pathway was attributed to the vine, or vines, rogued most recently and then in the following order: 'first', 'second', 'opposite', 'diagonal'; (2) where a new symptomatic vine had two or more 'nearest neighbours' rogued in the same year, the most probable GLRaV-3 infection pathway was attributed in the following order: 'first', 'second', 'opposite', 'diagonal'; and (3) any symptomatic vine or aggregation of two or more symptomatic vines not categorised as 'nearest neighbour' vine(s), was a 'random' infection(s). 


\subsubsection{Mealybug monitoring}

In each study block, mealybug monitoring relied on the collection of vine leaves annually from 2010 to 2013. Collections were undertaken in March each year to coincide with the emergence of the final generation of $P$. calceolariae and $P$. longispinus. Late in the growing season, mealybug numbers in the vine canopy are generally increasing, so where present, they are easier to find. To ensure leaf collections were from widely dispersed vines, each study block was divided into four sectors of approximately equal size. In each sector, one leaf from a $10-15 \mathrm{~cm}$ band above the cordon was taken from each of 100 vines (75 in 2010). Leaves were placed in a plastic bag labelled by vineyard name and sector number. The process was repeated in each sector until 400 leaves per block were collected (300 in 2010). In the laboratory, the leaves were inspected under a dissecting microscope. When mealybugs were found, an absolute count allowed a measure of the average number per leaf inspected, independent of life stage (crawler to adult). Mealybugs were visually identified to species level.

\subsubsection{Vine replants}

A replacement planting programme of vines produced in accordance with the grafted grapevine standard commenced from 2009. In most study blocks, imidacloprid was applied as a soil drench to the replacement vines but in organic blocks $\mathrm{C}$ and $\mathrm{E}$, its use was precluded. The process to visually identify any GLRaV-3-symptomatic replacement vines was the same as that described for mature vines.

\subsubsection{Statistics}

Data on percentage GLRaV-3 incidence were expressed as the number of symptomatic vines in a particular category ('first', 'second', 'opposite', 'diagonal', 'random') compared with the total number of vines in that category, and analysed using generalised linear models with binomial distribution. Data on changes to GLRaV-3 incidence over time were analysed for each position (using data from all blocks), with block and year as 
categorical variables. The variation in trends between blocks (the block $x$ year interaction) was used to check for over-dispersion. Data on the difference between the category within each block and year were analysed with category as a categorical variable. After 5 years of GLRaV-3 management, emerging trends enabled the study blocks to be divided into two groups for reporting purposes: group 1 represented blocks where virus control was tracking positively; group 2 represented blocks where virus control outcomes were poor or results were inconclusive as at 2013. Comparisons between mealybug numbers (average mealybugs per leaf) in a subset of group 1 (A, C, E) and group 2 (I, K) blocks were analysed using generalised linear models with Poisson distribution and estimating the dispersion from block to block variation within the two groups. All data were analysed with GenStat (version 14, 2011, VSNi Ltd).

\subsubsection{Ethical limitations}

When this research commenced in late 2009, it was already apparent to the Hawke's Bay winegrowing community that the economic impact of GLRaV-3 had the potential to be severe. Therefore, doing nothing to manage this destructive virus would simply have exacerbated the problem and imposed further financial losses. Consequently, it was considered unethical to ask any vineyard owner to volunteer for a long-term research programme that required an unmanaged component among vine plantings. Hence, without access to dedicated experimental sites, our study design was unable to accommodate any unmanaged plots.

\section{$4.4 \quad$ Results}

\subsubsection{GLRaV-3 incidence}

Across the nine study blocks in 2009 , an average of $11.8 \%$ (SEM $\pm 1.9 \%$ ) of vines ( $n=2,544)$ was GLRaV-3-symptomatic (Figure 4.4.1.1). Integrating visual diagnostics with winter roguing was an important contributor to the decline in the numbers of symptomatic vines removed annually. After correcting for the loss of block I in 2011 , the addition of data from blocks $L$ 
(2010), M, N (2011), and O (2012), and the planting of replacement vines (blocks A, B, D, E, F, J, M, and N), GLRaV-3 incidence continued to decline year-on-year, such that by 2013 , average incidence was $2.0 \%$ (SEM $\pm 0.6 \%$; $n=434$ vines). During the five years to 2013 , a total of 5,775 vines were visually identified with symptoms of GLRaV-3.

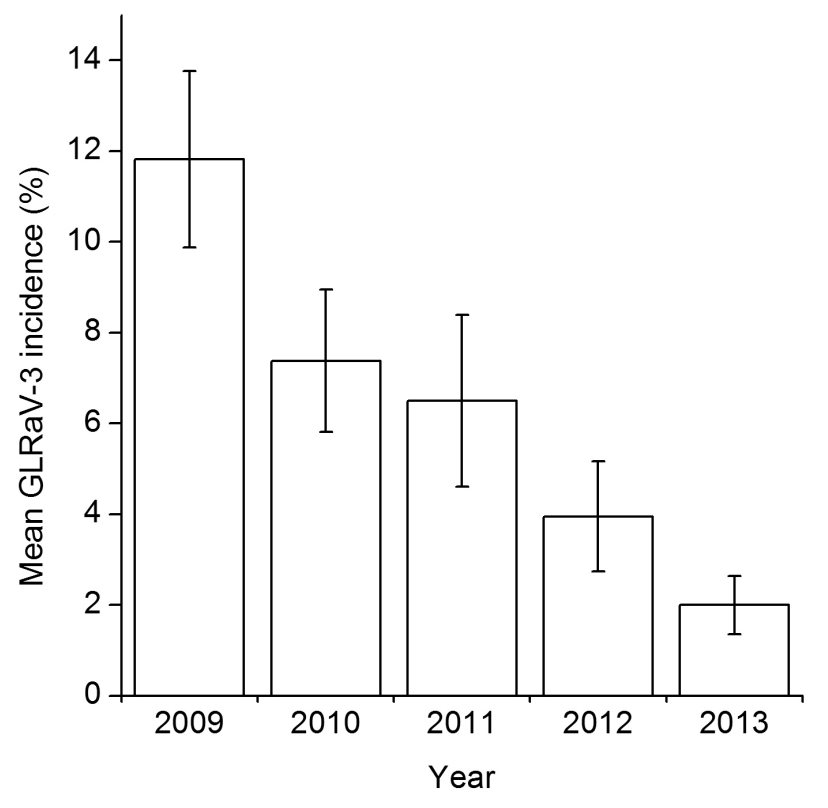

Figure 4.4.1.1. Mean ( \pm SEM) Grapevine leafroll-associated virus 3 (GLRaV-3) incidence recorded in the Hawke's Bay vineyard study blocks, 2009 to 2013 (n=9 blocks in 2009, 10 in 2010, 12 in each of 2011, 2012 and 2013). Where relevant, data were corrected to include the planting of replacement vines. Note: the 2009 incidence data will have included vines that acquired GLRaV-3 in the interval between initial planting and the start of this research.

When analysed by block, temporal changes to virus management outcomes were evident. Based on these interim results, the study blocks were divided into two groups: in group 1 (blocks $A, C, E, J, M, N$, and O) virus management was tracking positively; in group $2(\mathrm{~B}, \mathrm{D}, \mathrm{F}, \mathrm{I}, \mathrm{K}$, and $\mathrm{L})$ virus control outcomes were poor or the results were inconclusive as at April 2013.

Among group 1, effective GLRaV-3 control was evident in study blocks A, C, and $E$, with incidence of $<1.0 \%$ sustained since 2011 (C, E) or 2012 (A) (Figure 4.4.1.2A). In 2013, good progress towards virus control was also observed in block $\mathrm{J}$ ( $0.8 \%$ virus incidence), and blocks $\mathrm{N}$ and $\mathrm{O}$ (virus incidence of $1.3 \%$ and $1.1 \%$, respectively). Across these six blocks between 
2012 and 2013, the increase in cumulative vine loss was low, ranging from $0.0-1.2 \%$ (Figure 4.4.1.2C).

In block M, the low GLRaV-3 incidence of $0.4 \%$ recorded in 2013 was possibly an aberrant result influenced by early onset leaf senescence. Up until the fourth visit on 17 March 2013, we readily identified 13 GLRaV-3symptomatic vines using visual diagnostics. However, two weeks later (31 March) leaf condition in the Syrah vines across the block deteriorated to a point where visual diagnosis was no longer feasible (chapter 3 ). Thus, the extent to which this result reflected actual GLRaV-3 incidence was to be resolved when monitoring resumed in 2014.

Compared with group 1, the GLRaV-3 control outcomes in group 2 (B, D, F, I, $\mathrm{K}$, and $\mathrm{L}$ ) were less encouraging. In blocks I and $\mathrm{K}$ in particular, annual virus incidence remained relatively high (Figure 4.4.1.2B), with cumulative vine losses of $37 \%$ (2011) and 46\% (2013), respectively (Figure 4.4.1.2D). Ultimately, the effect of GLRaV-3 in both blocks was such that rather than continue to rogue, the vineyard owners instead removed the remaining vines in July 2011 (block I, 1,000 vines) and July 2013 (block K, 671 vines). The loss of the remaining 1,671 vines meant that across the entire study, total losses increased to 7,446 vines. After correcting for the planting of replacement vines in various blocks between 2009 and 2012 (3,702 vines; referred to below), $22 \%$ of the vines were removed in the 13 study blocks. However, vine removal in blocks I and $\mathrm{K}$ equated to $38 \%$ of total vine loss between 2009 and 2013.

Among the remaining blocks in group 2, justification for the continuation of a roguing strategy was inconclusive as at April 2013. Specifically, in blocks B and D, annual vine loss ranged from 3-5\% per annum, and by 2013 , cumulative vine loss was $40 \%$ and $25 \%$, respectively (Figure 4.4.1.2D). In block $F, 8.6 \%$ of the vines were removed in 2009 , but with annual virus incidence ranging from 1.6 to $2.3 \%$, cumulative vine loss increased to $13.7 \%$ in 2013. Likewise, after just four years of roguing in block $L$, virus incidence of $7.1 \%$ in 2010 increased more than three-fold to $23.8 \%$ by 2013 . 

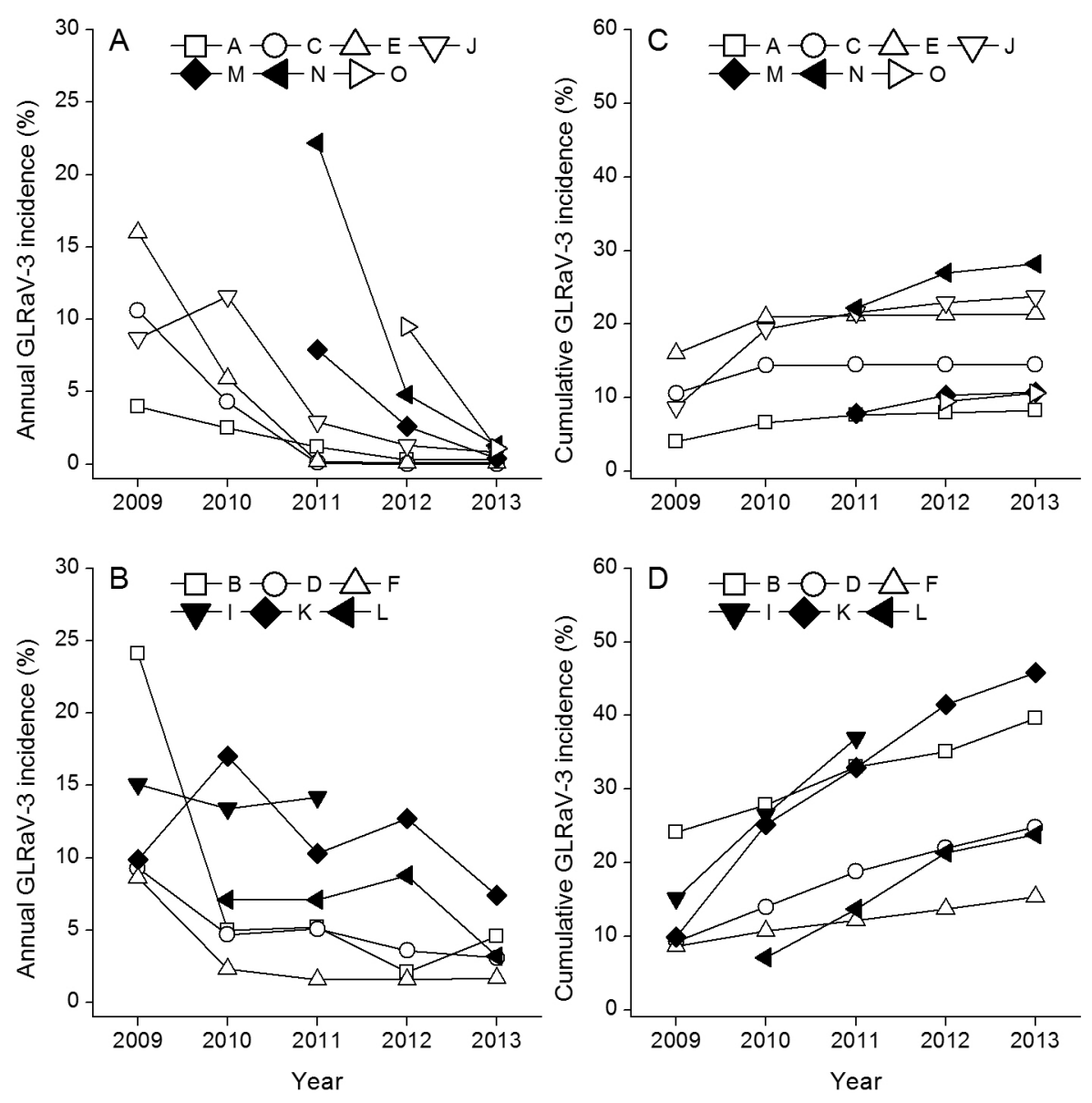

Figure 4.4.1.2. Percent annual Grapevine leafroll-associated virus 3 (GLRaV-3) incidence (graphs A, B) and cumulative GLRaV-3 incidence (graphs C, D) in the 13 Hawke's Bay vineyard study blocks, 2009 to 2013. On the basis of preliminary results, the study blocks were divided into two groups: in group 1 (blocks $A, C, E, J, M, N$, and O) good progress was being made towards effective virus control; in group $2(B, D, F, I, K$, and $L$ ) virus control was either ineffective or inconclusive. Where relevant, data were corrected to include the planting of replacement vines. Data from the first year of assessment in each block will have included vines that acquired GLRaV-3 in earlier years. In block I, the residual vines were removed in July 2011; blocks L, M, N, and O were recent additions to the study. In 2011, all residual vines in blocks $\mathrm{G}$ and $\mathrm{H}$ were removed for commercial reasons unrelated to GLRaV-3.

The contrasting but definitive virus management outcomes evident in a subset of group 1 and group 2 blocks offered scope for more detailed analysis. Specifically, the effective virus control achieved and sustained in the group 1 blocks $\mathrm{A}, \mathrm{C}$, and $\mathrm{E}$ contrasted the whole block removal undertaken in group 2 blocks I and K. In 2009, a total of 895 symptomatic vines were removed from these five blocks, of which $59.6 \%$ were identified in blocks A, C, and E, and $40.4 \%$ in blocks I and K. Annually thereafter, a 
progressive decline in the necessity for roguing was observed in blocks $A, C$, and $E$ so that by 2013 , just seven vines (11.7\%) were rogued while in the remaining block $K, 53$ symptomatic vines were identified. Thus, in blocks $A$, $\mathrm{C}$, and $\mathrm{E}$, there were significantly fewer rogued vines in all years, independent of category, compared with blocks I and $\mathrm{K}$ (binomial generalised linear model; $2010 p=0.016 ; 2011 p=0.005 ; 2012 p=0.005 ; 2013 p=0.021$ ).

In contrast to the vine losses recorded in blocks I and K, just $765(15.8 \%)$ of the original 4,827 vines planted in blocks $A, C$, and $E$ were rogued between 2009 and 2013. In 2012 and 2013, annual virus incidence ranged from 0.0 to $0.3 \%$ (Figure $4.4 .12 \mathrm{~A}$ ), with cumulative losses increasing only marginally in blocks $A$ and $E$ from 2010 or not at all in block $C$ from 2011 (Figure 4.4.1.2C).

\subsubsection{Nearest neighbour}

Between 2010 and 2013, symptomatic vines were generally in close proximity to a vine rogued at least 12 months earlier (Figure 4.4.2.1A). In $2010,68 \%$ of symptomatic vines were one of the four 'nearest neighbours' to a vine rogued in 2009 , with $32 \%$ of infections being a new 'random' outbreak. From 2011, the frequency of 'nearest neighbour' infections increased (range: $84-90 \%$ ), with a commensurate decline in new 'random' infections.

By excluding the 'random' category and focusing only on the four 'nearest neighbour' categories (Figure 4.4.2.1B), we could track the most probable virus transmission pathway to neighbouring vines. In all years, the virus, mediated by dispersing viruliferous mealybugs, had a strong within-row influence, which affected a higher percentage of 'first' (range: 50-58\%) and 'second' (range: 14-20\%) vines compared with the across-row categories. 

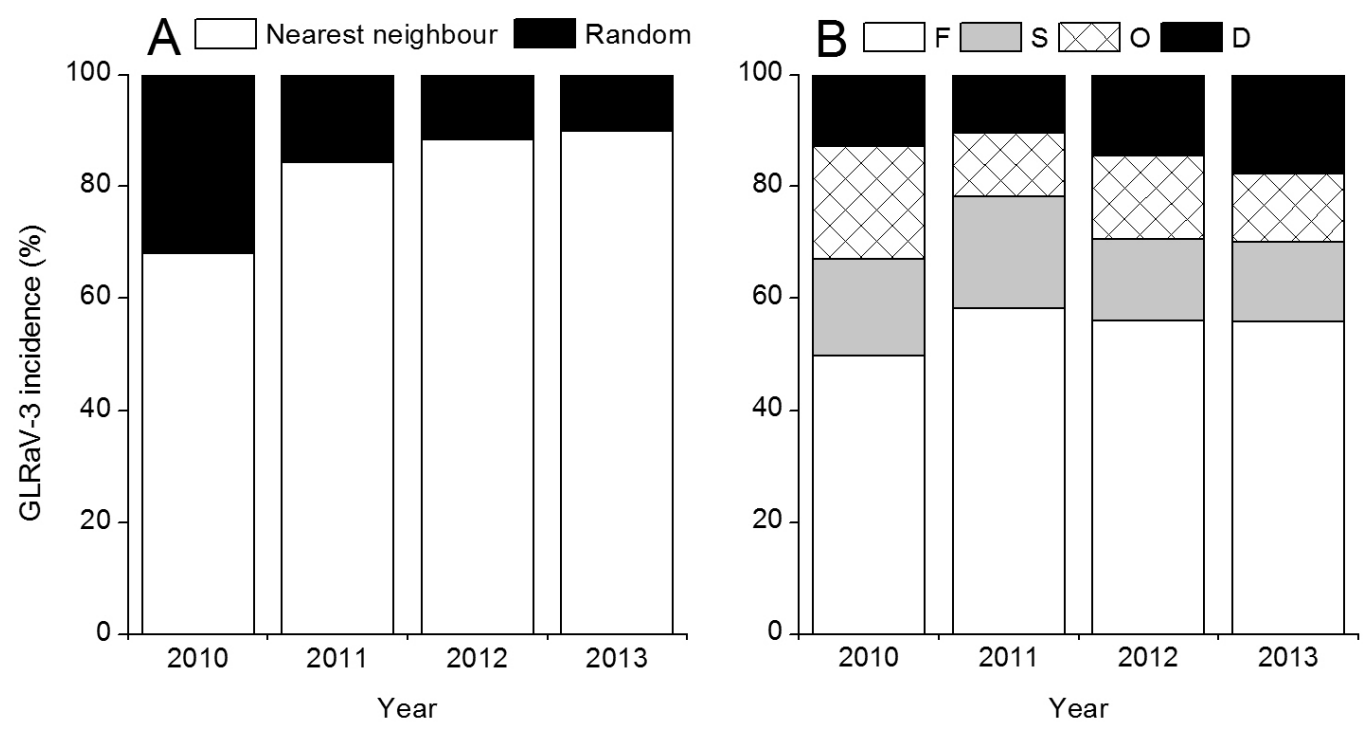

Figure 4.4.2.1. (A) Percentage of Grapevine leafroll-associated virus 3 (GLRaV-3)symptomatic vines recorded as either 'nearest neighbour' (combining 'first', 'second', 'opposite', 'diagonal') or 'random' infections; and (B) the GLRaV-3-symptomatic vines identified by 'nearest neighbour' category (excluding the 'random' category) in the Hawke's Bay vineyard study blocks, 2010 to 2013. F='first'; $S=$ ='second'; $O=$ ='opposite'; $D=$ ='diagonal' ( $\mathrm{n}=9$ study blocks in 2010, 10 in 2011, 11 in 2012, and 12 in 2013).

Analysis of GLRaV-3 incidence by block was undertaken in 2010, 2011, 2012, and 2013 (Supplementary table 4.4.2.1). Relative to 'random' outbreaks, newly infected vines were significantly more likely to be found among the 'nearest neighbour' categories in all years in almost all study blocks (binomial generalised linear models $P<0.001$ ). After excluding 'random' infections from the calculations, significant differences in virus incidence was found between 'nearest neighbour' categories in eight of the nine blocks in 2010 (binomial generalised linear models $P \leq 0.006$ ), in seven of the 10 blocks in 2011 ( $P \leq 0.013$ ), in eight of the 11 blocks in 2012

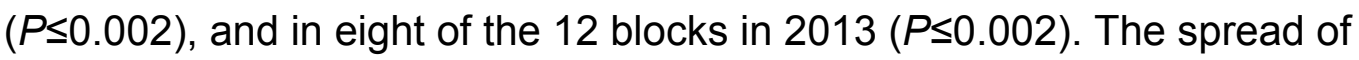
GLRaV-3 was typically within rows, with 'first' vines significantly more at risk relative to other 'nearest neighbour' categories in almost all the study blocks (pairwise likelihood ratio test $P \leq 0.013$; Supplementary table 4.4.2.1).

Comparative between-year data within a category showed significant differences in GLRaV-3 incidence, independent of study block (Figure 4.4.2.2). For example, in relative terms, 'first' vines in all study blocks were 
most at risk of GLRaV-3, with mean virus incidence of $26 \%$ in 2010 being significantly higher than in all other years (binomial generalised linear model $P<0.001$, after fitting a block effect). By 2013, mean virus incidence among 'first' vines reduced to $7.4 \%$. In other words, after four years of virus management, an average of $92.6 \%$ of 'first' vines had no visible virus symptoms.

For all other 'nearest neighbour' categories, a similar between-year pattern of decline in GLRaV-3 incidence was found (binomial generalised linear models; 'second' $P<0.001$; 'opposite' $P<0.001$; 'diagonal' $P=0.03$, after fitting a block effect).

There was also a year-on-year reduction in new 'random' outbreaks of GLRaV-3. In 2010, an average of 3.6\% of all the non-'nearest neighbour' vines were identified with virus symptoms; by 2013, 'random' outbreaks averaged just $0.4 \%$, a between year reduction that was highly significant (binomial generalised linear models $P<0.001$, after fitting a block effect). 


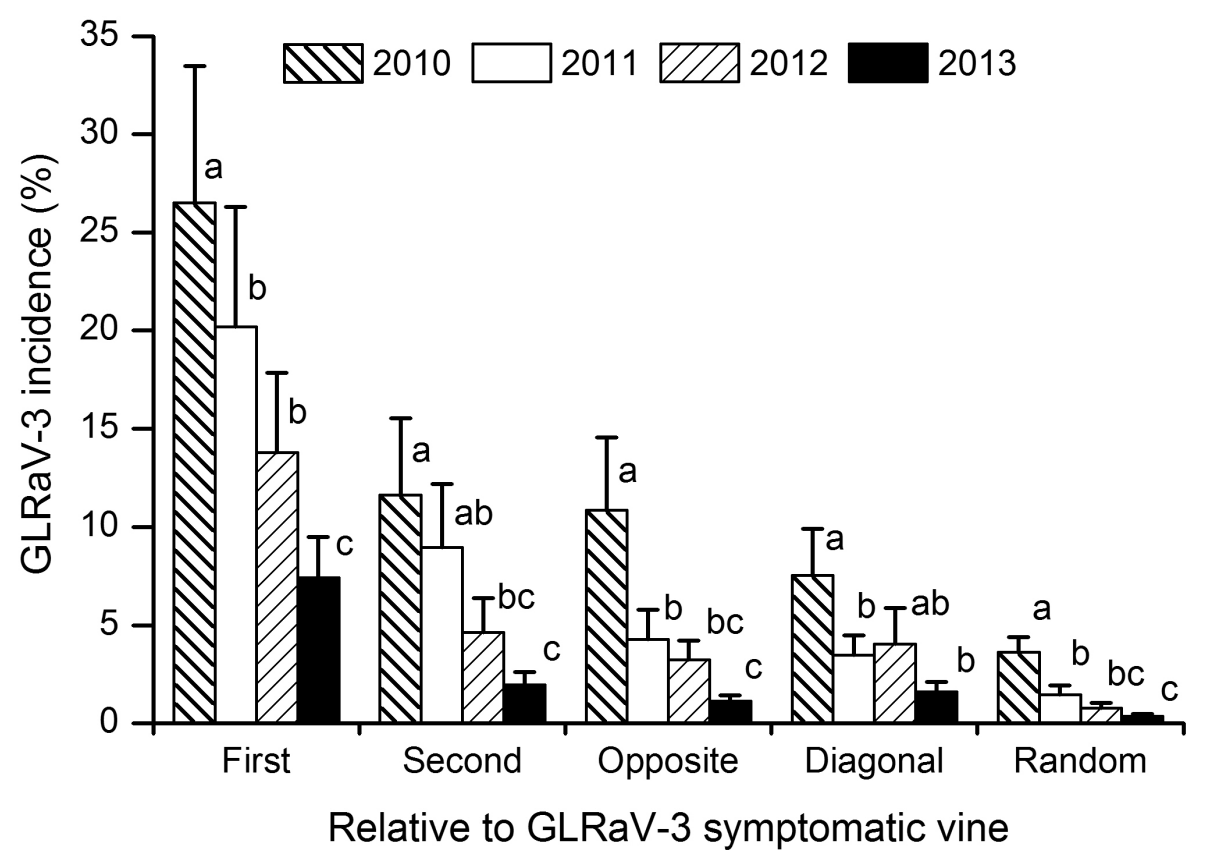

Figure 4.4.2.2. Mean (+SEM) Grapevine leafroll-associated virus 3 (GLRaV-3) incidence observed among 'nearest neighbour' and 'random' categories in the Hawke's Bay vineyard study blocks, 2010 to 2013 (n=9 study blocks in 2010, 10 in 2011, 11 in 2012, and 12 in 2013). Statistically significant differences between years within a category are denoted by different letters $(\alpha=0.05)$.

\subsubsection{Mealybug monitoring}

In this study, the dominant mealybug species found in the vine canopy was $P$. calceolariae. It represented $99 \%$ of all the mealybugs found between 2010 and 2013. The only other species found, $P$. longispinus, was restricted to blocks $\mathrm{B}$ and $\mathrm{J}$, but numbers recorded on vine leaves in those blocks were consistently lower relative to that of $P$. calceolariae.

During this study, mealybug abundance in the vine canopy varied widely between blocks (Figure 4.4.3.1; spread over two pages). Consistently low numbers of mealybugs were found in blocks $A$ (mean range: 0.02-0.2 mealybugs per vine leaf), $C(0.0-0.05)$, and $E(0.01-0.05)$. Good progress towards effective mealybug management was recorded in 2012 and/or 2013 in blocks $\mathrm{J}(0.03-0.05), \mathrm{M}(0.24), \mathrm{N}(0.16-0.24)$ and $\mathrm{O}(0.01)$. 
In contrast, numbers of mealybug were consistently high in blocks I (1.1-2.3), and $\mathrm{K}(0.4-1.5)$. Elsewhere, mealybug control was highly variable between years in blocks $B$ (mean range: 0.1-0.6 mealybugs per vine leaf), $D$ (0.03$0.5)$, and $F(0.2-1.4)$, and in the case of block $L$, mealybug management was relatively ineffective (0.3-0.4).

Like virus incidence, important insights into virus management outcomes were gained by analysing mealybug abundance in a subset of the group 1 (A, $\mathrm{C}, \mathrm{E})$ and group $2(\mathrm{I}, \mathrm{K})$ blocks. In blocks $\mathrm{A}, \mathrm{C}$, and $\mathrm{E}$, numbers of $P$. calceolariae were consistently low: from the 1,500 vine leaves inspected per block between 2010 and 2013, we found a total of 112, 40 and $42 P$. calceolariae, respectively (mean range: 0.0 to 0.17 per leaf). In contrast, a total of 1,223 P. calceolariae were found on the 700 vine leaves inspected in block I to 2011 (mean range: 1.1 to 2.3 per leaf), while in block $K, 1,029 P$. calceolariae was found on the 1,500 vine leaves inspected (mean range: 0.4 to 1.5 per leaf). Thus, in all years, mealybug abundance in blocks $A, C$, and $E$ was significantly lower than that recorded in blocks I and $\mathrm{K}$ (Poisson generalised linear model: $2010 p=0.022 ; 2011 p=0.007 ; 2012 p=0.013 ; 2013$ $p=0.036)$. 

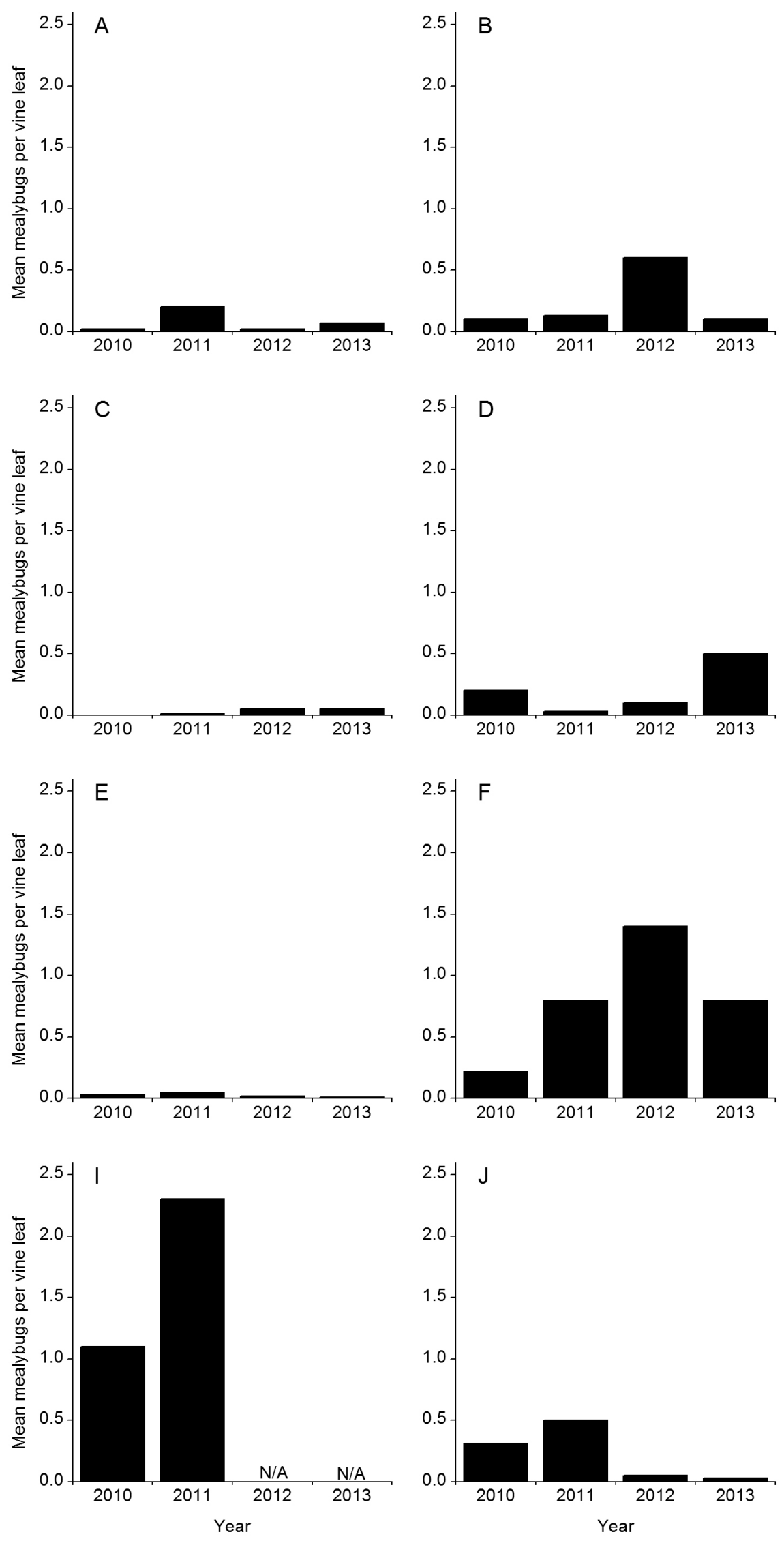

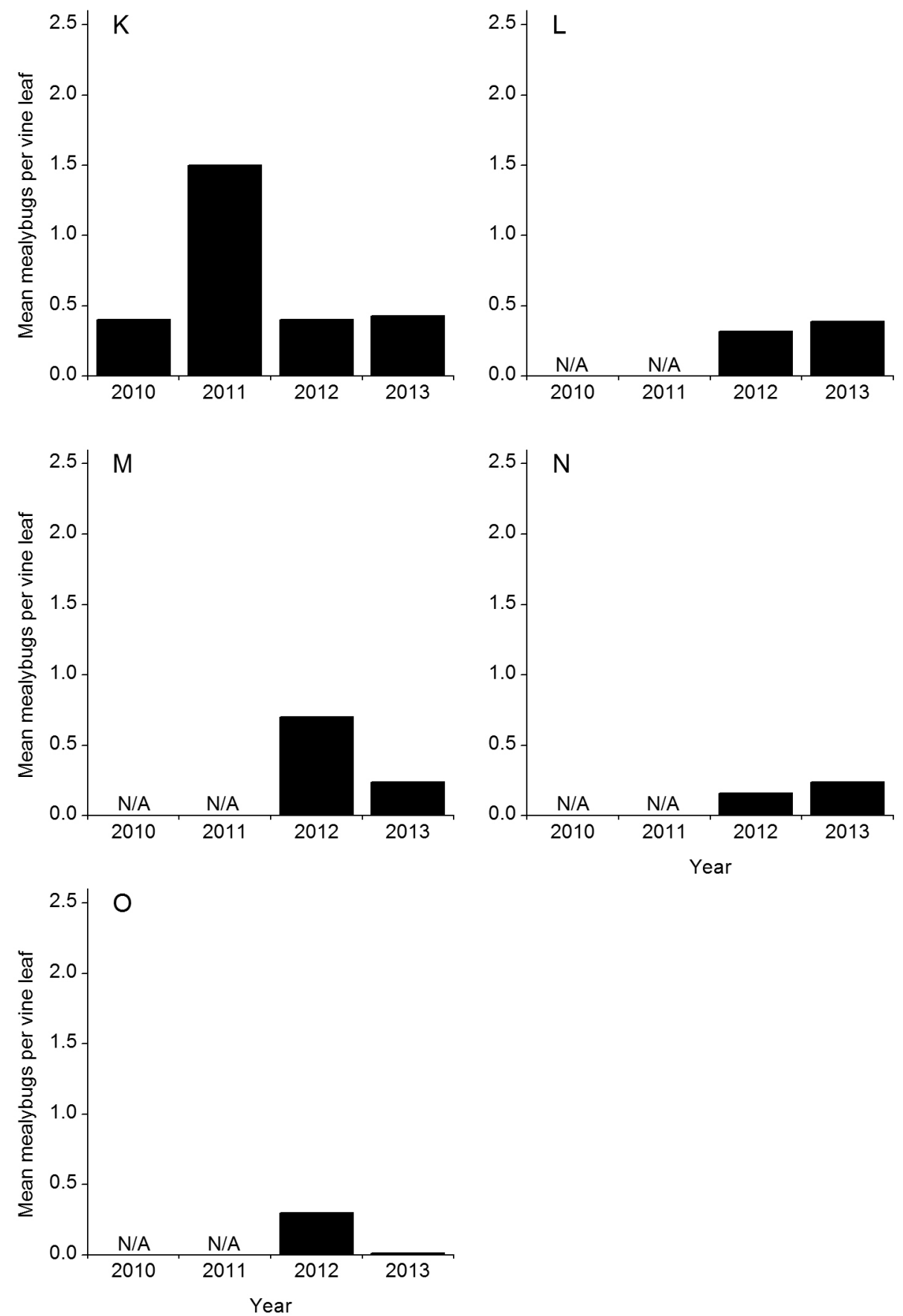

Figure 4.4.3.1. The mean number of mealybugs per vine leaf recorded in the 13 Hawke's Bay vineyard study blocks, 2010 to 2013 ( $n=400$ vine leaves inspected/block/year; 300 in 2010). In block I, the residual vines were removed in July 2011; blocks $L, M, N$, and O were recent additions to the study. Between 2009 and 2013, the vines in blocks $C$ and $E$ received no mealybug-specific insecticides. 
Using the same subset of group 1 (A, C, E) and group 2 (I, K) blocks, analysis of annual vine leaf collections allowed estimations of spatial and temporal changes to the distribution of $P$. calceolariae (Table 4.4.3.1). In A, C and $E$, mealybugs were found on $<3.0 \%$ of the sampled leaves per year (range: 0.0-2.8\%). By contrast, there was only a single occasion in blocks I and $\mathrm{K}$ when $<10 \%$ of the sampled leaves were found with mealybugs (range: 8.0-46.0\%). Hence, relative to blocks A, C, and E, late season vine leaf collections revealed $P$. calceolariae was widely distributed on vines across blocks I and $\mathrm{K}$ during all years of this study.

Table 4.4.3.1. Percentage of vine leaves found with $P$. calceolariae in five Hawke's Bay vineyard study blocks, 2010 to 2013 ( $n=400$ leaves/block/year; 300 in 2010). The blocks were a subset of the 13 study blocks, which were divided into two groups based on interim results for GLRaV-3 control: in group 1 (including blocks $A, C$, and $E$ ) the evidence suggested effective virus control; in group 2 blocks, GLRaV-3 control was inconclusive, or in the case of blocks I and $\mathrm{K}$, roguing was ineffective and was replaced with whole block removal.

\begin{tabular}{llllll}
\hline & \multicolumn{5}{c}{ Sampled vine leaves found with P. calceolariae (\%) } \\
\cline { 2 - 6 } Block & A & C & E & I & K \\
\hline 2010 & 0.7 & 0.0 & 1.7 & 31.7 & 8.0 \\
2011 & 2.8 & 0.5 & 2.3 & 46.0 & 28.3 \\
2012 & 1.3 & 0.3 & 1.8 & $-\ddagger$ & 18.5 \\
2013 & 1.0 & 1.5 & 0.3 & - & 11.8 \\
\hline
\end{tabular}

$\ddagger$ In 2012 and 2013, no data were available from block I following the removal of all the residual vines in July 2011

By combining 'nearest neighbour' and mealybug abundance data we further compared and contrasted the results from blocks $A, C$, and $E$ with I and $K$. Using the 'nearest neighbour' model, we examined the frequency with which consecutive 'first' and 'second' vines were observed with virus symptoms within a single season (Table 4.4.3.2). In blocks $A, C$, and $E$, this pattern of virus spread was rare in 2010 and 2011 and was absent altogether in 2012 and 2013. Conversely, in blocks I and K, consecutive 'first' and 'second' symptomatic vines were commonly observed in 2010 ( $n=46), 2011$ (37), and 2012 (15). 
Table 4.4.3.2. Numbers of consecutive 'first' and 'second' Grapevine leafroll-associated virus 3 (GLRaV-3)-symptomatic vines recorded in five study blocks within a single season between 2010 and 2013. The blocks were a subset of the 13 Hawke's Bay vineyard study blocks, which were divided into two groups based on interim results for GLRaV-3 control: in group 1 (including blocks $A, C$, and $E$ ) the evidence suggested effective virus control; in group 2 blocks, GLRaV-3 control was inconclusive, or in the case of blocks I and K, roguing was ineffective and was replaced with whole block removal.

\begin{tabular}{llllll}
\hline & \multicolumn{5}{l}{ Number of consecutive 'first' and 'second' GLRaV-3-infected vines } \\
\cline { 2 - 6 } Block & A & C & E & I & K \\
\hline 2010 & 0 & 1 & 6 & 23 & 23 \\
2011 & 1 & 0 & 0 & 27 & 10 \\
2012 & 0 & 0 & 0 & $-\ddagger$ & 15 \\
2013 & 0 & 0 & 0 & - & 4 \\
\hline
\end{tabular}

${ }^{\ddagger}$ In 2012 and 2013, no data were available from block I following the removal of all the residual vines in July 2011.

\subsubsection{Vine replants}

The planting of vines to replace all or at least some of those vines rogued previously was undertaken in eight blocks at various times during this study (Table 4.4.4.1). By April 2013, no GLRaV-3 symptoms had been observed among replacement vines planted in blocks $A, E, F, M$, and $N$.

Table 4.4.4.1. The timing and numbers of vines planted to replace the rogued vines in eight of the Hawke's Bay vineyard study blocks between 2009 and 2012. All vines were sourced from nurseries producing high-health planting material in accordance with the New Zealand grafted grapevine standard.

\begin{tabular}{|c|c|c|c|c|}
\hline \multirow[b]{2}{*}{ Block } & \multicolumn{4}{|c|}{ Timing and numbers of replacement vines planted } \\
\hline & 2009 & 2010 & 2011 & 2012 \\
\hline A & $-\ddagger$ & 101 & - & - \\
\hline B & - & 785 & 123 & - \\
\hline $\mathrm{D}$ & 390 & 197 & 203 & - \\
\hline E & - & - & 361 & 111 \\
\hline $\mathrm{F}$ & - & - & 229 & - \\
\hline J & - & - & 521 & - \\
\hline M & - & - & - & 321 \\
\hline $\mathrm{N}$ & - & - & 360 & - \\
\hline
\end{tabular}

${ }^{\ddagger}$ No vines planted 
In block B, 908 replacement Cabernet Sauvignon vines were planted between 2010 and 2011. In 2012, eight young vines were visually identified with GLRaV-3. A further 57 symptomatic vines were identified in 2013. The 65 symptomatic vines represented a loss of $7.2 \%$ of the replacement Cabernet Sauvignon vines.

In block D, 790 replacement Cabernet Sauvignon vines were planted between 2009 and 2011. In each of 2011 and 2012, 18 young vines were visually diagnosed with GLRaV-3; a further 15 were found in 2013. In total, $51(6.5 \%)$ replacement Cabernet Sauvignon vines were rogued between 2011 and 2013. In blocks B and D, symptomatic replacement vines were randomly dispersed throughout both blocks.

In block J, 521 replacement Merlot vines were planted in late 2011. In April 2013 , five replacement vines $(0.9 \%)$ were visually identified with symptoms of GLRaV-3. All five symptomatic vines were clustered, with three of them being consecutive vines in a single row.

\subsection{Discussion}

The results of this study demonstrated that as part of a range of tactics, visually identifying and roguing symptomatic vines has potential to be an effective means of managing GLRaV-3, especially when supported by low numbers of mealybugs. In a subset of group 1 blocks ( $A, C, E)$, integrating these factors culminated in effective virus control within 2-3 years of roguing having commenced, with new infections sustained below the $1 \%$ target through until the conclusion of this data collection period in 2013. Similarly, effective virus control appeared well on track in blocks $\mathrm{J}, \mathrm{N}$, and $\mathrm{O}$, where in 2013, incidence was $0.8-1.3 \%$. Moreover, the absence of symptomatic replacement vines in blocks $A, E$, and $N$ suggests the virus control initiatives undertaken were effective. These results were consistent with findings in South Africa where effective GLRaV-3 control relied on integrating the use of certified vine material with good vector management, continued roguing of symptomatic vines and other protocols (Pietersen et al. 2013). 
Before committing to roguing, Hawke's Bay vineyard owners need to be confident in its potential to effectively reduce GLRaV-3 incidence and to contain its spread under local conditions. Moreover, having adopted a roguing strategy, they must be able to manage virus in a way that minimises the loss of healthy, productive vines. Thus, a crucial economic consideration becomes one of differentiating vines that can be safely retained from those that must be rogued in order to contain and possibly suppress the virus.

This study demonstrated that of the 'nearest neighbour' categories, 'first' vines were most at risk of acquiring GLRaV-3, a result supporting the findings of others (Habili and Nutter 1997, Pietersen 2006, Pietersen et al. 2013). While an important result, the increased risk of virus to 'first' vines was relatively low and requires context. In 2013 , an average of $96 \%$ of 'first' vines was non-symptomatic across nine of the 12 study blocks remaining. Therefore, with most 'first' vines being apparently virus-free, owners continuing to rogue symptomatic vines only could be reasonably confident that this approach could effectively manage GLRaV-3. Moreover, retaining 'first' vines inevitably enhances the economic prospects for affected blocks, with fewer young vines needing to be established in resets competing for soil resources with adjacent mature vines. Assuming ongoing annual monitoring, any unseen asymptomatic 'first' vines remaining in situ should be readily identifiable the following season to enable removal (chapter 3 ).

The relative lack of effective virus control in several blocks, however, suggests that under certain conditions removing symptomatic vines only may be sub-optimal, as was found for all but the smallest outbreaks of cocoa swollen shoot disease in western Africa (Thresh and Owusu 1986). There, the more effective approach for controlling the spread of this mealybugvectored pathogen was to rogue the symptomatic tree plus all of the apparently healthy immediate neighbours (Thresh and Owusu 1986). In vineyards not part of the present study, simultaneously removing symptomatic and both 'first' vines (a ' $1+2$ ' strategy) was used by some owners, but its feasibility may be site-dependent. While we have yet to fully examine the feasibility of this approach, it is our view its adoption would be 
futile unless accompanied by effective measures targeting vector populations on the vines. For example, had a '1+2' strategy been applied in block I in 2009 , one quarter of all vines would have been removed rather than the $15 \%$ that were. Similarly, the $10 \%$ vine loss recorded in block K in 2009 would have immediately increased to $15 \%$ under a ' $1+2$ ' strategy. In these blocks, this approach would not have slowed virus spread nor, in our view, would it have saved the residual vines because mealybug numbers were simply too high. Indeed, vector mediated dispersal to consecutive 'first' and 'second' vines was such that had a '1+2' strategy been adopted, it would have been ineffective due to the high frequency of retained asymptomatic 'second' vines. Thus, for now, the recommendation to New Zealand vineyard owners has been to focus on roguing symptomatic vines only whilst supporting this strategy with effective mealybug management.

Insights such as these are important because in New Zealand, it has already been shown that roguing symptomatic and 'first' vines costs $N Z \$ 1,800$ per hectare more than roguing symptomatic vines only (Nimmo-Bell 2006). Therefore, to maximise vineyard longevity and profitability, the conditions under which roguing could or should be modified requires further evaluation based on differing virus/vector scenarios (see section 5.2).

While 'first' vines were, in relative terms, most at risk of acquiring GLRaV-3, other 'nearest neighbour' vines were also affected to some extent. In blocks I and $\mathrm{K}$ where roguing was replaced with whole block removal, 'second' vines were commonly infected. This result was attributed to poorly managed vector populations. Such within-row virus spread concurred with the findings of an Israeli study where GLRaV-3 was monitored over successive years (Sokolsky et al. 2013). However, in addition to within-row spread, Sokolsky et al. (2013) also observed relatively high virus incidence among their equivalent of 'opposite' vines. Depending on the statistical test they used, no significant difference in virus incidence was found among 'first', 'second', and 'opposite' vines, all of which were within a $3 \mathrm{~m}$ radius of an infected vine (Sokolsky et al. 2013). Such within- and across-row virus spread implied vector density was high relative to that found in Hawke's Bay, although with 
no vector data linked to the Israeli study, it is difficult to reliably compare and contrast the results.

The occurrence of 'random' infections is a further potentially troubling aspect of the epidemiology of GLRaV-3. With no predictability as to where these infected vines might occur, 'random' outbreaks can severely restrict control by increasing the spatial distribution of virus foci and thus widening areas of the vineyard requiring intervention. During much of this study, however, 'random' outbreaks were relatively rare events when compared with infections among 'nearest neighbours'. Indeed, in nine of the 12 study blocks remaining in 2013, infected vines in the 'random' category represented just five vines or fewer (mean: $0.4 \%$ ), which was significantly lower than for the same category in 2010 (3.6\%) and 2011 (1.4\%). In Israel too, the spread of GLRaV-3 to 'random' vines was significantly lower compared with their equivalent of our 'nearest neighbour' vines (Sokolsky et al. 2013).

If a roguing strategy is well implemented, it can be reasonably assumed that the incidence of 'random' infections will be influenced by the efficacy of vector control. Unlike the present study, and that of Sokolsky et al. (2013), earlier New Zealand research found GLRaV-3 infections were dominated by 'random' events, with the few aggregated infections largely confined to a single row and/or limited to the second half of the 6-year study (Charles et al. 2009). Annual monitoring of the mealybug $P$. longispinus found numbers were, on average, $>1.0$ per vine leaf in most years. However, in 1998 and 2001, numbers peaked at 33 and 22 per leaf, respectively. Such high densities of mealybug were undoubtedly linked to the insecticide programme incorporating just a single chlorpyrifos application in the first year of the study (Charles et al. 2009). Thereafter, mealybug insecticides were not applied to the vines. Although the 'random' outbreaks could not be readily explained, two likely influences were the widespread passive movement of viruliferous mealybugs on machinery and the natural windborne dispersal of crawlers (Charles et al. 2009). That so few 'random' infections were found in the present study during 2013 was probably influenced by reduced virus inoculum as a result of roguing and the relatively good vector control evident 
in most blocks. This latter result was attributed to the generally improved insecticide usage patterns evident in 2011 and 2012, particularly in respect of higher water rates (Supplementary table 4.3.1.2).

Throughout the present study, visual diagnosis of symptomatic vines was undertaken by the same experienced assessor. Moreover, close collaboration with vineyard owners throughout the study ensured annual roguing was consistently applied across all blocks in all years. Therefore, of the variables we monitored, mealybug abundance in the vine canopy provided the best explanation for the contrasting virus control outcomes: in blocks I and $\mathrm{K}$ where whole block removal replaced roguing, $P$. calceolariae numbers were between one and two orders of magnitude higher in all years compared with blocks A, C, and E where effective virus control was achieved and sustained.

Our study, however, is not the first to have identified a link between the speed of pathogen spread and vector abundance. In two Burgundy vineyards for example, GLRaV-1 was monitored over eight years (Le Maguet et al. 2013). In one vineyard, a significant correlation was found between temporal changes to virus incidence (from $5 \%$ to $86 \%$ ) and the widespread distribution of the mealybug vector Phenacoccus aceris, which was found on threequarters of the vines. In the second vineyard over the same period, GLRaV-1 incidence was largely unchanged at about $5 \%$, a result attributed to the same vector species found on just $6 \%$ of vines (Le Maguet et al. 2013).

In New Zealand, increased GLRaV-3 incidence was found in Chardonnay vines in the 12-months immediately following $P$. longispinus numbers exceeding a mean of five per leaf (Charles et al. 2009). To contain virus spread, these authors suggested mealybug density be maintained below this number, although it was acknowledged this 'threshold' was only a starting point to enable the development of an effective virus management strategy. In our view, however, a density of five vectors per leaf, regardless of the species, is likely to greatly exceed the tolerance required to adequately contain GLRaV-3. Evidence from the present study supports this view: in 
blocks I and $\mathrm{K}$, peak numbers of $P$. calceolariae (1.5-2.3 per leaf) were substantially lower than the five $P$. longispinus per leaf reported by Charles et al. (2009), and yet despite lower numbers, virus control was not achieved in either block.

While the notion of a mealybug threshold makes intuitive sense and could one day assist owners with insecticide decisions, defining a 'universal' threshold value is fraught. For example, vector tolerance is likely to be highly variable and determined by many factors, not least of which is virus incidence at discovery. If a mealybug threshold concept was to be developed, we would first need to have a better understanding of the different GLRaV-3 genetic variants (Chooi et al. 2013b) and the efficiency with which these are transmitted by different life stages of different vector species (Cabaleiro and Segura 1997a, Petersen and Charles 1997, Sandanayaka et al. 2013).

In this study, owners adopted varying management approaches that were likely to have impacted the numbers of $P$. calceolariae observed on the vines. In the conventionally managed blocks I and $\mathrm{K}$, the use of registered insecticides was sanctioned by New Zealand Winegrowers, although it is accepted that $P$. calceolariae and $P$. Iongispinus can be difficult to control (Charles et al. 2010). However, a review of spray diaries in both blocks revealed water rates were one quarter the recommended 1,000 L/ha. Thus, poor vine wetting and coverage of contact insecticides may explain the relatively ineffective control of a cryptic pest colonising cracks and crevices on trunks and cordons. By contrast, the organic status of blocks $C$ and $E$ prevented insecticide use. While the relative absence of $P$. calceolariae from the vines in both blocks may be due to organic farming activities, substantial mealybug infestations in organic vineyards not part of the present study suggest it may not be a general trend (Bell, unpublished data, 2013). The effect of biological control (Charles et al. 2010) and cultural practices require further investigation, along with a range of other factors possibly contributing to the outcomes observed in blocks $\mathrm{C}$ and $\mathrm{E}$. 
Unlike blocks I and $\mathrm{K}$, improved mealybug control in blocks $\mathrm{A}, \mathrm{J}$, and $\mathrm{O}$ in 2012 and 2013 was undoubtedly an important contributor to the reduced virus incidence observed in these blocks in 2013. Achieving this outcome was almost certainly linked to higher water rates in spring 2011 and 2012, which improved vine wetting and insecticide coverage (Lo et al. 2009).

When roguing commenced in blocks $A, J$, and $O$, and in blocks $C$ and $E$, virus incidence ranged from $4-16 \%$. However, despite the presence of mealybugs in the vine canopy in these blocks in all years, continual reductions in the need for roguing suggest there may be some tolerance for $P$. calceolariae in vineyards affected by GLRaV-3. While quantifying a mealybug threshold in this context may be difficult, the positive outcomes in these blocks were nonetheless important for the New Zealand wine sector. Specifically, had it been necessary for us to advocate for $P$. calceolariae eradication as a prerequisite for effective GLRaV-3 control, vineyard owners would not have committed, as they have, to a roguing-based strategy.

While positive outcomes were found in a number of study blocks, there were others where the viability of continuing to rogue remained uncertain. Among these group 2 blocks was B, D, F and L. Unlike the relatively ineffectual virus control observed in $\mathrm{B}, \mathrm{F}$ and $\mathrm{L}$, which could be broadly attributed to inconsistent mealybug control, mealybug management in block $D$ was considered satisfactory until 2012 (mean: 0.1 mealybugs per leaf). However, the 3-5\% annual virus incidence observed between 2010 and 2013 suggests the results in block $D$ were influenced by a combination of factors, such as vector pressure and virus history.

In 2006, an estimated $95 \%$ of the Cabernet Sauvignon vines in block D were virus-infected, prompting the removal of all vines soon thereafter (Bell, unpublished data, 2012). Under these circumstances, owners sometimes decide to fallow the land for 6-12 months but it seems the success of reducing sources of virus inoculum is defined more by the activity undertaken during the fallow period than it is by its duration (G. Pietersen pers. comm.). As was shown in South Africa, herbicide did not kill the roots of older vines, 
resulting in high numbers of live remnant roots observed during subsequent vine planting (Pietersen et al. 2013). This situation appears to have been replicated in block $D$ where retained infrastructure (posts, wires, and irrigation) reduced opportunities to effectively remove remnant roots by mechanical means. Therefore, by the time replacement high-health vines were planted in 2007 , buried remnant roots were found across the block. The potential for these roots to be long term virus reservoirs (Bell et al. 2009, chapter 2) meant the newly planted high-health vines were spatially correlated with an area previously affected by virus (Pietersen 2006). In turn, there was a risk that in moving from remnant roots to the replacement vines, viruliferous mealybugs would perpetuate the virus cycle upon the resumption of feeding (Pietersen 2004). Hence, the existence of a significant virus reservoir may have lowered the tolerance for mealybugs to less than the 0.1 per leaf found until 2012, and this aspect could explain why virus control has been relatively slow.

While the block $\mathrm{D}$ result demonstrates further the difficulty of determining a universal mealybug threshold, it is important to note that we lack important empirical data related to the role of remnant vine roots. Specifically, there is currently no evidence that the GLRaV-3 detected in remnant roots (chapter 2) was infectious, and there are no definitive links between these roots, viruliferous vectors and GLRaV-3 transmission to healthy vines. Despite these knowledge gaps, the wine sector accepts the potential for this transmission pathway to impose vine losses in future. To mitigate this risk, protocols have been developed around vine removal, vector management and vine planting (Hoskins et al. 2011), and these aspects have been highlighted in technology transfer (e.g. Supplementary figures 6.3.1, 6.3.3, and 6.3.4).

In conclusion, this study showed that annual visual assessments and roguing symptomatic vines can maintain GLRaV-3 incidence at $<1 \%$. This outcome was only achieved, however, when supported by low densities of the principle virus vector. Where mealybug control was ineffective, GLRaV-3 continued to spread to the point where it rapidly became uneconomic to 
retain the residual vines within those blocks. In yet other study blocks, the viability of continued roguing remained uncertain due to the influence of factors like the historical context of the virus, lowered tolerance for vectors or inconsistent vector control. The relative effect of these factors or others, either in isolation or in combination, should be the subject of further research. However, taken together, results from several Hawke's Bay study blocks support the findings of Pietersen et al. (2013) and their recommendation that for effective GLRaV-3 control, an integrated management approach be adopted. 


\section{General Discussion}

In respect of GLRaV-3, no single management tactic currently available can deliver effective and sustained control when adopted in isolation. Instead, the required strategy is one that simultaneously targets the virus and its vectors (Pietersen et al. 2013). During my PhD, I studied whether adopting an integrated management plan was able to reduce and maintain GLRaV-3 incidence to $<1 \%$ under Hawke's Bay conditions. A summary of the main findings are as follows: (1) serological and molecular tests detected GLRaV-3 in healthy remnant vine roots up to 4 years after one of three herbicide active ingredients was applied to aerial parts of the vine; (2) based on foliar symptoms in several red berry cultivars, visual diagnostics was a reliable indicator of GLRaV-3 infection, with identification efficacy unaffected by the genetically divergent virus populations detected in this study; (3) when guided by visual diagnostics, annually roguing symptomatic vines slowed the spread of GLRaV-3 and reduced overall incidence; and (4) evidence from at least three study blocks suggests a focus on identifying and removing symptomatic vines contained GLRaV-3 effectively when supported by low numbers of mealybug vectors in the vine canopy. Together, these empirical data contribute to the development of an integrated plan that if implemented, can effectively manage GLRaV-3 in blocks planted in red berry cultivars.

\subsection{Synthesis}

In planting vines produced in accordance with the grafted grapevine standard, owners attempt to minimise the risk of introducing GLRaV-3 into vineyards (Anonymous 2006). The benefits of a high-health planting programme, however, may be quickly negated if conditions in the vineyard are not conducive to sustaining long-lived, healthy vines. Where threats to vine health are identified, remediation is required. The results of this study suggest remnant roots of vines removed due to GLRaV-3 pose a threat to the health of replacement vines. ELISA and/or real-time PCR detected GLRaV-3 in many of the remnant roots tested, independent of the herbicide active ingredient applied, its use pattern, and the duration of the fallow period (Bell 
et al. 2009, chapter 2). With remnant vine roots predicted to be sources of GLRaV-3 inoculum (Pietersen 2004), these data supported the virus reservoir influence.

Given the potential for GLRaV-3 to adversely affect the economic performance of vineyards, the results of this study reinforced recommendations to develop robust protocols for removing and disposing of infected vines and their roots (Pietersen 2004, Pietersen et al. 2013). However, unlike aerial parts, removing the roots of infected vines cannot always be accomplished easily, with inaccessibility and the cost of labour often precluding efficient removal. That Planococcus ficus in South Africa (Walton and Pringle 2004) and viruliferous P. calceolariae in Hawke's Bay were found on some remnant roots (chapter 2) suggests certified virus-free vines have an increased risk of being infected when planted into areas containing multiple sources of virus inoculum. In other words, in accordance with the prediction of Pietersen (2004), virus may be perpetuated by viruliferous vectors dispersing from remnant roots to healthy vines. An investigation into this possible infection pathway is discussed further in section 5.2.

The roots originating from vines treated with herbicide were in remarkably good condition, independent of the active ingredient or the interval between treatment and root excavation. Rather than being dry and brittle, the roots were instead moist and relatively healthy, and therefore suitable for serological and molecular testing. For glyphosate especially, live roots were a concern because prior to removing infected vines, it was, for many owners, the herbicide of choice based on its low residual soil activity relative to other active ingredients used in this study (Newton et al. 1984, Thompson et al. 2000 , Young 2013). Consequently, my results suggest there is no justification for the continued use of glyphosate as part of an integrated plan to manage GLRaV-3. Observations from South Africa support this view: after discovering live remnant vine roots during soil preparation for future vine plantings, it was concluded glyphosate applied to foliage was ineffective at killing grapevines (Pietersen et al. 2013). Therefore, in supporting the virus reservoir 
hypothesis, my results, along with evidence from South Africa, suggest risk mitigation requires the removal of entire vines, including the roots (Pietersen 2004, 2006, Pietersen et al. 2013, chapter 2). Consequently, New Zealand Winegrowers have re-evaluated vine removal and now emphasise the importance of vector control for effective virus management (discussed further in section 5.3).

The efficacy of visual symptom identification was also examined in this study (chapter 3). Specifically tested was the extent to which foliar changes in red berry cultivars (Golino et al. 2002, Maree et al. 2013) reliably aided the visual identification of vines infected with GLRaV-3. With no published data to support the efficacy of GLRaV-3 visual diagnosis, my objective was to assess the accuracy of this method relative to ELISA protocols, and to determine its reliability as a basis for roguing under Hawke's Bay conditions. Based on the results of this study, visual symptom identification was shown to be a robust method for accurately identifying vines infected with GLRaV-3. Moreover, most symptomless vines ELISA tested were virus-free. Hence, rather than having to validate field assessments with ELISA, owners can instead be confident that visual diagnosis alone reliably supports integrated virus management. Furthermore, based on the GLRaV-3 genetic variants detected in this study, the reliability of visual diagnostics was unaffected. In blocks planted in Cabernet Sauvignon (A), Syrah (D), and Malbec (E) vines, serological and molecular tests detected three and possibly four GLRaV-3 genetic variants (Chooi et al. 2013a, chapter 3 ). From these varieties, the vines tested were initially identified solely on the basis of foliar symptoms, thus demonstrating the feasibility of visual assessments to detect GLRaV-3 in genetically divergent populations, both as single and (some) dual infections (Chooi et al. 2013a). The potential for other aspects of this interaction to confound visual assessments is discussed further in section 5.2.

Of the asymptomatic infections detected in the Cabernet Sauvignon (C) and Syrah (D) vines, incidence was low (range: 0.2-0.5\%), with no single GLRaV3 variant more or less prevalent. Whether the few asymptomatic vines detected lacked foliar symptoms at the time of monitoring or if symptom 
development was so rudimentary that it was simply overlooked, remains unclear. Irrespective of cause, it seems that for the GLRaV-3 genetic variants reported in this study, the risk of not detecting infected vines due to delayed and/or obscured symptom development was low. Therefore, the omission of a small number of latent infections in one year would be unlikely to confound virus management, particularly when supported by good vector control and ongoing annual roguing (Pietersen et al. 2013, chapter 4). In respect of GLRaV-3, this result was encouraging considering that asymptomatic infections have been shown to confound control measures adopted in other crops affected by other diseases (Thresh and Owusu 1986, Dallot et al. 2004, Rappussi et al. 2012).

These results were important for a sector increasingly adopting roguing as the preferred means of managing the virus in red berry cultivars (Hoskins et al. 2011). Specifically, owners now have empirical data to support the use of visual diagnostics, which were comparable with ELISA in terms of accuracy, quick to perform and hence, cost-effective. However, for this methodology to add value to a roguing strategy, assessors must be able to distinguish between the foliar symptoms of GLRaV-3 and those generated by magnesium deficiency and/or damaged canes (Jordan 1993, Nicholson 2013). Inaccurate virus incidence data can rapidly reduce the viability of affected blocks (Atallah et al. 2012). While ELISA can reliably determine the health status of individual vines (Cohen et al. 2012), the cost and logistics of processing potentially large quantities of vine samples mean few owners can test for virus on the scale and frequency required to guide annual roguing decisions. Instead, what this study has conclusively shown was that ELISA testing was not required to support roguing decisions. However, when used to corroborate decisions for training purposes, ELISA was beneficial. Assessor education is discussed further in section 5.2.

In New Zealand and elsewhere in the world, the optimal time to undertake visual assessments for GLRaV-3 is late in the growing season when the development of foliar symptoms are most pronounced (Maree et al. 2013, Pietersen et al. 2013). Indeed, based on my results, two inspections timed 
between mid-March and mid-April identified most symptomatic vines within target areas. However, with New Zealand characterised as a cool-climate viticulture region, owners have to contend with the possibility of late-season defoliating frosts preventing the commencement or completion of visual assessments. Furthermore, cooler autumn conditions may contribute to early onset leaf senescence, thus limiting the ability of assessors to visually identify GLRaV-3 symptomatic vines. However, by planning and monitoring weather forecasts, visual assessments can be applied over a relatively extended period late in the growing season, so with no absolutely prescriptive timeline, this task can be accommodated to fit harvest deadlines.

Having increased our understanding of visual symptom identification in red berry cultivars, it was important to evaluate its efficacy in the context of roguing. Specifically, what the wine sector were seeking from this study were details outlining the parameters under which roguing could successfully contain virus spread. For instance, could owners remove symptomatic vines to control GLRaV-3, or was the likelihood of success improved by also removing non-symptomatic neighbouring vines? For all but the smallest outbreaks of swollen shoot disease in cocoa in West Africa, the removal of symptomatic trees was ineffective (Thresh and Owusu 1986). There, the better approach for controlling the spread of this mealybug-vectored pathogen was roguing the symptomatic tree plus all of the apparently healthy immediate neighbours. For economic reasons, most growers resisted this approach. Unless roguing symptomatic vines was shown to be similarly ineffective, removing additional vines would probably also be resisted by most vineyard owners in New Zealand.

In light of this position, my objective was to assess if roguing symptomatic vines, supported by low numbers of insect vectors could effectively control GLRaV-3 (chapter 4). Underpinning this objective were questions related to roguing efficacy, and the extent of vine removal required to successfully control the virus. In addition, I predicted that the varying management approaches among the different owners would provide information on how vector numbers influenced the results of virus control. The guidance offered 
by an earlier New Zealand study suggested effective GLRaV-3 control required a mealybug threshold not exceeding five $P$. longispinus per vine leaf (Charles et al. 2009). The findings of my research highlighted four important aspects related to roguing.

Firstly, evidence from study blocks A, C, and E suggested integrating visual assessments and roguing with low vector abundance in the vine canopy could effectively control GLRaV-3. Indeed, within 2-3 years of management commencing, numbers of newly infected vines was sustained below $1 \%$ in these blocks. In addition, the absence of virus symptoms among replacement certified virus-free vines in blocks $A$ and $E$ further supported the argument of effective virus control. In study blocks $\mathrm{J}, \mathrm{M}$, and $\mathrm{O}$, evidence of continued year-on-year reductions in virus incidence suggested good progress towards control (chapter 4). Thus, having demonstrated the efficacy of roguing in some study blocks, these data support the finding of Pietersen et al. (2013) and reinforce the value of an integrated approach in order to control GLRaV3.

Secondly, the data showed that removing symptomatic vines was, in general, effective at slowing virus spread. Previous studies noted that the spread of GLRaV-3 was typically along rows, with the vines adjacent to an infected vine often at most risk of acquiring virus through vector mediated dispersal (Habili and Nutter 1997, Pietersen 2006). In the present study, within-row virus spread to 'first' vines was also observed, with transmission by viruliferous $P$. calceolariae the most likely explanation for this pattern (chapter 4). These results could be interpreted to justify also removing 'first' vines as a means of slowing or even preventing further within-row virus spread. However, this increase in risk was relatively low, with there being no evidence to support removing 'first' vines: in nine of the 12 study blocks remaining in 2013, an average of $96 \%$ of 'first' vines adjacent to those rogued in 2012, or earlier, had no symptoms of GLRaV-3. To maximise vineyard longevity and profitability, the conditions under which roguing could or should be modified requires further evaluation (referred to in section 5.2). However, pending the outcome of such research, the recommendation to owners continues to be to 
rogue symptomatic vines only, which understandably remains their preferred option. By retaining 'first' vines, the economic prospects of affected blocks is enhanced due to a greater proportion of older vines and with it, improvements to some of the characteristics attributed to wine from older vines (Goode 2014). Moreover, as well as reducing yield losses, retaining 'first' vines also reduces the number of newly planted vines competing with adjacent mature vines for soil resources. Hence, fewer vines are at risk of delayed maturity.

Thirdly, this study demonstrated that after implementing an integrated virus management plan, numbers of 'random' infections decreased over time. In practical terms, this result meant that in nine of the 12 study blocks in 2013, new 'random' infections represented just five vines or fewer (mean: 0.4\%), which was significantly lower than for the same category in 2010 (3.6\%) and 2011 (1.4\%). That so few 'random' infections were found during 2013 was almost certainly influenced by annual roguing having reduced sources of virus inoculum since 2009. Also benefiting this result was the relatively good vector control observed in most study blocks since 2011, a result perhaps reflecting improved insecticide practices such as higher water rates, and biological control (Charles 1993, Lo et al. 2009, Charles et al. 2010, chapter 4). This result contrasted the observations of Charles et al. (2009) where the many 'random' infections were possibly linked to infrequent insecticide use releasing mealybugs from an important control mechanism. If continuity around good vector control is maintained over the remaining two years of the present study, the incidence of 'random' infections should continue to decline in most blocks. In practical terms, fewer 'random' infections will decrease the spatial distribution of virus foci, thereby reducing areas within those blocks requiring intensive and ongoing intervention.

Finally, evidence from this study indicated that a low abundance of $P$. calceolariae in the vine canopy was often a precursor to efficient virus control. In demonstrating the effectiveness of roguing as implemented in this study, the results suggest complete eradication of $P$. calceolariae is not a prerequisite for effective virus management (chapter 4). This result was 
important because if advocating for virus management had required the eradication of this species from the vines, it would have been unlikely owners would have committed, as they have, to roguing. Instead, owners accept that although no definitive mealybug threshold exists at this time (Charles et al. 2009), the evidence suggests some tolerance for $P$. calceolariae on the vines. In Hawke's Bay, this result was encouraging because mealybugs are not only important GLRaV-3 vectors, they are essentially ubiquitous in vineyards (Charles 1993, Charles et al. 2010). Thus, having demonstrated a link between low numbers of $P$. calceolariae, efficient virus control and therefore the loss of few relatively vines, this study also highlighted links between ineffective vector control and significant vine loss. Specifically, in study blocks I and K, cumulative vine losses culminated in roguing eventually being replaced with whole block removal (chapter 4). With visual diagnostics undertaken by the same assessor since 2010, and standardised roguing protocols adopted across all blocks in all years, the monitored variable, vine infestations of mealybug, probably best explained this result: in both blocks, $P$. calceolariae numbers on vine leaves were between one and two orders of magnitude higher in all years compared with study blocks A, C, and E. These data add to evidence already available demonstrating explicit links between vector abundance and the distribution and speed of pathogen spread (Charles et al. 2009, Le Maguet et al. 2013, Pietersen et al. 2013).

Also compelling, are the implicit links between vector abundance and disease spread. In simulating the parameters of a roguing and plant replacement strategy, Sisterson and Stenger (2013) evaluated pathogen spread in a perennial crop monoculture in a 100-farm crop growing region (the study was not validated by comparison to real data). The model parameters indicated widespread compliance by farmers who were efficiently roguing and replacing plants would slow pathogen spread, minimise plant loss and increase yields (note: in respect of GLRaV-3 control, compliance on a regional scale was also assumed to be important in New Zealand, and although not part of the present study, the results will be reported separately by others). By contrast, poor compliance or inefficient plant replacement failed to slow pathogen spread, resulting in the loss of many plants and 
reduced yield (Sisterson and Stenger 2013). In acknowledging the simplicity of the model to ensure broad applicability, the authors argued that roguing alone was unlikely to adequately contain disease spread, and that prospects for success had to be accompanied by the adoption of diverse tactics. A similar recommendation was emphasised for controlling GLRaV-3 (Pietersen et al. 2013). For vector-transmitted pathogens, integrating efficient vector control with factors like effective diagnostics, roguing and root removal, would be expected to reduce plant loss and increase crop yield (Pietersen et al. 2013, Sisterson and Stenger 2013, chapters 2, 3, and 4).

\subsection{Constraints and future research}

New research prospects were identified during this doctoral study.

Additionally, there were aspects of the original study plan that remain unanswered or incomplete. If pursued, these research opportunities could yield new and potentially important insights into GLRaV-3 management.

During this doctoral research, I was unable to determine the extent of the links between the virus, vector and remnant vine roots (chapter 2). Despite evidence of remnant vine roots colonised by PI. ficus in South Africa and $P$. calceolariae in the present study (Walton and Pringle 2004, Bell et al. 2009, chapter 2), there are no definitive data linking these associations to new virus outbreaks. Thus, in seeking to build upon an idea first proposed by Pietersen (2004), my hypothesis was that $P$. calceolariae feeding on remnant vine roots could acquire GLRaV-3 and transmit it to healthy vines. In early 2012, a bioassay was established in a glasshouse to test this hypothesis. It incorporated potted Pinot noir vines exposed to $P$. calceolariae reared on GLRaV-3-infected remnant roots. However, by April 2014, no virus symptoms were observed on any of the 40 certified virus-free sentinel vines.

On reflection, designing a suitable experiment to test the virus acquisition and transmission hypothesis may be problematic. In South Africa, 3,965 newly planted certified virus-free vines replaced Cabernet Sauvignon vines removed because they were all GLRaV-3-infected (Pietersen 2004). Within 
15-months of planting, 89 young vines were visually identified with virus (G. Pietersen pers. com.). It was proposed that because these new infections were randomly distributed through the block, it was likely that viruliferous vectors had dispersed from the remnant roots of the infected Cabernet Sauvignon vines (Pietersen 2004). However, with just $2 \%$ of young vines infected, this virus transmission pathway may be quite rare, suggesting that to have confidence in the results of the bioassay, a substantially larger number of sentinel vines than was used is required. Hence, it seems that combining controlled glasshouse experiments with field observations are needed to better understand the relationship between subterranean vectors, remnant roots, and GLRaV-3 acquisition and transmission.

Visual diagnostics reliably identified GLRaV-3 infections comprising genetically divergent populations (chapter 3 ). Therefore, it can be assumed roguing efficacy is unlikely to be confounded by the variety/variant combinations found in this study. However, whether visual diagnostics are confounded by genetic variants (as single or mixed infections) and/or vine cultivars not part of this study remains unclear. Hence, the potential for variety/variant interactions to alter or delay symptom development, and to cause mild or severe symptoms, requires further clarification (Jooste et al. 2011, Bester et al. 2012, Chooi et al. 2013b). Similarly, studies are needed to assess if these variables influence GLRaV-3 transmission efficiency by the different life stages of different vector species (Cabaleiro and Segura 1997b, Petersen and Charles 1997, Sandanayaka et al. 2013).

The efficacy of visual diagnostics may be confounded by assessors with minimal experience (chapter 3). In mistaking the foliar symptoms of cane damage and/or magnesium deficiency for that of GLRaV-3 (Jordan 1993, Nicholson 2013), assessors could over- or under-estimate virus incidence. Either way, undetected errors could affect the economic viability of vineyards through the loss of otherwise healthy vines or by failing to promptly remove sources of virus inoculum (Atallah et al. 2012). Such is the importance of visual diagnostics to the future viability of vineyards affected by GLRaV-3 that training must continue to be made available to relevant sector personnel. 
Based on the results of this study, the removal of symptomatic vines only appears to have been the optimal roguing strategy (chapter 4). However, it is possible that under differing conditions, this strategy may not be optimal for all blocks affected by GLRaV-3. In study block D for example, the planting of certified virus-free vines in 2007 followed immediately after $100 \%$ of the vines were removed because of GLRaV-3. With the block infrastructure retained, it was obviously difficult to access and remove the remnant vine roots. As reservoirs of GLRaV-3 (Bell et al. 2009, chapter 2), these persistent vine roots, and the possibility of resident viruliferous vectors, may explain why roguing has been relatively ineffective in this block. Under these circumstances, it may have been advantageous to have rogued symptomatic plus 'first' vines from the outset, rather than roguing symptomatic vines only. Hence, the extent to which virus control could benefit from different roguing options may vary according to circumstances, and this aspect should be the subject of future research. Specifically, by using parameters around differing virus/vector scenarios, modelling could fulfil an important role in determining an optimal roguing strategy (or strategies).

\subsection{Technology transfer}

One of the goals of this doctoral study was to convey new knowledge and recommendations to sector stakeholders as soon as it was practicable to do so. To achieve this goal, New Zealand Winegrowers gave me access to multiple communication channels in order to connect with end-users. Annual technical reports available via the sector website (nzwine.com) were augmented by seminars, workshops, field-days, and conferences (Table 5.3.1). Records supplied by New Zealand Winegrowers indicated that between 2010 and 2014 the total audience was c. 1,700 people.

Presentations in Auckland (1), Gisborne (1), Hawke's Bay (22), Wairarapa (4) and Marlborough (10) comprised students, viticulturists, winemakers, and vineyard owners. Popular articles were published in the bi-monthly journal, New Zealand Winegrower (www.ruralnewsgroup.co.nz/winegrower). 
Table 5.3.1. A summary of the technology transfer undertaken as part of the commitment of this PhD research to New Zealand Winegrowers, August 2009 to February 2014.

\begin{tabular}{|c|c|c|c|c|c|}
\hline & \multicolumn{5}{|c|}{ Technology transfer to the year ended 30 June } \\
\hline & 2010 & 2011 & 2012 & 2013 & $2014^{\ddagger}$ \\
\hline $\begin{array}{l}\text { Seminars/workshops/field-days/ } \\
\text { conferences }\end{array}$ & 6 & 9 & 7 & 9 & 10 \\
\hline Interim and final annual reports ${ }^{\dagger}$ & 3 & 2 & 2 & 2 & - \\
\hline Popular articles $^{\dagger}$ & 2 & 3 & 4 & 2 & 2 \\
\hline Factsheets $^{\dagger}$ & 2 & - & - & - & 3 \\
\hline Video presentation $^{\dagger}$ & - & - & - & - & 1 \\
\hline Annual direct or indirect sector interactions & 13 & 14 & 13 & 13 & 16 \\
\hline \multicolumn{6}{|l|}{ ‡ To February 2014} \\
\hline
\end{tabular}

New Zealand Winegrowers have also produced factsheets as a further means of communicating with end-users (Supplementary figures 5.3.1 to 5.3.5). Available on the sector website, each of the 13 factsheets written to February 2014 covered a specific topic directly related to GLRaV-3. My input was sought into the development of five of these factsheets, the content of which offers an objective measure of how data specifically linked to this $\mathrm{PhD}$ was used by the sector to further advance virus control initiatives.

The factsheet Vine removal and leafroll 3 (NZVE108), aimed to standardise and enhance vine removal procedures. Based on the results of this study together with evidence from South Africa (Pietersen et al. 2013), this factsheet was revised in February 2014. It now recommends removing as many vine roots as possible, which were noted as being long term reservoirs of GLRaV-3 (chapter 2). Also recommended was cessation to the historical practice of applying glyphosate to GLRaV-3-infected vines prior to removal. Instead, the renewed emphasis was on improving vector control, and on removing symptomatic vines only whilst retaining within-row adjacent vines (chapter 4).

A second factsheet, Leafroll symptoms on red varieties (NZVE101), was also revised in February 2014. It too reflected data from my studies, with specific 
reference to the frequency of visits per block (two or more), the optimal timing for those visits (mid-March to mid-April), and the risk of frosts and early onset leaf senescence (chapter 3). Further, it advised that the risk of a single visit per block could be mitigated by effective mealybug control, with roguing symptomatic vines only reiterated (chapter 4). Having identified inaccurate visual diagnostics as a serious impediment to the effectiveness of GLRaV-3 management, New Zealand Winegrowers sought my involvement in a series of workshops in Hawke's Bay and Marlborough in 2013 and 2014. The aim of these workshops was to educate the sector about the role and application of visual diagnostics in red berry cultivars (chapter 3 ).

Finally, the importance of mealybugs to GLRaV-3 control was highlighted in two factsheets written in 2009: Mealybugs - knowing the pest (NZVE105) and How to look for mealybugs (NZVE106). A third factsheet, Pre-harvest mealybug monitoring (NZVE111), was written in 2013 and drew extensively on the collection and assessment methodology used during this $\mathrm{PhD}$ research (chapter 4). Instead of bunch inspections for mealybug counts, leaf monitoring was recommended. The timing of leaf collections was suggested for late in the growing season when mealybug populations, where present, are typically easier to find. Recommendations included collecting 100 vine leaves from each of four equal size sectors per block, and then returning to a laboratory where microscopy can aid absolute counts of mealybugs, independent of life stage. The factsheet makes explicit reference to results from this $\mathrm{PhD}$ showing links between virus control outcomes and the effectiveness of mealybug control (chapter 4).

\subsection{Conclusion}

Evidence from this study showed that integrating visual diagnostics and roguing with low numbers of mealybug vectors progressively reduced GLRaV-3 incidence. Importantly, in several study blocks virus incidence was sustained below the 1\% target within 2-3 years of the process commencing. While the specific contribution of root removal to these positive results could not be ascertained, data supporting the virus reservoir hypothesis reinforced 
arguments favouring the removal of entire vines. That viruliferous $P$. calceolariae was found on some of the extracted remnant roots suggests effective virus control was not only conditional upon robust vine removal protocols, but also on the ability of assessors to reliably identify symptomatic vines. Based on the results of this study, owners now have empirical data showing that under Hawke's Bay conditions, late season visual diagnostics can reliably detect GLRaV-3 symptomatic vines among red berry cultivars. When undertaken by trained assessors, visual symptom identification was quick to perform; its sensitivity and specificity were comparable with ELISA without also incurring test-related costs and delays. Moreover, the evidence suggests diagnostic efficacy was unaffected by the GLRaV-3 genetic variants detected in this study.

Once identified, roguing symptomatic vines was shown to be an effective virus control tactic. Not only was incidence reduced, so too was the risk of virus spread to 'nearest neighbour' vines. Whilst removing virus foci was important to overall control, evidence from several study blocks suggested this positive result was well supported by consistently low numbers of mealybug in the vine canopy. Under these conditions, the risk of vector mediated virus spread to neighbouring healthy vines was greatly reduced. In two study blocks, however, a comparable focus on roguing symptomatic vines did not contain virus spread, eventually culminating in roguing being replaced with whole block removal. In both blocks, consistently high numbers of mealybug were found in the vine canopy. Hence, rather than demonstrating the failings of roguing, the need for whole block removal probably reflected a poorly implemented plan lacking suitable integration. Assuming the merits of integration are accepted and implemented by the New Zealand wine sector, this thesis presents a solid platform of empirical data to further develop a sustainable and effective plan to manage GLRaV-3. 


\section{References}

Almeida, R.P.P., Daane, K.M., Bell, V.A., Blaisdell, G.K., Cooper, M.L., Herrbach, E. and Pietersen, G. (2013) Ecology and management of grapevine leafroll disease. Frontiers in Microbiology 4, 94.

Anonymous (2006) New Zealand Winegrowers Grafted Grapevine Standard. http://www.nzwine.com/assets/sm/upload/4o/gd/ou/ah/GGS_V_2_3_Fi nal.pdf [accessed 15 March 2014].

Anonymous (2013) New Zealand Winegrowers Annual Report 2013. http://www.nzwine.com/assets/sm/upload/da/9i/te/eu/NZW_Annual_R eport_2013_web.pdf [accessed 18 April 2014].

Atallah, S.S., Gomez, M.I., Fuchs, M.F. and Martinson, T.E. (2012) Economic impact of Grapevine Leafroll Disease on Vitis vinifera cv. Cabernet franc in Finger Lakes vineyards of New York. American Journal of Enology and Viticulture 63, 73-79.

Bahder, B.W., Poojari, S., Alabi, O.J., Naidu, R.A. and Walsh, D.B. (2013) Pseudococcus maritimus (Hemiptera: Pseudococcidae) and Parthenolecanium corni (Hemiptera: Coccidae) are capable of transmitting Grapevine leafroll-associated virus 3 between Vitis * labruscana and Vitis vinifera. Environmental Entomology 42, 12921298.

Barrass, I.C., Jerie, P. and Ward, S.A. (1994) Aerial dispersal of first-instar and 2nd-instar longtailed mealybug, Pseudococcus longispinus (Targioni-Tozzetti) (Pseudococcidae, Hemiptera). Australian Journal of Experimental Agriculture 34, 1205-1208.

Bell, V.A., Bonfiglioli, R.G.E., Walker, J.T.S., Lo, P.L., Mackay, J.F. and McGregor, S.E. (2009) Grapevine leafroll-associated virus 3 persistence in Vitis vinifera remnant roots. Journal of Plant Pathology 91, 527-533. 
Belli, G., Fortusini, A., Casati, P., Belli, L., Bianco, P.A. and Prati, S. (1994) Transmission of a grapevine leafroll associated closterovirus by the scale insect Pulvinaria vitis L. Rivista di Patologia Vegetale 4, 105108.

Bester, R., Maree, H.J. and Burger, J.T. (2012) Complete nucleotide sequence of a new strain of grapevine leafroll-associated virus 3 in South Africa. Archives of Virology 157, 1815-1819.

Beverland, M. and Bretherton, P.B. (1998) The strategic challenges facing the New Zealand wine industry. Journal of Wine Research 9, 55-64.

Beverland, M. and Lockshin, L.S. (2001) Organisational life cycles in small New Zealand wineries. Journal of Small Business Management 39, 354-362.

Bonfiglioli, R.G.E. and Hoskins, N. (2006) Managing virus in New Zealand vineyards. The Australian \& New Zealand Grapegrower \& Winemaker 515, 43-46.

Bonfiglioli, R.G.E., Hoskins, N. and Edwards, F. (2002) Grapevine leafroll virus type 3 is spreading in New Zealand. The Australian \& New Zealand Grapegrower \& Winemaker 457, 58-61.

Bonfiglioli, R.G.E. and Stewart, D. (2005) Learning about leafroll 3. New Zealand Winegrower 9, 88-90.

Bordeu, E., Troncoso, D.O. and Zaviezo, T. (2012) Influence of mealybug (Pseudococcus spp.)-infested bunches on wine quality in Carmenere and Chardonnay grapes. International Journal of Food Science and Technology 47, 232-239.

Bragato, R. (1902) Report to the Department of Agriculture New Zealand. 451-455. 
Cabaleiro, C. and Segura, A. (1997a) Some characteristics of the transmission of grapevine leafroll associated virus 3 by Planococcus citri Risso. European Journal of Plant Pathology 103, 373-378.

Cabaleiro, C., Segura, A. and Garcia-Berrios, J.J. (1999) Effects of Grapevine leafroll-associated virus 3 on the physiology and must of Vitis vinifera L. CV. Albarino following contamination in the field. American Journal of Enology and Viticulture 50, 40-44.

Cabaleiro, C. and Segura, S. (1997b) Field transmission of Grapevine leafroll associated virus 3 (GLRaV-3) by the mealybug Planococcus citri. Plant Disease 81, 283-287.

Chamberlain, E.E. (1967) Leaf roll virus in the grapevines. Wine Review 4 , 29-32.

Chamberlain, E.E., Over de Linden, A.J. and Berrysmith, F. (1970) Virus disease of grapevines in New Zealand. New Zealand Journal of Agricultural Research 13, 338-358.

Charles, J.G. (1981) Distribution and life history of the longtailed mealybug, Pseudococcus longispinus (Homoptera: Pseudococcidae), in Auckland vineyards. New Zealand Journal of Zoology 8, 285-293.

Charles, J.G. (1982) Economic damage and preliminary economic thresholds for mealybugs (Pseudococcus longispinus T-T.) in Auckland vineyards. New Zealand Journal of Agricultural Research 25, 415-420.

Charles, J.G. (1993) A survey of mealybugs and their natural enemies in horticultural crops in North Island, New Zealand, with implications for biological control. Biocontrol Science and Technology 3, 405-418.

Charles, J.G., Bell, V.A., Lo, P.L., Cole, L.M. and Chhagan, A. (2010) Mealybugs (Hemiptera: Pseudococcidae) and their natural enemies in 
New Zealand vineyards from 1993-2009 New Zealand Entomologist 33, 84-91.

Charles, J.G., Cohen, D., Walker, J.T.S., Forgie, S.A., Bell, V.A. and Breen, K.C. (2006) A review of the ecology of grapevine leafroll associated virus type 3 (GLRaV-3). New Zealand Plant Protection 59, 330-337.

Charles, J.G., Froud, K.J., van den Brink, R. and Allan, D.J. (2009) Mealybugs and the spread of Grapevine leafroll-associated virus 3 (GLRaV-3) in a New Zealand vineyard. Australasian Plant Pathology 38, 576-583.

Chooi, K.M., Cohen, D. and Pearson, M.N. (2013a) Generic and sequencevariant specific molecular assays for the detection of the highly variable Grapevine leafroll-associated virus 3. Journal of Virological Methods 189, 20-29.

Chooi, K.M., Cohen, D. and Pearson, M.N. (2013b) Molecular characterisation of two divergent variants of Grapevine leafrollassociated virus 3 in New Zealand. Archives of Virology 158, 15971602.

Chooi, K.M., Pearson, M.N., Cohen, D. and MacDiarmid, R.M. (2012) Development of generic and variant-specific molecular assays for the detection of the highly variable Grapevine leafroll-associated virus 3. Proceedings of the 17th Congress of the International Council for the Study of Virus and Virus-like Diseases of the Grapevine (ICVG); October 7-14, 2012; Davis, California, USA pp. 142-143.

Clarke, A.D. and Honore, E.N. (1973) Weeds in Auckland vineyards. Proceedings of the 26th New Zealand Weed and Pest Control Conference, Auckland. 112-116.

Cohen, D., Chooi, K.M., Bell, V.A., Blouin, A.G., Pearson, M.N. and MacDiarmid, R.M. (2012) Detection of new strains of GLRaV-3 in New 
Zealand using ELISA and RT-PCR. Proceedings of the 17th Congress of the International Council for the Study of Virus and Viruslike Diseases of the Grapevine (ICVG); October 7-14, 2012; Davis, California, USA pp. 118-119.

Cohen, D., van den Brink, R. and Habili, N. (2004) Detection of leafroll virus in newly-infected grapevines. The Australian \& New Zealand Grapegrower \& Winemaker Annual Technical Issue 56-59.

Constable, F.E., Connellan, J., Nicholas, P. and Rodoni, B.C. (2013) The reliability of woody indexing for detection of grapevine virus-associated diseases in three different climatic conditions in Australia. Australian Journal of Grape and Wine Research 19, 74-80.

Cox, J. (1977) Survey of mealybug species (Homoptera: Pseudococcidae) in Auckland orchards and vineyards. New Zealand Journal of Agricultural Research 20, 259-261.

Daane, K.M., Almeida, R.P.P., Bell, V.A., Walker, J.T.S., Botton, M., Fallahzadeh, M., Mani, M., Miano, J.L., Sforza, R., Walton, V.M. and Zaviezo, T. (2012) Biology and management of mealybugs in vineyards. In: Bostanian, N.J., Vincent, C., and Isaacs, R., eds. Arthropod Management in Vineyards: Pests, Approaches, and Future Directions (Springer Netherlands) pp. 271-307.

Daane, K.M., Bentley, W.J., Walton, V.M., Malakar-Kuenen, R., Millar, J.G., Ingels, C.A., Weber, E.A. and Gispert, C. (2006) New controls investigated for vine mealybug. California Agriculture 60, 31-38.

Daane, K.M., Cooper, M.L., Triapitsyn, S.V., Walton, V.M., Yokota, G.Y., Haviland, D.R., Bentley, W.J., Godfrey, K.E. and Wunderlich, L.R. (2008) Vineyard managers and researchers seek sustainable solutions for mealybugs, a changing pest complex. (Special issue: 
Sustainable viticulture. Wine grapes go green.). California Agriculture 62, 167-176.

Dallot, S., Gottwald, T., Labonne, G. and Quiot, J.B. (2004) Factors affecting the spread of Plum pox virus strain $\mathrm{M}$ in peach orchards subjected to roguing in France. Phytopathology 94, 1390-1398.

Douglas, N. and Kruger, K. (2008) Transmission efficiency of Grapevine leafroll-associated virus 3 (GLRaV-3) by the mealybugs Planococcus ficus and Pseudococcus longispinus (Hemiptera: Pseudococcidae). European Journal of Plant Pathology 122, 207-212.

Endeshaw, S.T., Sabbatini, P., Romanazzi, G., Schilder, A.C. and Neri, D. (2014) Effects of Grapevine leafroll-associated virus 3 infection on growth, leaf gas exchange, yield and basic fruit chemistry of Vitis vinifera L. cv. Cabernet Franc. Scientia Horticulturae 170, 228-236.

Engelbrecht, D.J. and Kasdorf, G.G.F. (1990) Transmission of grapevine leafroll disease and associated closteroviruses by the vine mealybug, Planococcus ficus. Phytophylactica 22, 341-346.

Figadere, B.A., McElfresh, J.S., Borchardt, D., Daane, K.M., Bentley, W. and Millar, J.G. (2007) trans-alpha-Necrodyl isobutyrate, the sex pheromone of the grape mealybug, Pseudococcus maritimus. Tetrahedron Letters 48, 8434-8437.

Forsline, P.L., Hoch, J., Lamboy, W.F., Hu, J.S., McFerson, J.R., Golino, D.A. and Gonsalves, D. (1996) Comparative effectiveness of symptomatology and ELISA for detecting two isolates of grapevine leafroll on graft-inoculated Cabernet franc. American Journal of Enology and Viticulture 47, 239-243.

Fox, R.T.V. (1997) The present and future use of technology to detect plant pathogens to guide disease control in sustainable farming systems. Agriculture Ecosystems \& Environment 64, 125-132. 
Furness, G.O. (1976) The dispersal, age-structure and natural enemies of the long-tailed mealybug, Pseudococcus longispinus (TargioniTozzetti), in relation to sampling and control. Australian Journal of Zoology 24, 237-247.

Geiger, C.A. and Daane, K.M. (2001) Seasonal movement and distribution of the grape mealybug (Homoptera: Pseudococcidae): developing a sampling program for San Joaquin Valley vineyards. Journal of Economic Entomology 94, 291-301.

Geiger, C.A., Daane, K.M., Bentley, W.J., Yokota, G.Y. and Martin, L.A. (2001) Sampling program for grape mealybugs improves pest management. California Agriculture 55, 19-27.

Godfrey, L.D. and Pickel, C. (1998) Seasonal dynamics and management schemes for a subterranean mealybug, Rhizoecus kondonis Kuwana, pest of alfalfa. Southwestern Entomologist 23, 343-350.

Golino, D.A. and Almeida, R.P.P. (2008) Studies needed of vectors spreading leafroll disease in California vineyards. California Agriculture 62, 174.

Golino, D.A., Sim, S.T., Gill, R. and Rowhani, A. (2002) California mealybugs can spread grapevine leafroll disease. California Agriculture 56, 196201.

Golino, D.A., Weber, E., Sim, S. and Rowhani, A. (2008) Leafroll disease is spreading rapidly in a Napa Valley vineyard. California Agriculture 62 , 156-160.

Goode, J. (2014) Age before beauty: New Zealand's Pinot noir challenge. Wine \& Spirits 33(1), 34-35. 
Grasswitz, T.R. and James, D.G. (2008) Movement of grape mealybug, Pseudococcus maritimus, on and between host plants. Entomologia Experimentalis et Applicata 129, 268-275.

Gray, R.A. (1952) Composition of honeydew excreted by pineapple mealybugs. Science 115, 129-133.

Grogan, R.G. (1981) The science and art of plant-disease diagnosis. Annual Review of Phytopathology 19, 333-351.

Gullan, P.J. (2000) Identification of the immature instars of mealybugs (Hemiptera : Pseudococcidae) found on citrus in Australia. Australian Journal of Entomology 39, 160-166.

Habili, N. and Nutter, F.W., Jr. (1997) Temporal and spatial analysis of grapevine leafroll-associated virus 3 in Pinot Noir grapevines in Australia. Plant Disease 81, 625-628.

Hinkens, D.M., McElfresh, J.S. and Millar, J.G. (2001) Identification and synthesis of the sex pheromone of the vine mealybug, Planococcus ficus. Tetrahedron Letters 42, 1619-1621.

Hoefort, L.L. and Gifford, E.M. (1967) Grapevine leafroll virus - history and anatomical effects. Hilgardia 38, 403-426.

Hoskins, N., Thompson, C. and Andrew, R. (2011) New Zealand winegrowers working hard to eliminate leafroll. Australian and New Zealand Grapegrower and Winemaker 569, 23-25.

Hu, J.S., Sether, D.M. and Ullman, D.E. (1996) Detection of pineapple closterovirus in pineapple plants and mealybugs using monoclonal antibodies. Plant Pathology 45, 829-836.

Jooste, A.E.C., Maree, H.J., Bellstedt, D.U., Goszczynski, D.E., Pietersen, G. and Burger, J.T. (2010) Three genetic grapevine leafroll-associated 
virus 3 variants identified from South African vineyards show high variability in their 5 ' UTR. Archives of Virology 155, 1997-2006.

Jooste, A.E.C., Pietersen, G. and Burger, J.T. (2011) Distribution of grapevine leafroll associated virus-3 variants in South African vineyards. European Journal of Plant Pathology 131, 371-381.

Jordan, D. (1993) Leafroll spread in New Zealand vineyards. Australian \& New Zealand Wine Industry Journal 8, 322-324.

Klaassen, V.A., Sim, S.T., Dangl, G.S., Osman, F., Al Rwahnih, M., Rowhani, A. and Golino, D.A. (2011) Vitis californica and Vitis californica $\times$ Vitis vinifera Hybrids are hosts for Grapevine leafroll-associated virus-2 and -3 and Grapevine virus A and B. Plant Disease 95, 657-665.

Krell, R.K., Perring, T.M., Farrar, C.A., Park, Y.L. and Gispert, C. (2006) Intraplant sampling of grapevines for Pierce's disease diagnosis. Plant Disease 90, 351-357.

Kruger, K. and Douglas-Smit, N. (2013) Grapevine leafroll-associated virus 3 (GLRaV-3) transmission by three soft scale insect species (Hemiptera: Coccidae) with notes on their biology. African Entomology 21, 1-8.

Le Maguet, J., Fuchs, J.J., Chadoeuf, J., Beuve, M., Herrbach, E. and Lemaire, O. (2013) The role of the mealybug Phenacoccus aceris in the spread of Grapevine leafroll-associated virus-1 (GLRaV-1) in two French vineyards. European Journal of Plant Pathology 135, 415-427.

Lo, P.L., Bell, V.A. and Walker, J.T.S. (2009) Maximising the effectiveness of insecticides to control mealybugs in vineyards. New Zealand Plant Protection 62, 296-301.

Lo, P.L. and Walker, J.T.S. (2011) Soil applications of two neonicotinoid insecticides to control mealybugs (Pseudococcidae) in vineyards. New Zealand Plant Protection 64, 101-106. 
Mackay, J.F., Edwards, F. and Bonfiglioli, R.G.E. (2009) Increasing the detection rates of Grapevine leafroll-associated virus 3 (GLRaV-3). New Zealand Winegrower 13, 87-89.

MacKenzie, D.J., McLean, M.A., Mukerji, S. and Green, M. (1997) Improved RNA extraction from woody plants for the detection of viral pathogens by reverse transcription-polymerase chain reaction. Plant Disease $\mathbf{8 1}$, 222-226.

Mahfoudhi, N., Digiaro, M. and Dhouibi, M.H. (2009) Transmission of grapevine leafroll viruses by Planococcus ficus (Hemiptera: Pseudococcidae) and Ceroplastes rusci (Hemiptera: Coccidae). Plant Disease 93, 999-1002.

Mannini, F., Mollo, A. and Credi, R. (2012) Field performance and wine quality modification in a clone of Vitis vinifera cv. Dolcetto after GLRaV-3 elimination. American Journal of Enology and Viticulture 63, 144-147.

Maree, H.J., Almeida, R.P.P., Bester, R., Chooi, K.M., Cohen, D., Dolja, V.V., Fuchs, M.F., Golino, D.A., Jooste, A.E.C., Martelli, G.P., Naidu, R.A., Rowhani, A., Saldarelli, P. and Burger, J.T. (2013) Grapevine leafrollassociated virus 3 . Frontiers in Microbiology 4, 82.

Martelli, G. (1986) Virus and virus-like diseases of the grapevine in the Mediterranean area. FAO Plant Protection Bulletin 34, 25-42.

Martelli, G.P. (2014) Grapevine leafroll. Journal of Plant Pathology 96, S51S70.

Martelli, G.P., Agranovsky, A.A., Bar-Joseph, M., Boscia, D., Candresse, T., Coutts, R.H.A., Dolja, V.V., Falk, B.W., Gonsalves, D., Jelkmann, W., Karasev, A.V., Minafra, A., Namba, S., Vetten, H.J., Wisler, G.C. and Yoshikawa, N. (2002) The family Closteroviridae revised. Archives of Virology 147, 2039-2044. 
Martelli, G.P. and Boudon-Padieu, E. (2006) Directory of infectious diseases of grapevines and viroses and virus-like diseases of the grapevine: bibliographic report 1998-2004 (CIHEAM-IAM Bari, Italy).

Matthews, C. (2006) Epidemiology of grapevine leafroll disease within New Zealand vineyards. MSc thesis. University of Auckland, Auckland, New Zealand,

McKissock, A. (1964) Two important virus diseases of grapevines in New Zealand. New Zealand Journal of Agricultural Research 108, 332-339.

Millar, J.G., Daane, K.M., McElfresh, J.S., Moreira, J.A., Malakar-Kuenen, R., Guillen, M. and Bentley, W.J. (2002) Development and optimization of methods for using sex pheromone for monitoring the mealybug Planococcus ficus (Homoptera: Pseudococcidae) in California vineyards. Journal of Economic Entomology 95, 706-714.

Millar, J.G., Midland, S.L., McElfresh, J.S. and Daane, K.M. (2005) (2,3,4,4Tetramethylcyclopentyl)methyl acetate, a sex pheromone from the obscure mealybug: First example of a new structural class of monoterpenes. Journal of Chemical Ecology 31, 2999-3005.

Newton, M., Howard, K.M., Kelpsas, B.R., Danhaus, R., Lottman, C.M. and Dubelman, S. (1984) Fate of glyphosate in an Oregon forest ecosystem. Journal of Agricultural and Food Chemistry 32, 11441151.

Nicholson, T. (2013) Leafroll virus versus magnesium deficiency. New Zealand Winegrower 79, 22-24.

Nimmo-Bell (2006) The economic effects and financial impact of GLRaV-3. Bell, B., ed. (Nimmo-Bell \& Company Limited: Wellington, New Zealand) p. 18. 
NZIER (2009) Economic impact of the New Zealand wine industry. Ballingall, J., and Schilling, C., eds (NZIER: Wellington, New Zealand) p. 32.

O'Connor, B. (2006) Novachem manual. A New Zealand guide to agrichemicals for plant protection. O'Connor, B., ed. (Novachem Services Limited: Palmerston North, New Zealand) p. 488.

Osman, F. and Rowhani, A. (2006) Application of a spotting sample preparation technique for the detection of pathogens in woody plants by RT-PCR and real-time PCR (TaqMan). Journal of Virological Methods 133, 130-136.

Over de Linden, A.J. and Chamberlain, E.E. (1970a) Effect of grapevine leafroll virus on vine growth and fruit yield and quality. New Zealand Journal of Agricultural Research 13, 689-698.

Over de Linden, A.J. and Chamberlain, E.E. (1970b) Production of virus-free grapevines in New Zealand. New Zealand Journal of Agricultural Research 13, 991-1000.

Pearson, M.N., Clover, G.R.G., Guy, P.L., Fletcher, J.D. and Beever, R.E. (2006) A review of the plant virus, viroid and mollicute records for New Zealand. Australasian Plant Pathology 35, 217-252.

Permar, T.A., Garnsey, S.M., Gumpf, D.J. and Lee, R.F. (1990) A monoclonal-antibody that discriminates strains of citrus tristeza virus. Phytopathology 80, 224-228.

Petersen, C.L. and Charles, J.G. (1997) Transmission of grapevine leafrollassociated closteroviruses by Pseudococcus longispinus and $P$. calceolariae. Plant Pathology 46, 509-515.

Pietersen, G. (2004) Spread of Grapevine leafroll disease in South Africa - a difficult but not insurmountable problem. 
www.wynboer.co.za/recentarticles/0406leaf.php3 [accessed 28 March 2014].

Pietersen, G. (2006) Spatio-temporal distribution dynamics of grapevine leafroll disease in Western Cape vineyards. Extended abstracts of the 15th Meeting of the International Council for the Study of Virus and Virus-like diseases of the Grapevine; April 3-7; Stellenbosch, South Africa pp. 126-127.

Pietersen, G., Spreeth, N., Oosthuizen, T., van Rensburg, A., van Rensburg, M., Lottering, D., Rossouw, N. and Tooth, D. (2013) Control of grapevine leafroll disease spread at a commercial wine estate in South Africa: a case study. American Journal of Enology and Viticulture 64, 296-305.

Rappussi, M.C.C., Eckstein, B., Flores, D., Haas, I.C.R., Amorim, L. and Bedendo, I.P. (2012) Cauliflower stunt associated with a phytoplasma of subgroup 16Srlll-J and the spatial pattern of disease. European Journal of Plant Pathology 133, 829-840.

Rowhani, A., Uyemoto, J.K. and Golino, D.A. (1997) A comparison between serological and biological assays in detecting grapevine leafroll associated viruses. Plant Disease 81, 799-801.

Rowhani, A., Uyemoto, J.K., Golino, D.A. and Martelli, G. (2005) Pathogen testing and certification of Vitis and Prunus species. Annual Review of Phytopathology 43, 261-278.

Sandanayaka, W.R.M., Blouin, A.G., Prado, E. and Cohen, D. (2013) Stylet penetration behaviour of Pseudococcus longispinus in relation to acquisition of grapevine leafroll virus 3. Arthropod-Plant Interactions 7, 137-146. 
Sforza, R., Boudon-Padieu, E. and Greif, C. (2003) New mealybug species vectoring Grapevine leafroll-associated viruses-1 and -3 (GLRaV-1 and -3). European Journal of Plant Pathology 109, 975-981.

Sharma, A.M., Wang, J.B., Duffy, S., Zhang, S.M., Wong, M.K., Rashed, A., Cooper, M.L., Daane, K.M. and Almeida, R.P.P. (2011) Occurrence of grapevine leafroll-associated virus complex in Napa Valley. Plos One 6.

Sheu, G. (1936) Mein Winzerbuch (Reichsnährstand Verlags-Ges: Berlin).

Sisterson, M.S. and Stenger, D.C. (2013) Roguing with replacement in perennial crops: conditions for successful disease management. Phytopathology 103, 117-128.

Sokolsky, T., Cohen, Y., Zahavi, T., Sapir, G. and Sharon, R. (2013) Potential efficiency of grapevine leafroll disease management strategies using simulation and real spatio-temporal disease infection data. Australian Journal of Grape and Wine Research 19, 431-438.

Spharim, I. and Shalhevet, S. (1988) Formulating policy to cope with virus disease in citrus orchards. Agricultural Systems 27, 215-224.

Sturz, A.V., Diamond, J.F. and Stewart, J.G. (1997) Evaluation of mosaic symptom expression as an indirect measure of the incidence of PVY degrees in potato cv. Shepody. Canadian Journal of Plant Pathology 19, 145-148.

Teliz, D., Tanne, E., Gonsalves, D. and Zee, F. (1987) Field serological detection of viral-antigens associated with grapevine leafroll disease. Plant Disease 71, 704-709.

Thomas, W.T. (1976) The impact of virus diseases on quality and yield in the vineyard. Wine Review 13, 17-31. 
Thompson, D.G., Pitt, D.G., Buscarini, T.M., Staznik, B. and Thomas, D.R. (2000) Comparative fate of glyphosate and triclopyr herbicides in the forest floor and mineral soil of an Acadian forest regeneration site. Canadian Journal of Forest Research 30, 1808-1816.

Thresh, J.M. and Owusu, G.K. (1986) The control of cocoa swollen shoot disease in Ghana: an evaluation of eradication procedures. Crop Protection 5, 41-52.

Tsai, C.W., Chau, J., Fernandez, L., Bosco, D., Daane, K.M. and Almeida, R.P.P. (2008) Transmission of Grapevine leafroll-associated virus 3 by the vine mealybug (Planococcus ficus). Phytopathology 98, 10931098.

Unelius, C.R., El-Sayed, A.M., Twidle, A., Bunn, B., Zaviezo, T., Flores, M.F., Bell, V. and Bergmann, J. (2011) The absolute configuration of the sex pheromone of the citrophilous mealybug, Pseudococcus calceolariae. Journal of Chemical Ecology 37, 166-172.

Vega, A., Gutierrez, R.A., Pena-Neira, A., Cramer, G.R. and Arce-Johnson, P. (2011) Compatible GLRaV-3 viral infections affect berry ripening decreasing sugar accumulation and anthocyanin biosynthesis in Vitis vinifera. Plant Molecular Biology 77, 261-274.

Wakgari, W.M. and Giliomee, J.H. (2003) The biology of three mealybug species (Hemiptera : Pseudococcidae) found on citrus in the Western Cape Province, South Africa. African Entomology 11, 173-182.

Walker, J.T.S., Charles, J.G., Froud, K.J. and Connolly, P.G. (2004) Leafroll virus in vineyards: modelling the spread and economic impact. Report No. 12795. (The Horticulture and Food Research Institute of New Zealand Limited: Auckland, New Zealand).

Walter, B. and Martelli, G.P. (1997) Clonal and sanitary selection of the grapevine. In: Walter, B., ed. Sanitary Selection of the Grapevine: 
Protocols for Detection of Viruses and Virus-Like Diseases (Inst Natl Recherche Agronomique: Paris) pp. 43-95.

Walton, V.M., Daane, K.M. and Pringle, K.L. (2004) Monitoring Planococcus ficus in South African vineyards with sex pheromone-baited traps. Crop Protection 23, 1089-1096.

Walton, V.M. and Pringle, K.L. (2004) A survey of mealybugs and associated natural enemies in vineyards in the Western Cape Province, South Africa. South African Journal of Enology and Viticulture 25, 23-25.

Wilson, M.M.J. and Goddard, R.W. (2004) Creating value in the New Zealand wine industry. International Journal of Wine Marketing 16, 6273.

Young, S. (2013) New Zealand Novachem Agrichemical Manual. Young, S., ed. (Agrimedia Limited: Christchurch, New Zealand) p. 768.

Zou, Y.F. and Millar, J.G. (2009) Synthesis of the pheromone of the longtailed mealybug, a sterically congested, irregular monoterpenoid. Journal of Organic Chemistry 74, 7207-7209. 


\section{$7 \quad$ Appendices}

\subsection{Supplementary tables}

Supplementary table 3.4.1.1. The detection and differentiation of Grapevine leafrollassociated virus 3 (GLRaV-3) genetic variants using multiplex reverse transcriptionpolymerase chain reaction (mRT-PCR) from Malbec vine cane scrapings. In a Hawke's Bay vineyard study block $(E), 50$ vines tested were initially identified with GLRaV-3 based on foliar symptoms only. Eighty non-symptomatic 'first' vines were also tested, of which two asymptomatic vines (no symptoms, enzyme-linked immunosorbent assay positive) were detected (table continued overleaf).

\begin{tabular}{|c|c|c|c|}
\hline \multirow[b]{2}{*}{ Vine coordinates } & \multicolumn{3}{|c|}{ mRT-PCR results ${ }^{\ddagger}$} \\
\hline & Group I & NZ2 & Groups I to V \\
\hline $90-17-1^{\dagger}$ & $\checkmark$ & & \\
\hline $90-2-3$ & $\checkmark$ & & \\
\hline $90-18-2$ & $\checkmark$ & & \\
\hline $91-16-2$ & $\checkmark$ & & \\
\hline $91-17-4$ & $\checkmark$ & & \\
\hline $92-15-4$ & $\checkmark$ & & \\
\hline $93-22-2$ & $\checkmark$ & & \\
\hline $94-24-4$ & $\checkmark$ & & \\
\hline $94-25-1$ & $\checkmark$ & & \\
\hline $94-25-3$ & $\checkmark$ & & \\
\hline $94-25-4$ & $\checkmark$ & & \\
\hline $95-6-4$ & $\checkmark$ & & \\
\hline $95-20-1$ & $\checkmark$ & & \\
\hline $95-20-2$ & $\checkmark$ & & \\
\hline $96-9-1$ & $\checkmark$ & & \\
\hline $96-9-3$ & $\checkmark$ & & \\
\hline $96-18-4$ & $\checkmark$ & & \\
\hline $96-19-2$ & $\checkmark$ & & \\
\hline $96-20-2$ & $\checkmark$ & & \\
\hline $97-8-3$ & $\checkmark$ & & \\
\hline $97-12-4$ & $\checkmark$ & & \\
\hline $97-18-4$ & $\checkmark$ & & \\
\hline $97-19-2$ & $\checkmark$ & & \\
\hline $97-19-3$ & & & $\checkmark$ \\
\hline $98-8-4$ & $\checkmark$ & & \\
\hline 98-9-2 & $\checkmark$ & & \\
\hline $99-13-2$ & $\checkmark$ & & \\
\hline $99-25-1$ & $\checkmark$ & & \\
\hline $101-7-3$ & $\checkmark$ & & \\
\hline
\end{tabular}




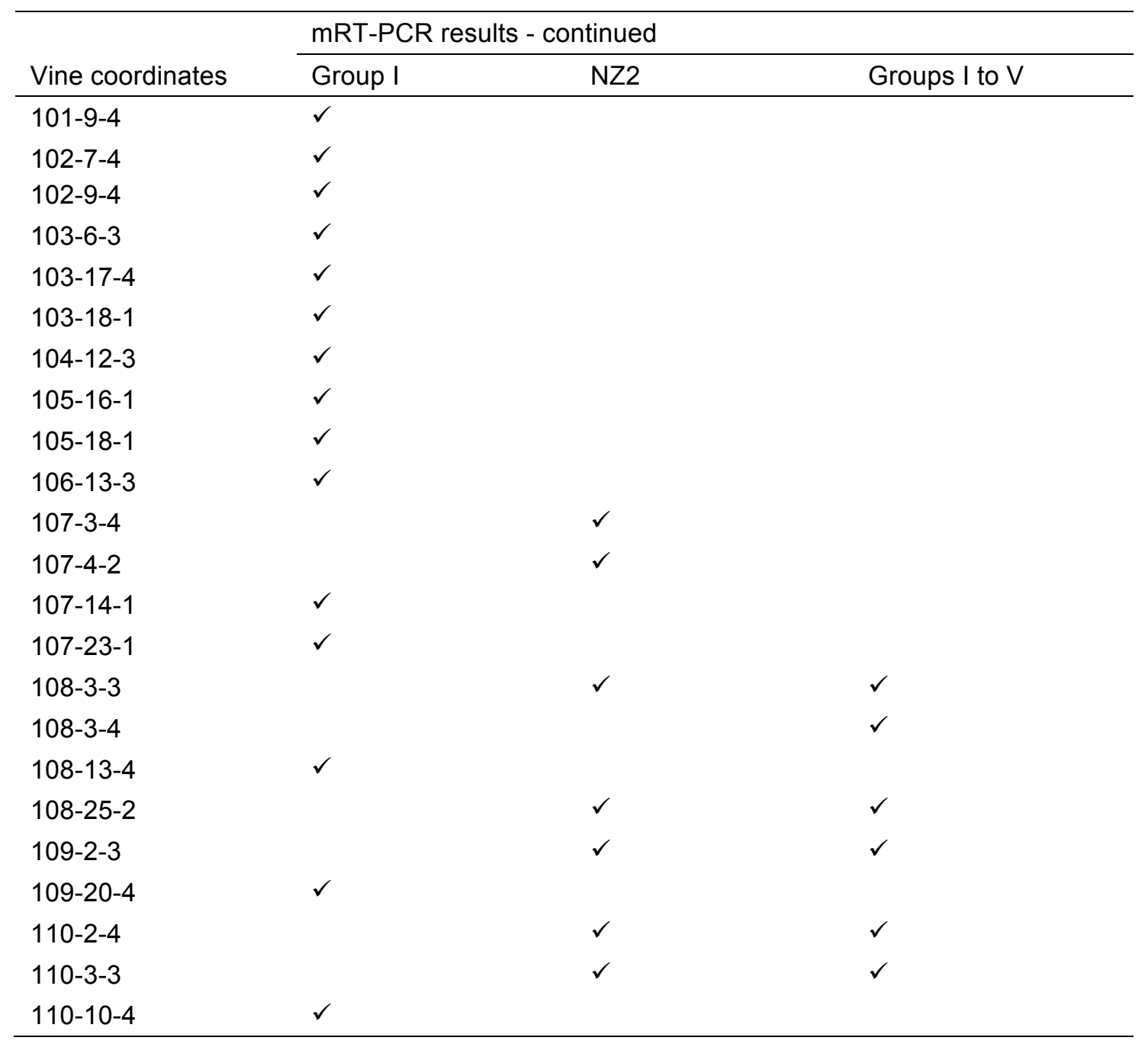

${ }^{\ddagger}$ The mRT-PCR assay used five primer sets (plus one internal plant control): four targeted GLRaV-3 variants group I, group II, NZ-1, NZ2. A fifth generic primer targeted variants from groups I to V, as stated by Chooi et al. (2013a)

${ }^{\dagger}$ Row 90 , bay 17 , vine number one

Of the GLRaV-3-infected Malbec vines, group II and NZ-1 variants were not detected 
Supplementary table 4.3.1.2. Mealybug insecticide spray diary records for the 13 Hawke's Bay vineyard study blocks, 2009 to 2012 (table continued overleaf).

\begin{tabular}{|c|c|}
\hline Block & Mealybug insecticide spray programmes \\
\hline \multirow[t]{4}{*}{ A } & 2009 Tokuthion $®$ \& D-C-Tron/Oil-Mate $\| ®, 2$ Oct, 1,000 L/ha \\
\hline & 2010 Tokuthion® \& D-C-Tron/Oil-Mate II®, 4 Oct, 1,000 L/ha \\
\hline & $\begin{array}{l}2011 \text { Tokuthion } ® \text { \& D-C-Tron/Oil-Mate II®, } 5 \text { Oct, 1,000 L/ha; Mortar }{ }^{\text {TM }}, 16 \text { Nov, } \\
500 \text { L/ha }\end{array}$ \\
\hline & $\begin{array}{l}2012 \text { Tokuthion } ® \text { \& D-C-Tron/Oil-Mate II®, } 5 \text { Oct, 1,000 L/ha; Mortar }{ }^{\mathrm{TM}} \text {, } 31 \text { Oct, } \\
400 \text { L/ha; Movento®, } 19 \text { Nov, } 400 \text { L/ha }\end{array}$ \\
\hline \multirow[t]{4}{*}{ B } & 2009 No mealybug insecticides applied \\
\hline & 2010 Tokuthion $\circledast$, 29 Sep, 150 L/ha; Applaud® \& JMS Stylet-Oil, 20 Oct, 200 L/ha \\
\hline & 2011 Tokuthion ${ }^{\circledR}, 7$ Sep, 1,000 L/ha; Mortar ${ }^{\mathrm{TM}}, 15$ \& 28 Nov, 750 L/ha \\
\hline & $\begin{array}{l}2012 \text { Tokuthion }{ }^{\circledR}, 26 \text { Sep, } 1,000 \text { L/ha; Mortar }{ }^{\mathrm{TM}}, 31 \text { Oct, } 350 \text { L/ha; Movento®, } 1 \text { \& } \\
21 \text { Nov, } 400 \text { L/ha. }\end{array}$ \\
\hline \multirow[t]{4}{*}{$\mathrm{C}$} & 2009 Organic - no insecticides applied \\
\hline & 2010 Organic - no insecticides applied \\
\hline & 2011 Organic - no insecticides applied \\
\hline & 2012 Organic - no insecticides applied \\
\hline \multirow[t]{4}{*}{ D } & $\begin{array}{l}2009 \text { Tokuthion } \circledast \text { \& oil, } 10 \text { Sep, 1,000 L/ha; Applaud }(29 \text { Oct, } 500 \text { L/ha; Applaud } \AA \text {, } \\
13 \text { Nov, } 500 \text { L/ha }\end{array}$ \\
\hline & 2010 Applaud®, 26 Oct, 1,000 L/ha; Applaud®, 9 Nov, 1,000 L/ha \\
\hline & 2011 Applaud®, 5 Nov, 1,000 L/ha; Applaud®, 17 Nov, 1,000 L/ha. \\
\hline & 2012 Movento®, 26 Nov, 500 L/ha; Movento $®, 10$ Dec, 500 L/ha. \\
\hline \multirow[t]{4}{*}{$\mathrm{E}$} & 2009 Organic - no insecticides applied \\
\hline & 2010 Organic - no insecticides applied \\
\hline & 2011 Organic - no insecticides applied \\
\hline & 2012 Organic - no insecticides applied \\
\hline \multirow[t]{4}{*}{$\mathrm{F}$} & 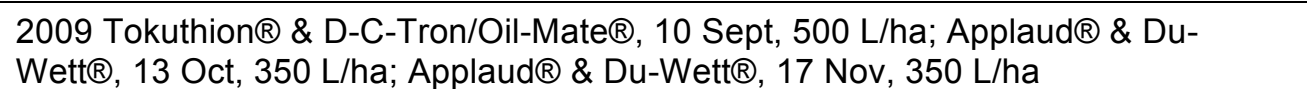 \\
\hline & 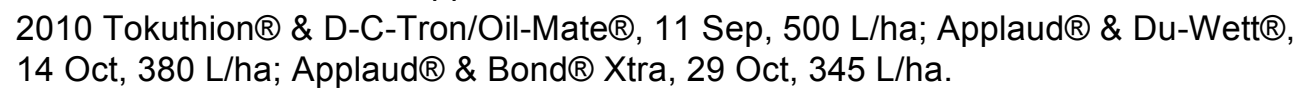 \\
\hline & $\begin{array}{l}2011 \text { Tokuthion } \circledast \text { \& D-C-Tron/Oil-Mate } ®, 14 \text { Sep, } 575 \text { L/ha; Applaud®, } 15 \text { Oct, } 402 \\
\text { L/ha; Applaud } 囚, 24 \text { Oct, } 575 \text { L/ha. }\end{array}$ \\
\hline & 2012 Mortar $^{\mathrm{TM}}, 29$ Oct, 344 L/ha; Movento®, 22 Nov, 459 L/ha. \\
\hline
\end{tabular}




\begin{tabular}{|c|c|}
\hline Block & Mealybug insecticide spray programmes - continued \\
\hline \multirow[t]{2}{*}{$1^{\ddagger}$} & 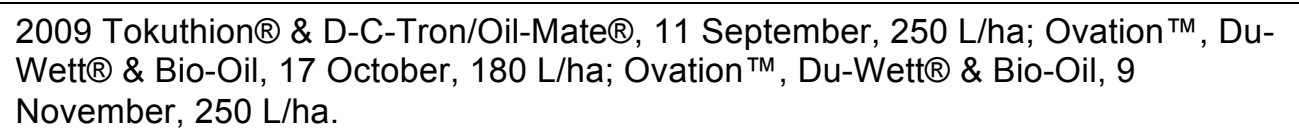 \\
\hline & $\begin{array}{l}2010 \text { Tokuthion } \AA \text { \& D-C-Tron/Oil-Mate } \AA \text {, } 16 \text { September, } 500 \text { L/ha; Applaud } \circledast \text {, Du- } \\
\text { Wett } \circledast \text { \& Bio-Oil, } 15 \text { October, } 200 \text { L/ha; Applaud®, Du-Wett } \& \text { \& Bio-Oil, } 9 \\
\text { November, } 200 \text { L/ha. }\end{array}$ \\
\hline \multirow[t]{4}{*}{$\mathrm{J}$} & $\begin{array}{l}2009 \text { Tokuthion } \AA \text { \& D-C-Tron/Oil-Mate } ®, 16 \text { Sep, } 250 \text { L/ha; Ovation }{ }^{\mathrm{TM}} \text {, Du-Wett } ® \text { \& } \\
\text { Bio-Oil, } 16 \text { Oct, } 180 \text { L/ha; Ovation }{ }^{\mathrm{TM}} \text {, Du-Wett } ® \text { \& Bio Oil, } 9 \text { Nov, } 250 \text { L/ha }\end{array}$ \\
\hline & $\begin{array}{l}2010 \text { Applaud®, Du-Wett } ₫ \text { \& Bio-Oil, } 15 \text { Oct, } 200 \text { L/ha; Applaud } 囚 \text {, Du-Wett } ₫ \& \text { Bio- } \\
\text { Oil, } 5 \text { Nov, } 200 \text { L/ha }\end{array}$ \\
\hline & $\begin{array}{l}2011 \text { Tokuthion }{ }^{\circledR} \& \text { D-C-Tron/Oil-Mate } ®, 16 \text { Sep, 1,000 L/ha; Mortar }{ }^{\mathrm{TM}}, 17 \text { Oct, } \\
\text { 1,000 L/ha; Ovation }{ }^{\mathrm{TM}}, 22 \mathrm{Nov}, 1,000 \mathrm{~L} / \mathrm{ha}\end{array}$ \\
\hline & $\begin{array}{l}2012 \text { Tokuthion } \circledast \& \text { D-C-Tron/Oil-Mate } ®, 7 \text { Sep, 1,000 L/ha; Movento } ®, 29 \text { Oct, } \\
400 \text { L/ha; Movento } ®, 14 \text { Nov, } 400 \text { L/ha }\end{array}$ \\
\hline \multirow[t]{4}{*}{ K } & 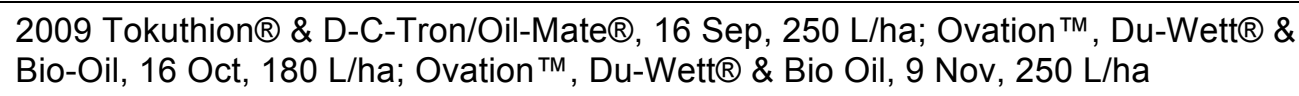 \\
\hline & 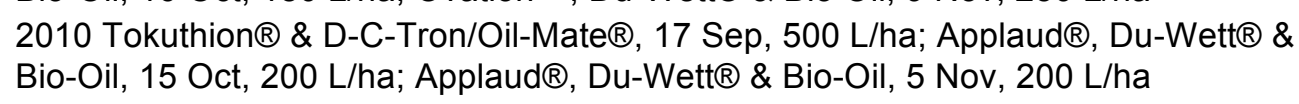 \\
\hline & $\begin{array}{l}2011 \text { Tokuthion }{ }^{\circledR} \& \text { D-C-Tron/Oil-Mate } ®, 16 \text { Sep, } 1,000 \text { L/ha; Mortar }{ }^{\mathrm{TM}}, 17 \text { Oct, } \\
\text { 1,000 L/ha; Ovation }{ }^{\mathrm{TM}}, 22 \mathrm{Nov}, 1,000 \mathrm{~L} / \mathrm{ha} \text {. }\end{array}$ \\
\hline & 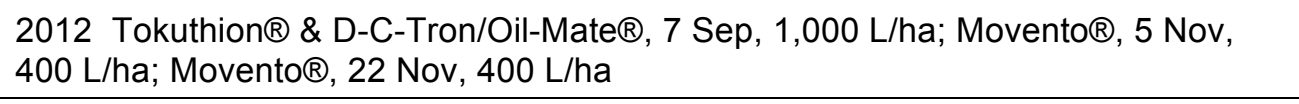 \\
\hline \multirow[t]{2}{*}{ L } & $\begin{array}{l}2011 \text { Tokuthion }{ }^{\circledR} \& \text { D-C-Tron/Oil-Mate }{ }^{\circledR}, 16 \text { Sep, } 1,000 \text { L/ha; Ovation }{ }^{\mathrm{TM}}, 25 \text { Oct, } \\
\text { 1,000 L/ha; Ovation }{ }^{\mathrm{TM}}, 22 \text { Nov, 1,000 L/ha. }\end{array}$ \\
\hline & 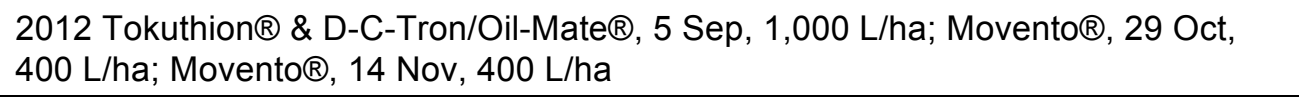 \\
\hline \multirow[t]{2}{*}{ M } & 2011 Pilan®, 18 Nov, 930 L/ha; Pilan®, 25 Nov, 680 L/ha. \\
\hline & 2012 Pilan®, 25 Oct, 250 L/ha; Pilan®, 10 Nov, 250 L/ha. \\
\hline \multirow[t]{2}{*}{$\mathrm{N}$} & 2011 Pilan®, 21 Nov, 680 L/ha; Pilan®, 26 Nov, 680 L/ha. \\
\hline & 2012 Pilan®, 24 Oct, 250 L/ha; Pilan®, 9 Nov, 250 L/ha. \\
\hline \multirow[t]{2}{*}{$\mathrm{O}$} & 2011 Mortar $^{\mathrm{TM}}, 1 \& 15$ Nov, 1,000 L/ha. \\
\hline & $\begin{array}{l}2012 \text { Tokuthion } \circledast \text { \& D-C-Tron Plus, } 13 \text { Sep, } 500 \text { L/ha (applied with hand lance); } \\
\text { Mortar }{ }^{\mathrm{TM}}, 1 \mathrm{Nov}, 1,000 \mathrm{~L} / \text { ha; Movento } 囚, 15 \mathrm{Nov}, 500 \mathrm{~L} / \mathrm{ha}\end{array}$ \\
\hline \multicolumn{2}{|c|}{ ‡ Post-roguing, all residual vines were removed in mid 2011} \\
\hline \multirow{2}{*}{\multicolumn{2}{|c|}{ 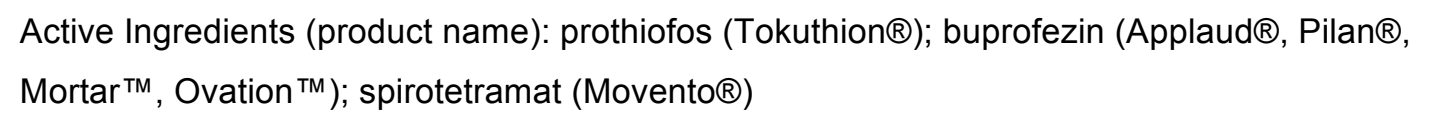 }} \\
\hline & \\
\hline \multicolumn{2}{|r|}{ Residual vines in blocks $\mathrm{G} \& \mathrm{H}$ were removed in mid 2011 for commercial reasons unrelated } \\
\hline \multicolumn{2}{|c|}{ to Grapevine leafroll-associated virus 3} \\
\hline
\end{tabular}


Supplementary table 4.4.2.1. Percent Grapevine leafroll-associated virus 3 (GLRaV-3) incidence among the 'nearest neighbour' and 'random' categories in the Hawke's Bay vineyard study blocks, 2010 to 2013. Results of fitting binomial generalised linear models in 2010 (this page, top table), 2011 (this page, lower table), 2012 (over page, top table) and 2013 (over page, lower table) (level of significance, $\alpha=0.05$ ).

\begin{tabular}{|c|c|c|c|c|c|c|c|c|}
\hline \multirow[b]{2}{*}{$\begin{array}{l}\text { Block } \\
\text { ID }\end{array}$} & \multicolumn{2}{|c|}{$\begin{array}{l}P \text { values for } \\
\text { difference... }\end{array}$} & \multicolumn{6}{|c|}{2010 GLRaV-3 incidence (\%) } \\
\hline & $\begin{array}{c}\text { between } \\
\text { categories } \\
\text { NN \& } R^{\ddagger}\end{array}$ & $\begin{array}{c}\text { between } \\
\text { categories } \\
\text { NN }\end{array}$ & First & Second & Opposite & Diagonal & Random & $\begin{array}{c}\text { Approx. } \\
\text { LSD } \\
(\%)\end{array}$ \\
\hline$A$ & $<0.001$ & $<0.001$ & $20.5 a^{\dagger}$ & $0.0 c$ & $5.6 b$ & $1.9 b c$ & $1.3 \mathrm{c}$ & 6.0 \\
\hline B & $<0.001$ & 0.006 & $11.1 \mathrm{a}$ & $3.9 b c$ & 7.3ab & $4.9 b c$ & $2.6 c$ & 3.6 \\
\hline $\mathrm{C}$ & 0.081 & 0.489 & $7.5 a$ & $5.4 a b$ & $3.4 a b$ & $4.2 a b$ & $3.1 b$ & 5.1 \\
\hline $\mathrm{D}$ & $<0.001$ & $<0.001$ & $10.6 a$ & $6.5 b$ & $6.4 b$ & $4.3 \mathrm{bc}$ & $2.6 c$ & 2.9 \\
\hline$E$ & $<0.001$ & $<0.001$ & $15.3 a$ & $5.7 b$ & $3.5 b c$ & $5.3 b$ & $2.6 c$ & 3.8 \\
\hline $\mathrm{F}$ & $<0.001$ & 0.006 & $14.1 \mathrm{a}$ & 6.3ab & $3.8 \mathrm{bc}$ & $1.3 b c$ & $1.8 \mathrm{c}$ & 6.5 \\
\hline I & $<0.001$ & $<0.001$ & $57.4 a$ & $26.0 b$ & $23.3 b$ & $17.1 \mathrm{~b}$ & $3.2 \mathrm{c}$ & 10.4 \\
\hline $\mathrm{J}$ & $<0.001$ & $<0.001$ & $42.4 a$ & $15.8 b$ & $8.8 \mathrm{c}$ & $6.5 \mathrm{c}$ & $8.4 \mathrm{c}$ & 6.6 \\
\hline $\mathrm{K}$ & $<0.001$ & $<0.001$ & $59.8 a$ & $35.0 \mathrm{~b}$ & $35.6 \mathrm{bc}$ & $22.1 \mathrm{c}$ & $6.8 \mathrm{~d}$ & 12.4 \\
\hline
\end{tabular}

${ }^{\ddagger} \mathrm{NN}=$ 'nearest neighbours'; $\mathrm{R}=$ ='random'

${ }^{\dagger}$ Within a row, percentages with a common letter beside them are not significantly different $(\alpha=0.05$; pairwise likelihood ratio test)

LSD=least significant difference

Blocks $\mathrm{G} \& \mathrm{H}$ were excluded from all analyses following the removal of the residual vines in July 2011 for reasons unrelated to GLRaV-3 (see section 4.3.1)

\begin{tabular}{|c|c|c|c|c|c|c|c|c|}
\hline \multirow[b]{2}{*}{$\begin{array}{l}\text { Block } \\
\text { ID }\end{array}$} & \multicolumn{2}{|c|}{$\begin{array}{l}P \text { values for } \\
\text { difference... }\end{array}$} & \multicolumn{6}{|c|}{2011 GLRaV-3 incidence (\%) } \\
\hline & $\begin{array}{c}\text { between } \\
\text { categories } \\
\text { NN \& R }\end{array}$ & $\begin{array}{c}\text { between } \\
\text { categories } \\
\text { NN }\end{array}$ & First & Second & Opposite & Diagonal & Random & $\begin{array}{c}\text { Approx. } \\
\text { LSD } \\
(\%)\end{array}$ \\
\hline$A$ & $<0.001$ & 0.285 & $6.3 a$ & 2.0ab & $2.2 \mathrm{ab}$ & 2.1ab & $0.5 b$ & 4.2 \\
\hline $\mathrm{B}$ & $<0.001$ & 0.013 & $13.1 \mathrm{a}$ & $7.4 \mathrm{~b}$ & $6.9 b$ & $7.7 \mathrm{~b}$ & $4.9 b$ & 3.9 \\
\hline $\mathrm{C}$ & 0.340 & 0.486 & $0.6 a$ & $0.0 a$ & $0.0 a$ & $0.0 a$ & $0.0 a$ & 0.5 \\
\hline $\mathrm{D}$ & $<0.001$ & $<0.001$ & $13.9 a$ & $5.7 b$ & $1.9 \mathrm{~cd}$ & $3.8 \mathrm{bc}$ & $1.5 \mathrm{~d}$ & 2.4 \\
\hline E & 0.048 & 0.279 & $0.9 a$ & $0.4 a b$ & $0.0 \mathrm{ab}$ & $0.3 a b$ & $0.0 \mathrm{~b}$ & 0.8 \\
\hline $\mathrm{F}$ & $<0.001$ & $<0.001$ & $19.8 a$ & $5.7 b$ & $1.6 b$ & $1.7 \mathrm{~b}$ & $0.3 c$ & 5.1 \\
\hline I & $<0.001$ & $<0.001$ & $47.9 a$ & $32.5 b$ & $15.5 c$ & $10.3 c$ & $2.1 d$ & 9.4 \\
\hline$J$ & $<0.001$ & $<0.001$ & $10.6 a$ & $3.4 b$ & $1.7 \mathrm{bc}$ & $2.2 \mathrm{~b}$ & $0.6 c$ & 3.0 \\
\hline $\mathrm{K}$ & $<0.001$ & $<0.001$ & $32.8 a$ & $13.2 b$ & $7.7 \mathrm{bc}$ & $4.1 \mathrm{c}$ & $2.7 \mathrm{c}$ & 7.2 \\
\hline $\mathrm{L}$ & $<0.001$ & $<0.001$ & $56.1 a$ & $19.3 b$ & $5.4 \mathrm{c}$ & $2.4 \mathrm{~cd}$ & $1.9 d$ & 6.7 \\
\hline
\end{tabular}




\begin{tabular}{|c|c|c|c|c|c|c|c|c|}
\hline \multirow[b]{2}{*}{$\begin{array}{l}\text { Block } \\
\text { ID }\end{array}$} & \multicolumn{2}{|c|}{$\begin{array}{l}P \text { values for } \\
\text { difference... }\end{array}$} & \multicolumn{6}{|c|}{2012 GLRaV-3 incidence (\%) } \\
\hline & $\begin{array}{c}\text { between } \\
\text { categories } \\
\text { NN \& R }\end{array}$ & $\begin{array}{c}\text { between } \\
\text { categories } \\
\text { NN }\end{array}$ & First & Second & Opposite & Diagonal & Random & $\begin{array}{l}\text { Approx. } \\
\text { LSD } \\
(\%)\end{array}$ \\
\hline A & 0.675 & 0.397 & $0.8 a$ & $0.0 a$ & $0.0 a$ & $0.0 a$ & $0.3 a$ & 0.8 \\
\hline B & $<0.001$ & $<0.001$ & $6.1 a$ & $1.8 b$ & $1.8 b$ & $1.0 \mathrm{bc}$ & $0.6 c$ & 1.8 \\
\hline C & 0.998 & 1.000 & $0.0 a$ & $0.0 a$ & $0.0 a$ & $0.0 a$ & $0.0 a$ & 0.0 \\
\hline D & $<0.001$ & 0.002 & $6.5 a$ & $3.0 b$ & $3.0 b$ & $3.2 b$ & $0.9 c$ & 1.9 \\
\hline$E$ & 0.107 & 0.234 & $0.5 a$ & $0.3 a$ & $0.0 a$ & $0.0 a$ & $0.0 a$ & 0.5 \\
\hline $\mathrm{F}$ & $<0.001$ & $<0.001$ & $18.0 \mathrm{a}$ & $2.8 \mathrm{bc}$ & $5.5 b$ & $1.4 \mathrm{~cd}$ & $0.3 d$ & 4.8 \\
\hline $\mathrm{J}$ & $<0.001$ & $<0.001$ & $4.9 a$ & $0.4 \mathrm{~b}$ & $0.8 b$ & $2.9 a$ & $0.1 b$ & 1.9 \\
\hline K & $<0.001$ & $<0.001$ & $29.8 a$ & $16.3 b$ & $5.9 \mathrm{~cd}$ & $13.3 b c$ & $3.2 \mathrm{~d}$ & 7.9 \\
\hline L & $<0.001$ & $<0.001$ & $38.7 a$ & $13.9 \mathrm{bc}$ & $10.5 \mathrm{c}$ & $18.5 b$ & $1.6 \mathrm{~d}$ & 7.0 \\
\hline$M$ & $<0.001$ & $<0.001$ & $20.5 a$ & $3.4 \mathrm{~b}$ & $2.7 \mathrm{~b}$ & $1.5 b c$ & $0.7 \mathrm{c}$ & 3.8 \\
\hline $\mathrm{N}$ & $<0.001$ & $<0.001$ & $25.9 a$ & $9.0 \mathrm{~b}$ & $5.4 \mathrm{bc}$ & $2.5 \mathrm{~cd}$ & $0.8 d$ & 5.7 \\
\hline
\end{tabular}

Block I was excluded from $2012 \& 2013$ analyses because all the residual vines were removed in July 2011

\begin{tabular}{|c|c|c|c|c|c|c|c|c|}
\hline \multirow[b]{2}{*}{$\begin{array}{l}\text { Block } \\
\text { ID }\end{array}$} & \multicolumn{2}{|c|}{$\begin{array}{l}P \text { values for } \\
\text { difference... }\end{array}$} & \multicolumn{6}{|c|}{2013 GLRaV-3 incidence (\%) } \\
\hline & $\begin{array}{c}\text { between } \\
\text { categories } \\
\text { NN \& R }\end{array}$ & $\begin{array}{c}\text { between } \\
\text { categories } \\
\text { NN }\end{array}$ & First & Second & Opposite & Diagonal & Random & $\begin{array}{c}\text { Approx. } \\
\text { LSD } \\
(\%)\end{array}$ \\
\hline$A$ & 0.846 & 0.112 & $1.6 a$ & $0.0 a$ & $0.0 a$ & $0.0 a$ & $0.3 a$ & 1.0 \\
\hline B & $<0.001$ & $<0.001$ & $7.4 a$ & $2.4 b$ & $3.1 b$ & $2.6 b$ & $1.0 c$ & 2.1 \\
\hline C & 0.998 & 1.000 & $0.0 a$ & $0.0 a$ & $0.0 a$ & $0.0 a$ & $0.0 a$ & 0.0 \\
\hline $\mathrm{D}$ & $<0.001$ & 0.166 & $4.4 a$ & $2.8 a b$ & $2.3 b$ & $3.2 \mathrm{ab}$ & $1.0 c$ & 1.7 \\
\hline$E$ & 0.188 & 0.411 & $0.3 a$ & $0.3 a$ & $0.0 a$ & $0.0 a$ & $0.0 a$ & 0.4 \\
\hline $\mathrm{F}$ & $<0.001$ & $<0.001$ & $19.0 \mathrm{a}$ & $5.0 \mathrm{~b}$ & $0.5 c$ & $2.7 b$ & $0.2 \mathrm{c}$ & 4.3 \\
\hline$J$ & $<0.001$ & 0.008 & $2.4 a$ & $0.0 \mathrm{bc}$ & $0.8 a b$ & $0.8 a b$ & $0.0 c$ & 1.2 \\
\hline $\mathrm{K}$ & $<0.001$ & $<0.001$ & $20.9 a$ & $4.7 b$ & $2.0 \mathrm{bc}$ & $5.2 b$ & $0.9 c$ & 5.6 \\
\hline$L$ & $<0.001$ & $<0.001$ & $15.1 \mathrm{a}$ & $5.9 b$ & $2.3 b$ & $3.3 b$ & $0.6 c$ & 4.2 \\
\hline$M$ & $<0.001$ & 0.002 & $3.8 \mathrm{a}$ & $0.0 \mathrm{~b}$ & $0.6 b$ & $0.6 b$ & $0.1 b$ & 1.5 \\
\hline $\mathrm{N}$ & $<0.001$ & $<0.001$ & $7.8 a$ & $0.6 \mathrm{bc}$ & $0.9 b$ & $0.5 b c$ & $0.0 c$ & 2.3 \\
\hline O & $<0.001$ & 0.002 & $6.3 a$ & $1.9 b$ & $1.0 \mathrm{bc}$ & $0.6 \mathrm{bc}$ & $0.3 c$ & 2.6 \\
\hline
\end{tabular}




\subsection{Supplementary figures}

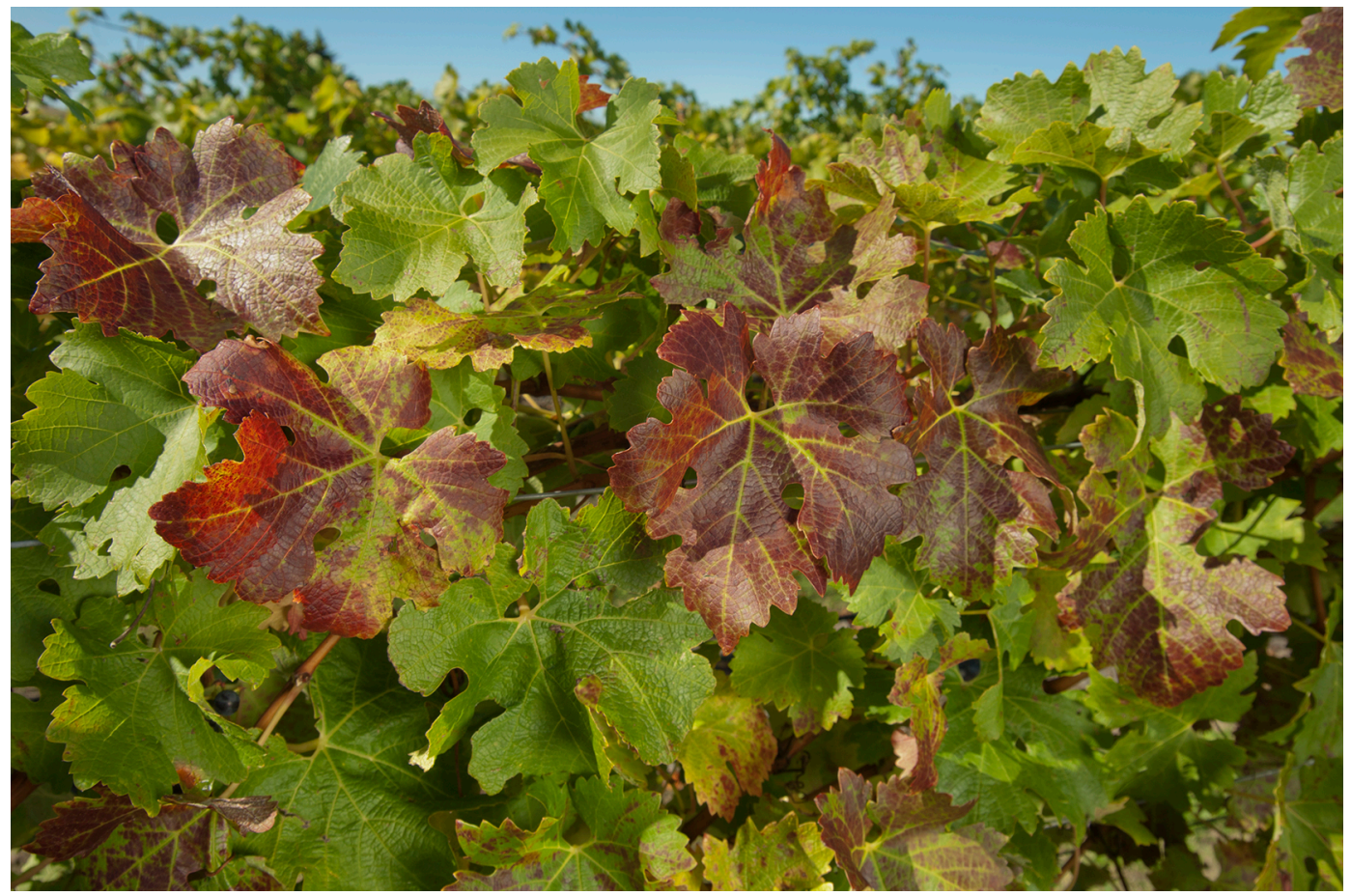

Supplementary figure 1.4.1. A Grapevine leafroll-associated virus 3-symptomatic Cabernet Sauvignon vine in Hawke's Bay, March 2012.
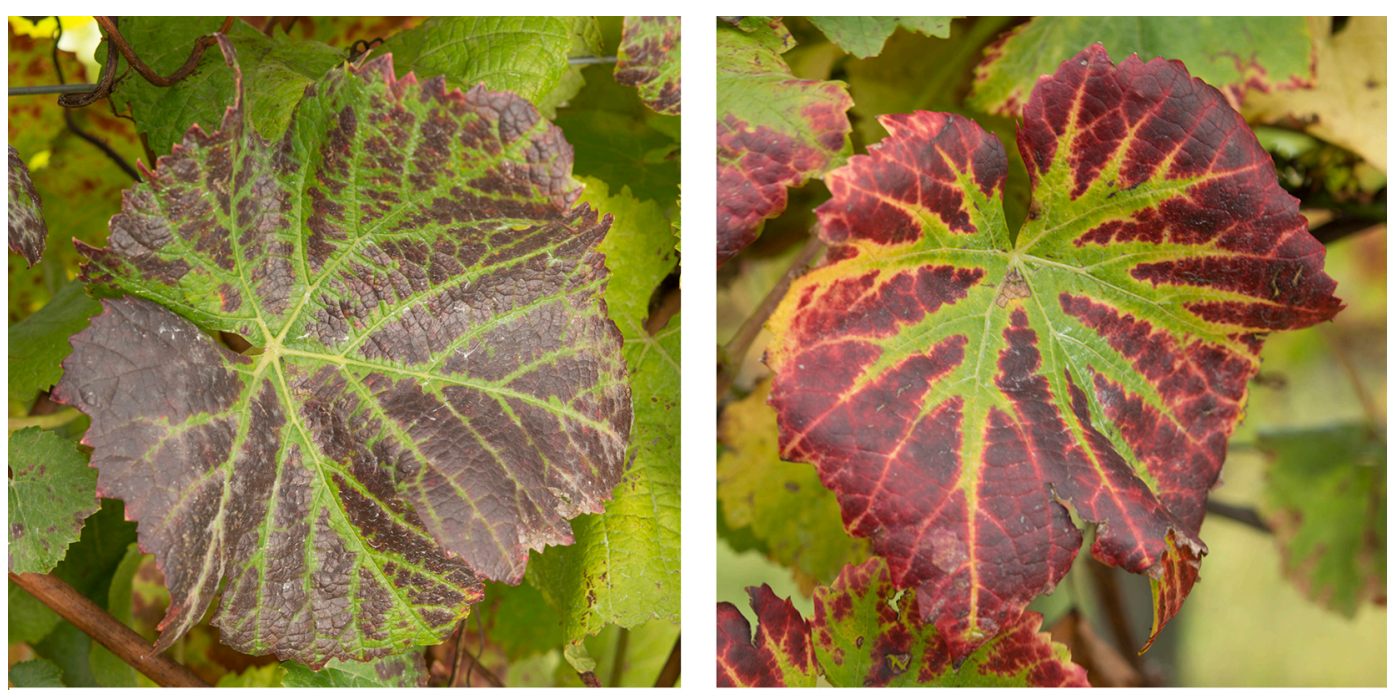

Supplementary figure 1.4.2. Comparison of foliar symptoms for Grapevine leafroll-associated virus 3 (left) and magnesium deficiency (right) in Pinot noir vines in Hawke's Bay, April 2014. 


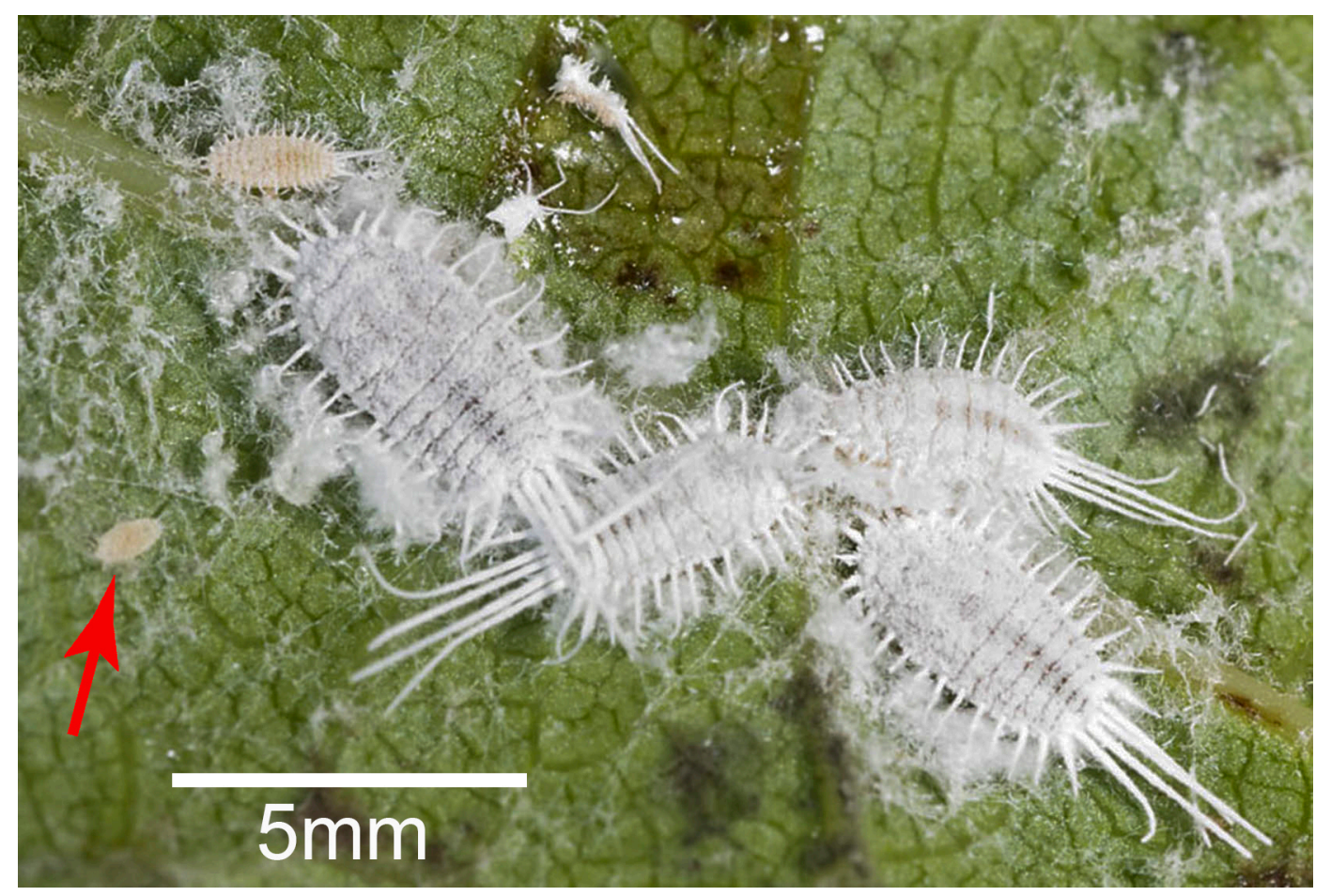

Supplementary figure 1.7.1. The mealybug Pseudococcus longispinus on the underside of a grapevine leaf in Hawke's Bay, March 2011. Red arrow points to a crawler or $1^{\text {st }}$ instar. 
Supplementary figure 5.3.1. New Zealand Winegrowers factsheet: Vine removal and leafroll 3 (NZVE108, February 2014) - page 119.

Supplementary figure 5.3.2. New Zealand Winegrowers factsheet: Leafroll symptoms on red varieties (NZVE101, February 2014) - page 121.

Supplementary figure 5.3.3. New Zealand Winegrowers factsheet: Mealybugs - knowing the pest (NZVE105, October 2009) - page 123.

Supplementary figure 5.3.4. New Zealand Winegrowers factsheet: How to look for mealybugs (NZVE106, October 2009) - page 125.

Supplementary figure 5.3.5. New Zealand Winegrowers factsheet: Pre-harvest mealybug monitoring (NZVE111, August 2013) - page 127. 


\section{NEW ZEALAND WINEGROWERS FACT SHEET}

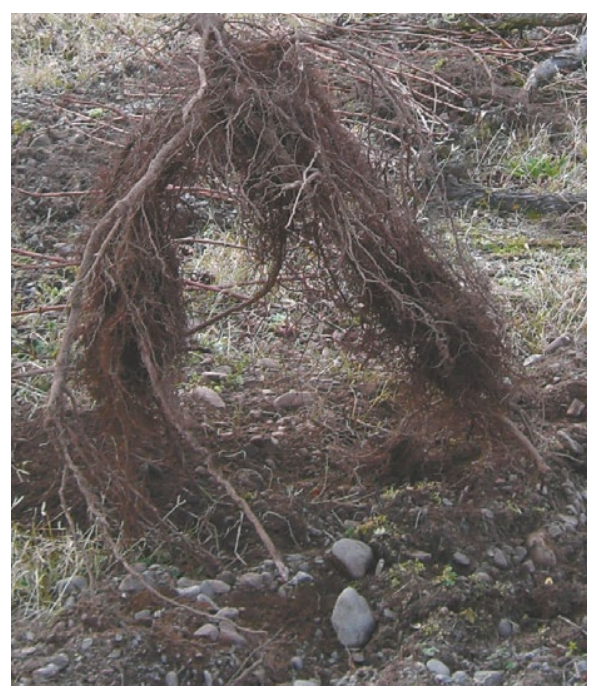

Remove as much of the vine as possible including root material.

\section{VINE REMOVAL AND LEAFROLL 3}

\section{KEY NOTES}

- This fact sheet replaces NZVE108 February 2011.

- For vine replants, refer to fact sheet NZVE 109 February 2011.

- Removing virus-infected vines should be done in conjunction with insecticide treatments for mealybugs in the same area to minimise the risk of virus spread.

- Remove as many vine roots as possible - remnant roots have been shown to be long-term reservoirs of Leafroll 3 Virus.

Where laboratory test results and/or field observations in red varieties indicate grapevines are infected with Grapevine leafroll-associated virus 3 (Leafroll 3), a vine removal programme should follow. Where infection incidence appears to be low to moderate ( $<20 \%$ of a block), owners may opt to "rogue." Roguing encompasses treatment and removal of individual virus-infected vines, with individual replanting to follow.

Current best estimates indicate that a block with an infection incidence above $20 \%$ is not compatible with roguing, but the decision on whether to rogue depends in part on the value of the fruit being produced. In areas with high mealybug populations, the spread of Leafroll 3 is likely to outpace the ability to identify and rogue vines in blocks where infection exceeds the $20 \%$ threshold. Where infection incidence is high, the scheduled removal and replanting of the entire vineyard may occur if fruit quality and/or yields decline.

Once you have identified infected vines (through field observations or laboratory ELISA testing), map and tag the vines, and then follow these instructions for treatment and removal. Remove symptomatic vines only. In other words, retain all neighbouring vines, including all of the within-row adjacent vines.

\section{NOTE}

Best-practice guidelines have previously emphasised the importance of trying to kill vine roots by treating the stumps with glyphosate herbicide (e.g. RoundUp). The focus has since shifted to killing mealybugs on the roots of the infected vines - and neighbouring vines - through the application of imidacloprid (trade names Confidor, Nuprid), followed by the removal of infected vines in winter after treatment.

Imidacloprid is registered for use on non-cropping vines only, so all treated vines must be clearly marked and any fruit removed within 10 weeks of fruitset.

\section{AUTUMN}

Apply imidacloprid (350g/l active ingredient) to the vine tagged for removal as soon as possible after harvest. It is critical that the vine has sufficient time prior to leaf fall to take up the chemica through the roots.

- Apply imidicloprid at $1.5 \mathrm{ml} / 500 \mathrm{ml}$ of water/vine, around the base of the tagged vine.

- If necessary, make a small hollow around the base of the trunk to prevent the drench from running away.

- Apply to moist soil. If rain is not likely, or irrigation is not available within two days of drenching, apply an additional 2 litres of water per vine, once the drench has soaked in.

- If virus spread in the area is rapid and mealybug numbers are high (that is, a high-risk area), treat the vine on either side of the infected vine with imidacloprid at the same rates. Monitor these vines in subsequent years for the expression of virus symptoms and, if infected, follow the same methodology for their removal.

- Wait a minimum of 6-8 weeks before removing the vine. When vines are removed, extract as much root material as possible.

- Any regrowth and/or volunteer vines should be removed at any stage, as they appear. (Typically, very little re-growth is observed once vine roots have been removed.) 


\section{NEW ZEALAND WINEGROWERS FACT SHEET}

\section{OPTIONAL FALLOW PERIOD}

In South African trials in regions where Leafroll 3 is problematic, vineyard managers have opted to leave the ground fallow for one or two years following vine removal, with replanting to be done the spring thereafter. This period should be used to remove all volunteer vines and as many remnant vine roots as possible to a maximum depth of about $300 \mathrm{~mm}$ (mealybug are unlikely to colonise deeper roots).

\section{FOLLOWING SPRING}

Replant in the following spring (or after fallow period) with a healthy new vine, certified according to the New Zealand Winegrowers Grafted Grapevine Standard. Make a second application of imidacloprid immediately after planting to protect the young vines from re-infection, using the same rates and methodology already described (refer to fact sheet NZVE 109 for planting instructions).

\section{AUTUMN AFTER REPLANTING}

A third application of imidacloprid can be made to the replanted vine in the autumn after planting, approximately 6-8 weeks prior to leaf fall. (The best results with imidacloprid have been reported with autumn applications.) All treated vines must be clearly marked, and the fruit removed the following spring within 10 weeks of fruitset.

Good control of mealybug populations within the vine canopy underpins vine removal. For more information, see NZVE 104 'Mealybug control for cropping vines.'

\section{ACKNOWLEDGMENT}

This fact sheet has been updated to include guidelines developed from data analysed by Vaughn Bell, Plant \& Food Research, as part of his PhD research into leafroll virus management.

\section{DISCLAIMER}

While care has been used in compiling this fact sheet neither New Zealand Winegrowers nor Plant \& Food Research give any prediction, warranty or assurance in relation to the accuracy of or fitness for any particular purpose, use or application of any information contained in this document. To the full extent permitted by law neither New Zealand Winegrowers nor Plant \& Food Research, nor any of their employees, shall be liable for any cost (including legal costs), claim, liability, loss, damage, injury or the like, which may be suffered or incurred as a direct or indirect result of the reliance by any person on any information contained in this document.
Co-funded by:

Ministry for Primary Industries Manatū Ahu Matua

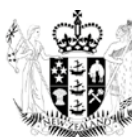

(c) New Zealand Winegrowers 2014

All Rights Reserved

FEBRUARY 2014 - NZVE108 VIRUS ELIMINATION PROJECT
CONTACT:

New Zealand Winegrowers

www.nzwine.com

Telephone number: 093033527 


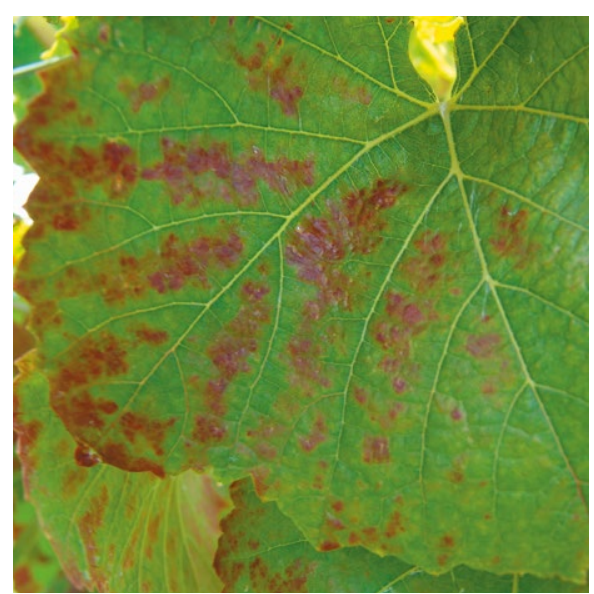

Mild symptoms of Leafroll 3 on Pinot noir.

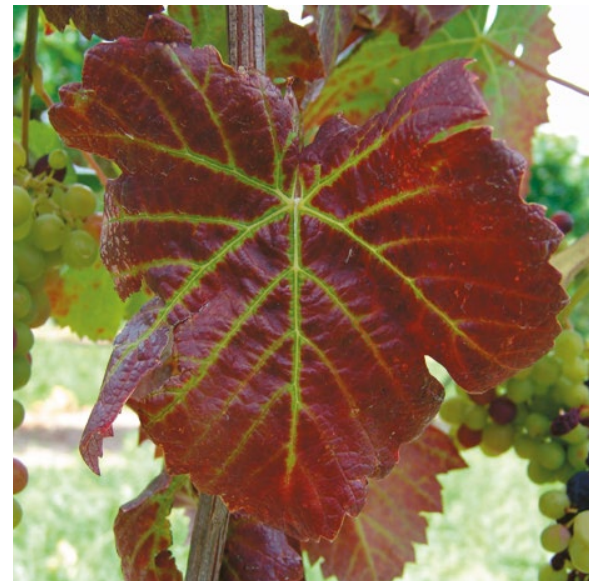

Severe symptoms of Leafroll 3 on Pinot noir.

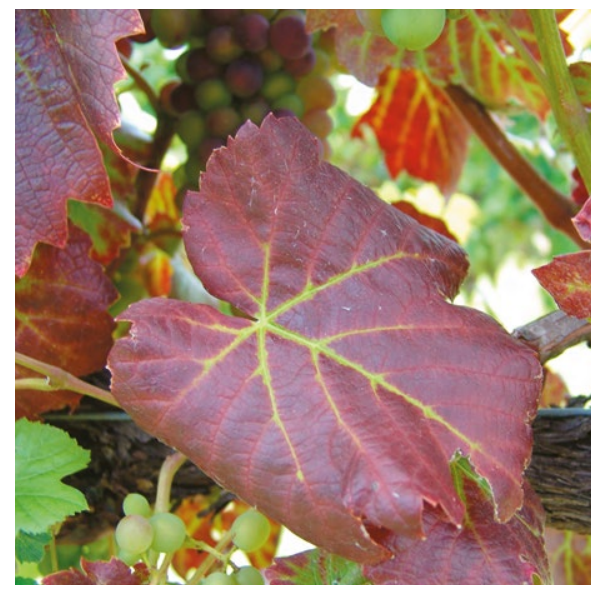

As rolling of leaves becomes more pronounced, leaves assume typical straight-edged shapes.

\section{LEAFROLL SYMPTOMS ON RED VARIETIES}

\section{KEY NOTES}

- This fact sheet replaces NZVE101 August 2009.

- Grapevine leafroll-associated virus 3 (Leafroll 3) typically shows symptoms on basal leaves from veraison onwards.

- Leaves develop typical red colouring parallel with the veins, which remain green. The leaf margin may - or may not - roll inwards, hence the name.

- Check for symptoms on mature leaves only.

- Leafroll 3 symptoms are visually most distinctive in red berry cultivars, and visual assessments should be limited to red varieties.

\section{BACKGROUND}

Grapevine leafroll-associated virus 3 (Leafroll 3) is by far the most commercially destructive virus present in New Zealand vineyards. Leafroll 3 is part of the Leafroll Virus group, all of which tend to express similar symptoms. Learning to recognise those symptoms is one of the first steps in managing the disease.

\section{DEVELOPMENT OF SYMPTOMS}

Symptoms will start to appear after veraison and persist until leaf-fall, appearing first on the older leaves at the base of shoots. The optimum period for visual assessment of Leafroll virus symptoms is late in the growing season. Symptoms often appear when vines are stressed. Leaves can redden for many reasons, not all of which are associated with Leafroll 3, including broken canes or shoots, feeding damage from mites, deficiency in magnesium and, to a lesser degree, phosphorus. If you are training yourself to recognise symptoms, it is important to confirm your suspicions by sending leaf or cane samples for laboratory testing or by accessing the library of images on the Flickr website (described in this fact sheet).

\section{SYMPTOM RECOGNITION}

- Leaves develop reddening symptoms from veraison (late January in most regions) onwards.

- Symptoms start at the base of cane and work upwards - check for symptoms on mature leaves only.

- Early expressions are red spots that form on leaf tissue in between the veins.

- These red spots gradually increase in size until they fill the inter-vein area with colouration parallel to the major leaf veins.

- Leaf veins usually remain green or are the last part to turn red.

- Leaf edges may begin to roll inwards (towards the underside of the leaf) and in some instances the rolling may be very pronounced

- Sometimes leaves can develop typica colouring, but have no rolled margins.

\section{OTHER INDICATIONS OF LEAFROLL 3}

- Delayed harvest - Brix may be slow to rise, or stop around 18 or 20

- Acids remain high.

- Fruit colour can be reduced.

- Yield can be reduced because of variable fruit set.

\section{OPTIMUM ASSESSMENT GUIDELINES}

Two or more visits per red variety block are recommended, and should be timed for between mid-March and mid-April. Multiple visits will increase the likelihood of visually identifying most, if not all, symptomatic vines in one season. Where a single visit per block is the only option, it will reduce the chance of detecting all symptomatic vines in a single season. In this situation, effective mealybug control is even more critical. 


\section{NEW ZEALAND WINEGROWERS FACT SHEET}

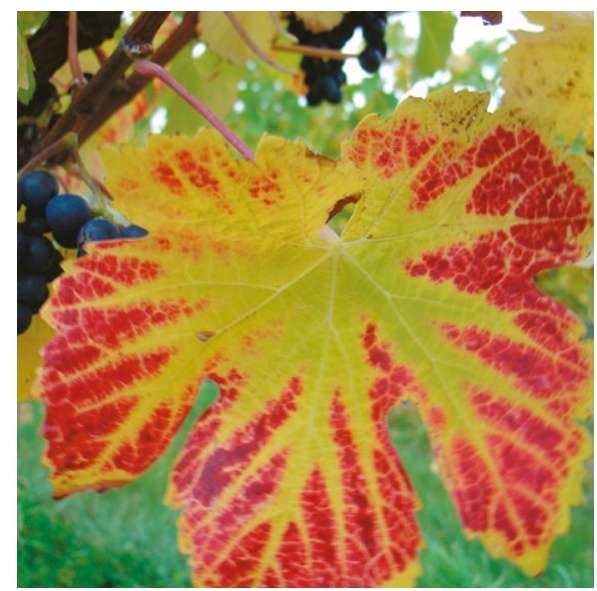

Magnesium deficiency typically shows as a lighter red on a yellow-green leaf. Leafroll 3 shows as a darker red with deep green veins. Magnesium deficiency also develops its red colourations in wedge-shaped patterns, while Leafroll 3 red colouration may continue to develop until only the veins remain green.

\section{FOR MORE INFORMATION}

New Zealand Winegrowers' Virus Elimination Project has published a photo library showing symptoms of Leafroll 3 infection on individual red varieties. The photo library is available on Flickr www.flickr.com and can be accessed by searching for "leafroll."

The project also provides a seven-part video series, outlining the key steps to control Leafroll 3 , including a video on symptom monitoring on red varieties. The videos can be accessed from the members' area of New Zealand Winegrowers' website: www.nzwine.com.

\section{Co-funded by:}

Ministry for Primary Industries Manatū Ahu Matua

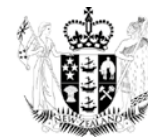

Deferring monitoring until April increases the risk of defoliation by frost or early senescence, which will confound symptom identification. Weather forecasts should be closely monitored.

Flagging tape should be tied around the trunk of each symptomatic vine so it can be identified for removal after harvest.

Tag and remove symptomatic vines only (see NZVE 108 - Vine removal and leafroll virus - for instructions)

\section{MAGNESIUM DEFICIENCY IN GRAPEVINES}

The symptoms of magnesium deficiency vary with variety, soil type and the time of year. They can appear similar to the symptoms expressed by Leafroll 3, so it's important to familiarise yourself with these characteristics:

- Where magnesium deficiency is present, leaves will show red wedgeshaped areas, extending inwards from the leaf margin between the main veins. The colour change is not parallel with the veins - this is a clear difference with leafroll symptoms

- Broad areas of pale green remain around the main veins.

- The leaf margins may turn brown

- Dead patches may develop in the red areas and at the leaf margins when magnesium deficiency is severe.

- The best time to look for symptoms is mid-season onwards, or when vines come under some stress at veraison and when soils start to dry out.

- Send samples to laboratory for leaf-blade nutrition tests to confirm your diagnosis.

\section{ACKNOWLEDGMENT}

This fact sheet was first written by Dr Rod Bonfiglioli and Nick Hoskins. Revised guidelines have been developed from data analysed by Vaughn Bell, Plant \& Food Research, as part of his PhD research into leafroll virus management.

\section{DISCLAIMER}

While care has been used in compiling this fact sheet neither New Zealand Winegrowers nor Plant \& Food Research give any prediction, warranty or assurance in relation to the accuracy of or fitness for any particular purpose, use or application of any information contained in this document. To the full extent permitted by law neither New Zealand Winegrowers nor Plant \& Food Research, nor any of their employees, shall be liable for any cost (including legal costs), claim, liability, loss, damage, injury or the like, which may be suffered or incurred as a direct or indirect result of the reliance by any person on any information contained in this document.

\section{CONTACT:}

New Zealand Winegrowers

www.nzwine.com

Telephone number: 093033527 


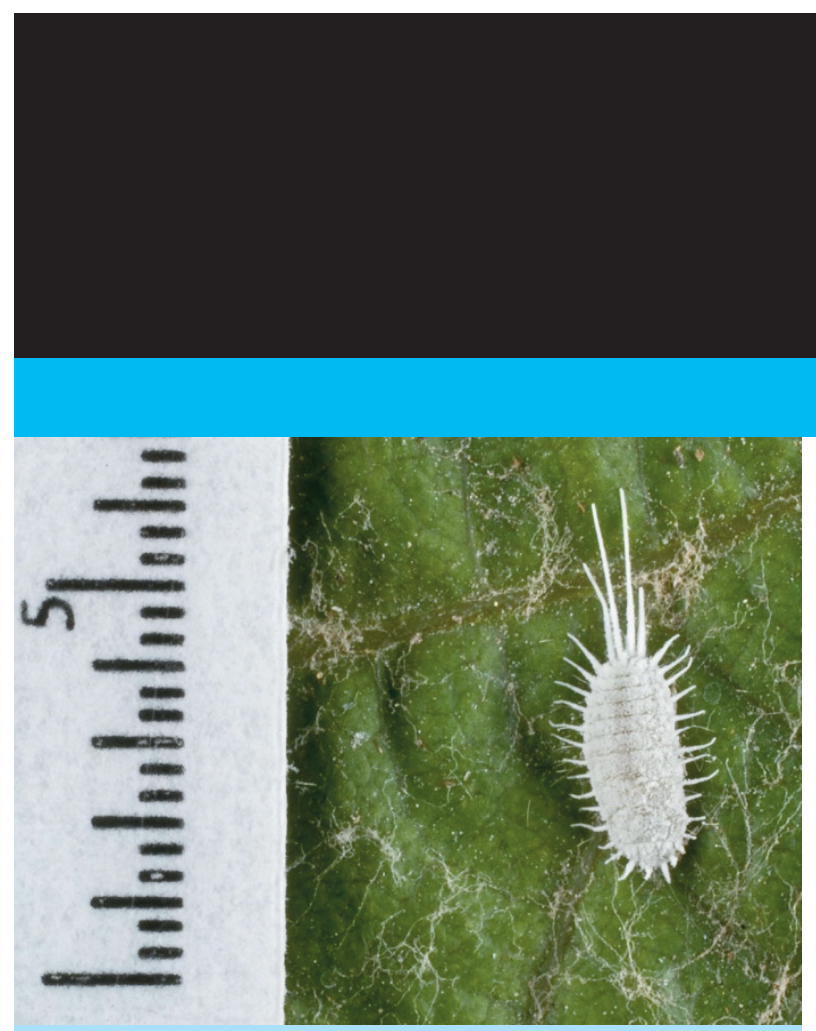

Mature longtailed mealybug (Pseudococcus longispinus).

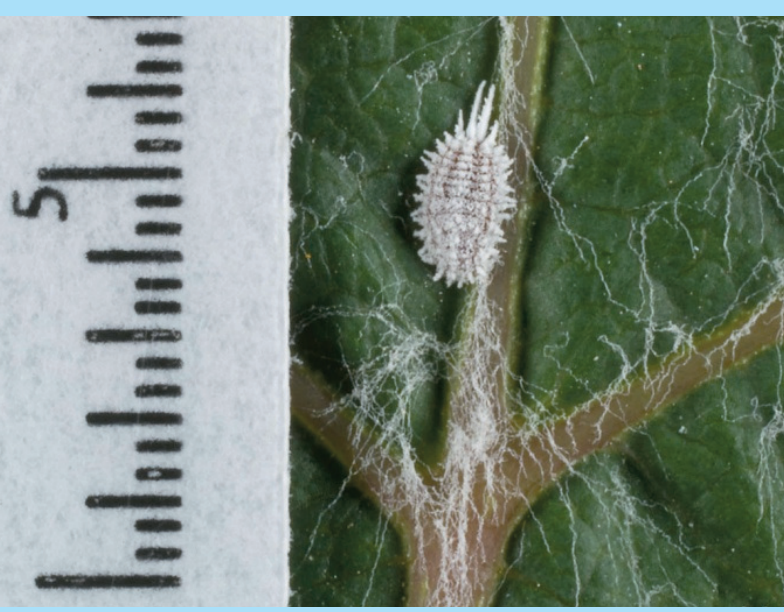

Juvenile citrophilus mealybug (Pseudococcus calceolariae).
NEW ZEALAND WINE

PURE DISCOVERY

NEW ZEALAND WINEGROWERS FACT SHEET

\section{MEALYBUGS - KNOWING THE PEST}

\section{KEY NOTES}

- Mealybugs are the most important vectors of Grapevine Leafrollassociated Virus Type 3 (GLRaV-3).

- Mealybugs acquire the virus by feeding on infected vines: when they move to healthy vines and start feeding, they transmit the virus.

- Mealybug control is one of the keys to reducing virus spread in New Zealand vineyards.

- Large numbers of mealybugs can result in contamination of the fruit and, although largely cosmetic, can potentially result in wine quality issues.

\section{WHICH SPECIES?}

Mealybugs are not specific to grapevines. Three mealybug species - longtailed, citrophilus and obscure-occur throughout most of New Zealand on a wide range of horticultural crops, weeds and garden plants. All three species can transmit GLRaV-3, but only longtailed and citrophilus mealybugs are commonly found in vineyards. Both species in the North Island and the northern South Island typically have two or three generations per year. Adult females of all species usually produce 100-400 offspring, depending on the nutritional quality of their host plant. Such high fecundity means that late-season populations may increase dramatically, especially if control measures are inadequate.

\section{WHERE THEY LIVE}

Mealybug populations in the vineyard are often unevenly distributed. They inhabit all parts of a grapevine, but prefer dark, shady and protected places, seeking out cracks and crevices, the insides of fruit bunches or the undersides of leaves. In winter, on a dormant vine, mealybugs can remain unseen in cracks and crevices in old pruning scars, under bark and on the roots.

Mealybugs that have survived over winter begin to move on to leaves at budburst. At this time of year, numbers are relatively low, making them hard to find early in the growing season.

\section{WHAT MAKES THEM A VECTOR?}

Mealybugs feed via sucking mouth parts that penetrate plant tissue to extract fluids from the phloem tissue. The virus is present in the phloem and the mealybugs become infectious through feeding.

\section{WHAT TO LOOK FOR}

Mealybugs are characterised by the distinctive powdery wax that covers them. Mealybugs vary greatly in size depending on life 


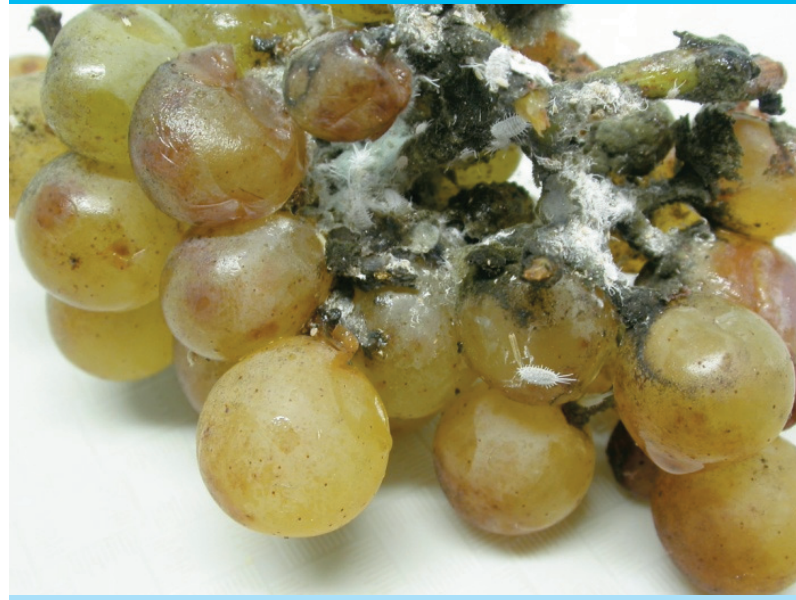

A longtailed mealybug colony: note the extent of the sooty mould within the bunch.

\section{OTHER SOURCES ON THE WEB}

- New Zealand Winegrowers www.nzwine.com/reports/

- Marlborough Wine Research Centre www.wineresearch.org.nz

- Plant \& Food Research www.plantandfood.co.nz

- Foundation Plant Services (UCD) http://fpms.ucdavis.edu/

- The Australian \& New Zealand Grapegrower \& Winemaker www.winebiz.com.au

\section{Contact:}

New Zealand Winegrowers www.nzwine.com Telephone 093033527

stage. The youngest life stage is the crawler, which is less than 0.5 $\mathrm{mm}$ in length. Crawlers are difficult to see with the naked eye, so in the field they are best observed through a 10x hand lens. Juvenile and adult female mealybugs are relatively easy to see, ranging from 2 to $5 \mathrm{~mm}$ in length.

The adult male mealybug is winged, and their form is very different from all other life stages. Adult males are not strong fliers, and often simply walk in search of a mate. With no mouthparts, adult males do not feed, so they are incapable of spreading GLRaV-3.

Often the first sign of mealybug presence is blackening of the leaves and fruit from sooty mould. This opportunistic fungi grows on the honeydew (sugar-rich waste product) expressed by the mealybugs. Under some conditions, the honeydew provides a clue - it glistens in full sun prior to a sooty mould infection.

\section{FOR MORE INFORMATION}

Updates on the Virus Elimination Project (supported by New Zealand Winegrowers) will be published in the "Research Supplement" of New Zealand Winegrower magazine.

The following articles and related reports can be found in the "Research and Reports" section of the New Zealand Winegrowers website - www.nzwine.com/reports/

- A review of Grapevine Leafroll-associated Virus Type 3 (GLRaV-3) from the New Zealand Wine Industry - A review by HortResearch (NZW 06-105)

- To determine the economic effects and financial impact of GLRaV-3 - A report by Nimmo-Bell \& Company

- New Zealand Winegrowers Grafted Grapevine Standard

\section{ACKNOWLEDGMENT}

This fact sheet was written with the assistance of Plant \& Food Research.

DISCLAIMER While care has been used in compiling this fact sheet neither New Zealand Winegrowers nor Plant \& Food Research give any prediction, warranty or assurance in relation to the accuracy of or fitness for any particular purpose, use or application of any information contained in this document. To the full extent permitted by law neither New Zealand Winegrowers nor Plant \& Food Research, nor any of their employees, shall be liable for any cost (including legal costs), claim, liability, loss, damage, injury or the like, which may be suffered or incurred as a direct or indirect result of the reliance by any person on any information contained in this document.

(c) New Zealand Winegrowers 2009. All Rights Reserved.

\section{Co-funded by:}

\section{Sustainable Farming Fund}

Ministry of Agriculture and Forestry Te Manatū Ahuwhenua, Ngāherehere
NEW ZEALAND WINE PURE DISCOVERY 


\section{Supplementary figure 5.3.4.}

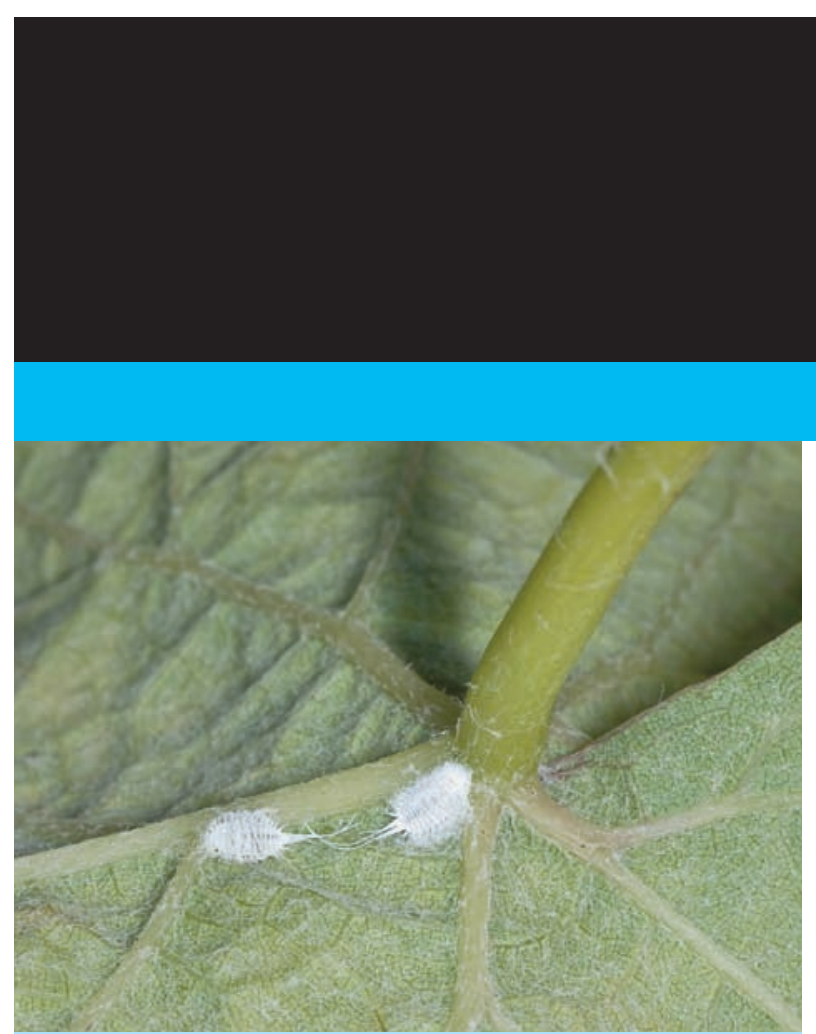

Longtailed mealybugs (Pseudococcus longispinus) tucked in beside a main vein on the underside of a grapevine leaf.

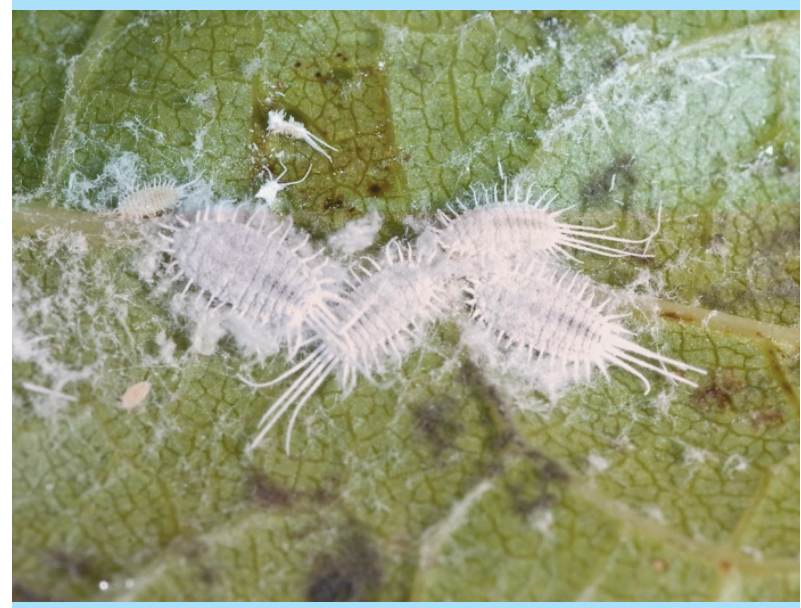

A small colony of longtailed mealybugs concentrated along a leaf vein. Note the waxy secretions on the surface of the leaf.

\section{HOW TO LOOK FOR MEALYBUGS}

\section{KEY NOTES}

- Mealybugs are commonly found along the bunch line of vines on the underside of leaves.

- Highest numbers are found late in the season.

- Sooty mould and ants can help identify an infestation of this pest.

- All vineyard staff should be trained to identify mealybugs.

\section{HOW TO FIND MEALYBUGS}

Walk through the vineyard late in the season, quickly inspecting many vines to determine infestations when mealybugs are at their most abundant levels. Vineyard personnel should incorporate mealybug inspections as an ongoing practice. Although mealybugs can be present early in the season, they are often in very low numbers and very difficult to find.

Summer and harvest: Check the vine foliage around the bunch line, with a particular focus on the underside of leaves where the petiole joins the main veins, and along the entire length of the main veins.

Mealybugs commonly aggregate in grape bunches and are typically found at the junction between the berry and the rachis. In tight bunches, some of the outer berries will have to be removed to see the mealybugs inside the bunch.

Post-harvest pruning: Pruning is a good time to find mealybugs, or signs of where they have been. The white waxy deposits that signal mealybug presence are often visible under the bark of the trunks, on old canes, spurs, or on remaining rachides. Take care not to confuse these deposits with spider and other infestations.

Mealybugs are also commonly found on many broadleaf weed species under the vines, such as nightshade.

Other indicators: Sooty mould grows on the honeydew secreted by mealybugs. When sooty mould is seen on leaves and other vine parts, it could indicate the presence of mealybugs, particularly in advanced infestations with large numbers of the pest. Also, some ant species are known to feed on the honeydew secreted by mealybugs. Look for areas where large numbers of ants are active in the vine canopy. It could indicate the presence of mealybugs.

\section{VINE REMOVAL}

As part of your roguing programme for virus-infested vines, it is important to look for mealybugs living on grapevine roots when vines are removed. All life stages may be clustered on any part of the root system, including both old and new roots. It is believed that mealybugs that persist on infected grapevine roots are still able to transmit the virus when they migrate to newly planted vines. 


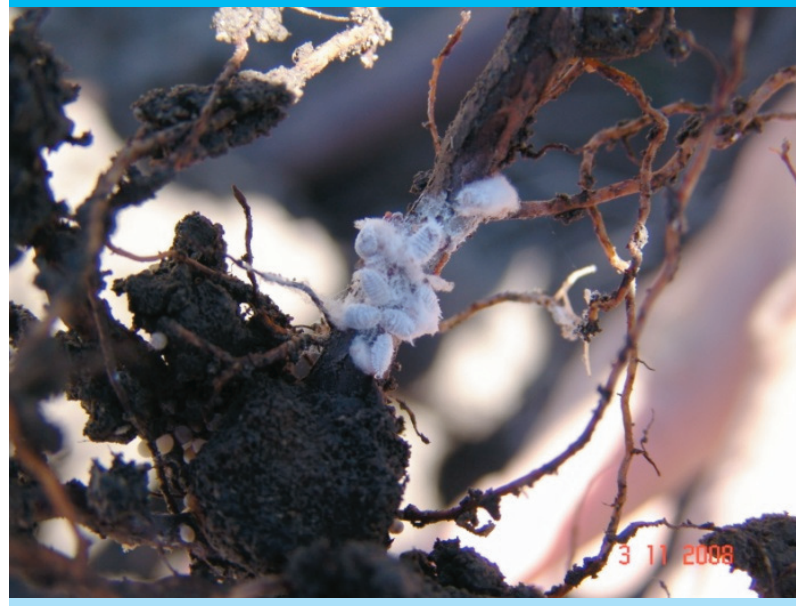

Citrophilus mealybugs (Pseudococcus calceolariae) clustered on grapevine roots.

(Photo courtesy of Dr Rod Bonfiglioli)

\section{OTHER SOURCES ON THE WEB}

- New Zealand Winegrowers www.nzwine.com/reports/

- Marlborough Wine Research Centre www.wineresearch.org.nz

- Plant \& Food Research www.plantandfood.co.nz

- Foundation Plant Services (UCD) http://fpms.ucdavis.edu/

- The Australian \& New Zealand Grapegrower \& Winemaker www.winebiz.com.au

\section{Contact:}

New Zealand Winegrowers www.nzwine.com Telephone 093033527

\section{MAPPING MEALYBUGS}

When you find mealybugs on a vine, mark the vine with paint or flagging tape. Construct a map of mealybug incidence so that you can plot changes over time. Use the information when planning control measures to make sure you target areas known to have high mealybug numbers.

\section{FOR MORE INFORMATION}

Updates on the Virus Elimination Project (supported by New Zealand Winegrowers) will be published in the "Research Supplement" of New Zealand Winegrower magazine.

The following articles and related reports can be found in the "Research and Reports" section of the New Zealand Winegrowers website - www.nzwine.com/reports/

- A review of Grapevine Leafroll-associated Virus Type 3 (GLRaV-3) from the New Zealand Wine Industry - A review by HortResearch (NZW 06-105)

- To determine the economic effects and financial impact of GLRaV-3 - A report by Nimmo-Bell \& Company

- New Zealand Winegrowers Grafted Grapevine Standard

\section{ACKNOWLEDGMENT}

This fact sheet was written with the assistance of Plant \& Food Research.

DISCLAIMER While care has been used in compiling this fact sheet neither New Zealand Winegrowers nor Plant \& Food Research give any prediction, warranty or assurance in relation to the accuracy of or fitness for any particular purpose, use or application of any information contained in this document. To the full extent permitted by law neither New Zealand Winegrowers nor Plant \& Food Research, nor any of their employees, shall be liable for any cost (including legal costs), claim, liability, loss, damage, injury or the like, which may be suffered or incurred as a direct or indirect result of the reliance by any person on any information contained in this document.

(C) New Zealand Winegrowers 2009. All Rights Reserved.

\section{Co-funded by:}

\section{Sustainable Farming Fund}

Ministry of Agriculture and Forestry Te Manatū Ahuwhenua, Ngāherehere
NEW ZEALAND WINE PURE DISCOVERY 
NEW ZEALAND WINEGROWERS FACT SHEET

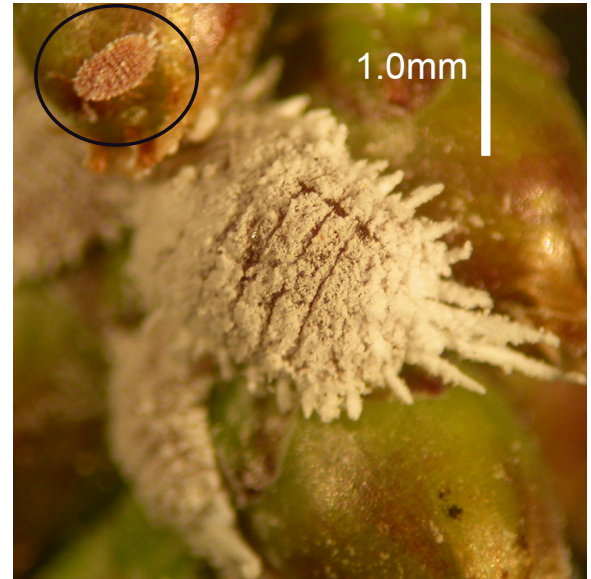

Citrophilus mealybugs (crawler in top left area, adults below).

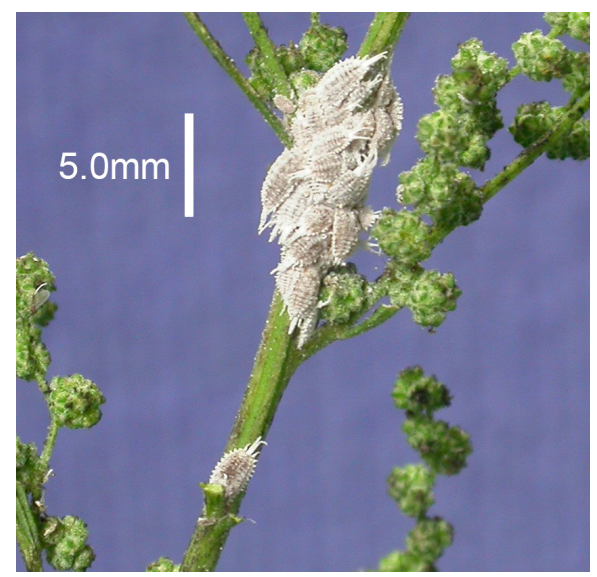

Citrophilus mealybugs.

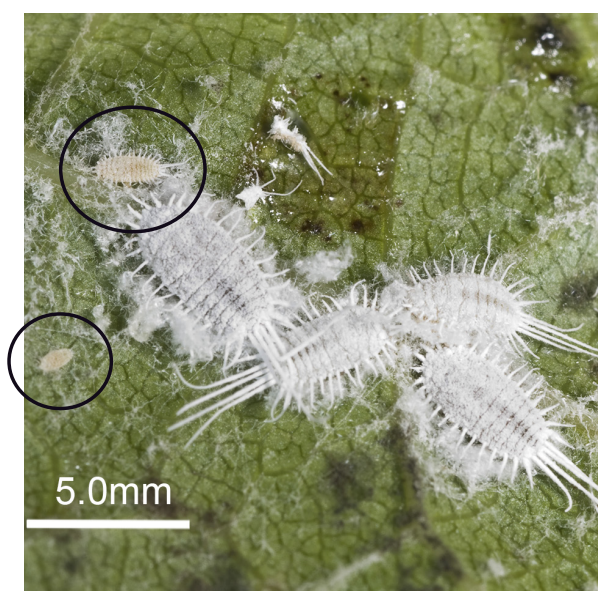

Longtailed mealybugs, including a crawler (left), juvenile (top left) and adults.

\section{PRE-HARVEST MEALYBUG MONITORING}

\section{KEY NOTES}

- Mealybugs are the main vector of Grapevine leafroll-associated virus 3 (Leafroll 3).

- A monitoring programme shortly before harvest can help determine the presence or absence of mealybugs in your vineyard.

- Where mealybugs are present in conjunction with Leafroll 3, control of the vector is essential to limit the spread of Leafroll 3 infection.

\section{THRESHOLD FOR ACTION}

In high-risk regions, no monitoring is required by Sustainable Winegrowing New Zealand (SWNZ) to justify the use of insecticides outlined in Fact Sheet NZVE104, 'Mealybug control for cropping vines.' The threshold for action in the following regions is simply determined by the co-existence of Leafroll 3 and the vector:

- Auckland

- Gisborne

- Hawke's Bay

- Martinborough

- Marlborough

- Nelson

Monitoring, however, may provide the vineyard manager with more precise information about the size of mealybug populations within each vineyard block and the effectiveness of the previous year's efforts at control. Monitoring requires consistency in approach spanning multiple years - one year's observations are of limited use.

In the regions already noted (where Leafroll 3 and mealybugs are known to co-exist), observation of mealybugs in grape bunches at harvest indicates that control is required.

\section{MONITORING METHODOLOGY}

Field monitoring for pests has historically relied largely on bunch sampling and inspection. In contrast, the monitoring conducted by Plant \& Food Research as part of the Virus Elimination Project relies on sampling leaves, which are removed, bagged and inspected under magnification in a laboratory. The reasons for this different approach are:

- Mealybugs are easier to see on a 'twodimensional' surface (typically, the underside of a leaf) than within a 'threedimensional' structure (the grape bunch).

- The flat surface of a leaf can easily be placed under a microscope, which is essential to view the tiny 'crawlers' ( $0.4 \mathrm{~mm}$ long) - the early life stage of mealybugs.

- In late summer, the light in the vineyard is too intense to make satisfactory observations in the field.

Timing: Plant \& Food Research scientists have collected samples from mid- to late-March in their trials in Hawke's Bay, noting that mealybug populations in the canopy are largest in March and April, a time coinciding with the emergence of the third generation. A single collection in the last few weeks before harvest - as opposed to smaller samples collected at intervals throughout the growing season - offers the best opportunity to identify the presence of mealybugs. In spring, mealybug population densities are low and patchily distributed so they can be hard to find. As the season progress, however, populations can increase exponentially:

- 1 st generation 1 female mealybug $=300$ eggs, of which $50 \%$ per generation are female

- 2 nd generation 150 females $\times 300$ eggs $=45,000$ mealybugs

- 3rd generation 22,500 females $\times 300$ eggs $=6.75$ million mealybugs 
Suggested sample collection method:

Each trial block (sizes range from 0.5ha to 2.Oha) is divided into four sectors of approximately the same size. In each sector, one leaf is taken from each of 100 random vines, with leaves selected from the bunch zone - a total of 400 leaves per block. Personnel walk the inter-row, selecting leaves from the rows on either side. Leaves are placed in a plastic bag, labelled by vineyard block name and sector number, with the process repeated in each sector. Bagged leaves stored in a chiller at $4^{\circ} \mathrm{C}$ will keep for 48 hours if needed.

Counting mealybugs using magnification: In the laboratory, each leaf is inspected under magnification to provide a count of the numbers of mealybugs present, which can then be interpreted as an average number of mealybugs per leaf. Mealybugs tend to tuck themselves into the bottom of the main vein on the underside of the leaf, but the entire leaf surface should be viewed. Different life stages of mealybugs will be observed, including adults (females), juveniles and crawlers. Crawlers require a magnification of at least five times to be viewed easily. All life stages are counted.

\section{Record keeping:}

Results are tabulated on an Exce spreadsheet for each trial block, each year. If the sampling methodology remains consistent, year-on-year data collection will provide some indication of the efficacy of mealybug control measures taken the year before. Population outbreaks suggest modification to the mealybug insecticide programme for the following spring may be required (e.g., increased water rates, correct sprayer calibration).

\section{MONITORING RESULTS}

The Plant \& Food Research trials have shown a correlation between the ability to control the spread of infection by Leafroll 3 and consistently low mealybug populations in the vineyard. Although no universal 'threshold value' has yet been formulated, the evidence indicates that, on average, there should be no more than 10 mealybugs per 100 vine leaves inspected. In blocks with Leafroll 3 incidence of 15\% or more, mealybug control may have to improve further if the risk of virus transmission to adjacent vines is to be reduced.

\section{ACKNOWLEDGMENT}

This fact sheet was written with the assistance of Plant \& Food Research.

\section{DISCLAIMER}

While care has been used in compiling this fact sheet neither New Zealand Winegrowers nor Plant \& Food Research give any prediction, warranty or assurance in relation to the accuracy of or fitness for any particular purpose, use or application of any information contained in this document. To the full extent permitted by law neither New Zealand Winegrowers nor Plant \& Food Research, nor any of their employees, shall be liable for any cost (including legal costs), claim, liability, loss, damage, injury or the like, which may be suffered or incurred as a direct or indirect result of the reliance by any person on any information contained in this document.
Co-funded by:

Ministry for Primary Industries Manatū Ahu Matua

\section{CONTACT:}

New Zealand Winegrowers

www.nzwine.com

Telephone number: 093033527 